\author{
SANDIA REPORT \\ SAND2005-7926 \\ Unlimited Release \\ Printed December 2005
}

\title{
Advanced Proton-Exchange Materials for Energy Efficient Fuel Cells
}

Chris J. Cornelius, Gary S. Grest, Michael R. Hibbs, Cy H. Fujimoto, Michael A. Hickner, and Chad L. Staiger

Prepared by

Sandia National Laboratories

Albuquerque, New Mexico 87185 and Livermore, California 94550

Sandia is a multiprogram laboratory operated by Sandia Corporation, a Lockheed Martin Company, for the United States Department of Energy's

National Nuclear Security Administration under Contract DE-AC04-94AL85000.

Approved for public release; further dissemination unlimited. 
Issued by Sandia National Laboratories, operated for the United States Department of Energy by Sandia Corporation.

NOTICE: This report was prepared as an account of work sponsored by an agency of the United States Government. Neither the United States Government, nor any agency thereof, nor any of their employees, nor any of their contractors, subcontractors, or their employees, make any warranty, express or implied, or assume any legal liability or responsibility for the accuracy, completeness, or usefulness of any information, apparatus, product, or process disclosed, or represent that its use would not infringe privately owned rights. Reference herein to any specific commercial product, process, or service by trade name, trademark, manufacturer, or otherwise, does not necessarily constitute or imply its endorsement, recommendation, or favoring by the United States Government, any agency thereof, or any of their contractors or subcontractors. The views and opinions expressed herein do not necessarily state or reflect those of the United States Government, any agency thereof, or any of their contractors.

Printed in the United States of America. This report has been reproduced directly from the best available copy.

Available to DOE and DOE contractors from

U.S. Department of Energy

Office of Scientific and Technical Information

P.O. Box 62

Oak Ridge, TN 37831

Telephone: (865)576-8401

Facsimile: (865)576-5728

E-Mail: $\quad$ reports@adonis.osti.gov

Online ordering: http://www.osti.gov/bridge

Available to the public from

U.S. Department of Commerce

National Technical Information Service

5285 Port Royal Rd

Springfield, VA 22161

Telephone: (800)553-6847

Facsimile: (703)605-6900

E-Mail: $\quad$ orders@ntis.fedworld.gov

Online order: http://www.ntis.gov/help/ordermethods.asp?loc=7-4-0\#online

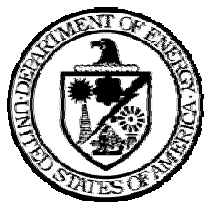


SAND2005-7926

Unlimited Release

Printed December 2005

\title{
Advanced Proton-Exchange Materials for Energy Efficient Fuel Cells
}

\section{Final Report}

\author{
Chris J. Cornelius, Gary S. Grest, Michael R. Hibbs, \\ Cy H. Fujimoto, Michael A. Hickner, and Chad L. Staiger \\ Chemical and Biological Technologies Department \\ J. Bruce Kelley, Program Manager \\ Sandia National Laboratories \\ P.O. Box 5800 \\ Albuquerque, New Mexico 87185-0734
}

\begin{abstract}
The Advanced Proton-Exchange Materials for Energy Efficient Fuel Cells Laboratory Directed Research and Development (LDRD) project began in October 2002 and ended in September 2005. This LDRD was funded by the Energy Efficiency and Renewable Energy strategic business unit. The purpose of this LDRD was to initiate the fundamental research necessary for the development of a novel proton-exchange membranes (PEM) to overcome the material and performance limitations of the "state of the art" Nafion that is used in both hydrogen and methanol fuel cells. An atomistic modeling effort was added to this LDRD in order to establish a frame work between predicted morphology and observed PEM morphology in order to relate it to fuel cell performance. Significant progress was made in the area of PEM material design, development, and demonstration during this LDRD. A fundamental understanding involving the role of the structure of the PEM material as a function of sulfonic acid content, polymer topology, chemical composition, molecular weight, and electrode electrolyte ink development was demonstrated during this LDRD. PEM materials based upon random and block polyimides, polybenzimidazoles, and polyphenylenes were created and evaluated for improvements in proton conductivity, reduced swelling, reduced $\mathrm{O}_{2}$ and $\mathrm{H}_{2}$ permeability, and increased thermal stability. Results from this work reveal that the family of polyphenylenes potentially solves several technical challenges associated with obtaining a high temperature PEM membrane. Fuel cell relevant properties such as high proton conductivity $(>120 \mathrm{mS} / \mathrm{cm})$, good thermal stability, and mechanical robustness were demonstrated during this LDRD. This report summarizes the technical accomplishments and results of this LDRD.
\end{abstract}




\section{Acknowledgements}

This LDRD project benefited from the technical assistance of Los Alamos National Labs Fuel Cell group (Bryan Pivovar) for insight on how to construct a membrane electrode assembly (MEA) and the testing of a polymer electrolyte membrane (PEM) within a hydrogen and methanol fuel cells for initial material performance. The collection and evaluation of some of our hydrogen fuel cell data was performed by Paul Daily. We would also like to thank Brian Einsla and Juan Yang in the Chemistry Department at Virginia Tech for performing the GPC analysis for the determination of the molecular weight. Finally, a special thank you is in order for the champions of this project James Gee and Larry Bustard. 


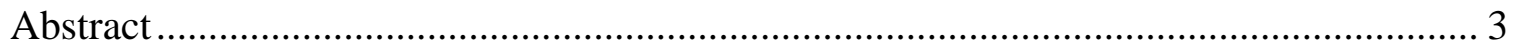

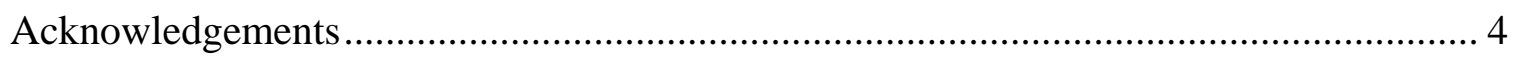

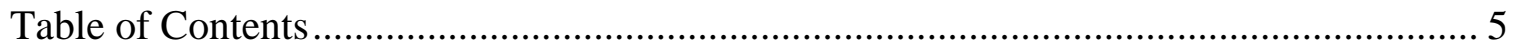

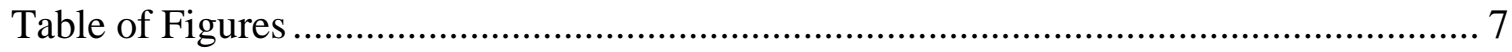

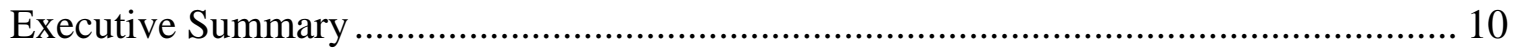

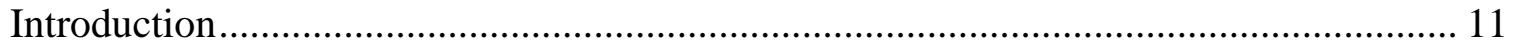

Molecular Simulations of Solvent Evaporation and Interdiffusion in Polymer Films ..... 13

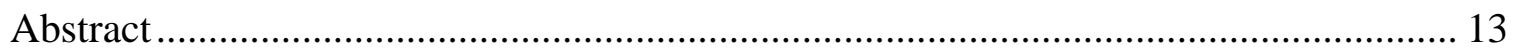

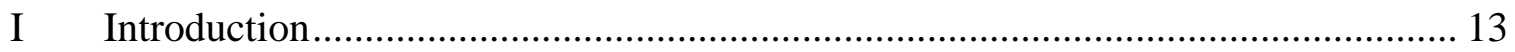

II Model and Simulations Details.................................................................... 17

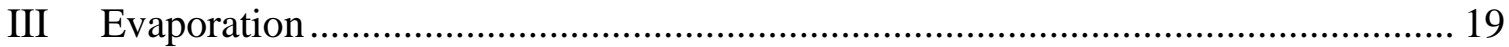

IV Interdiffusion of solvent into a homopolymer film................................................. 21

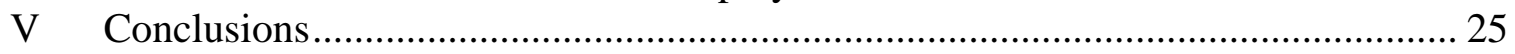

Sulfonated Random and Block Copolyimides ............................................................... 27

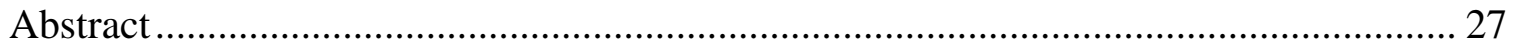

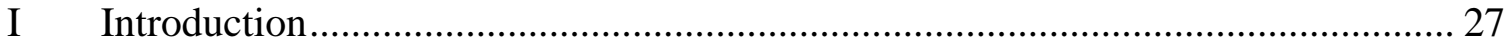

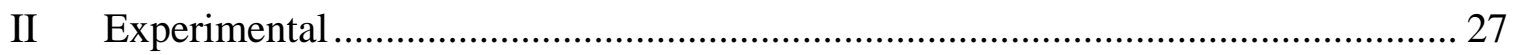

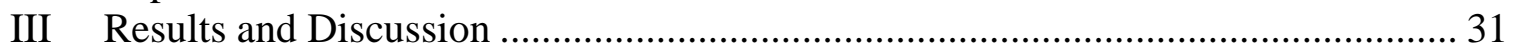

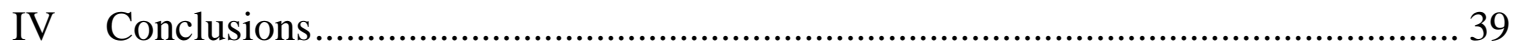

Gas Transport in Ladder Polymers ............................................................................. 40

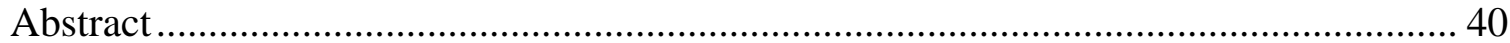

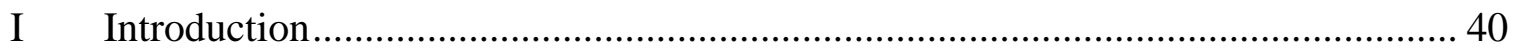

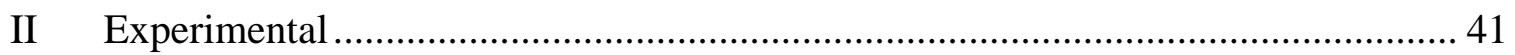

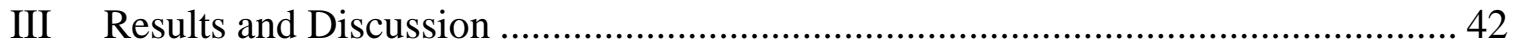

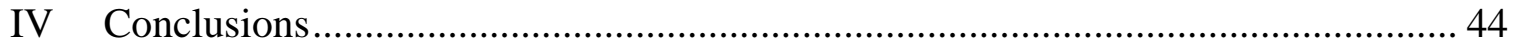

Polyphenylenes ........................................................................................................... 45

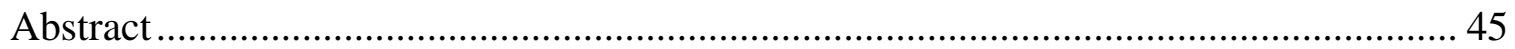

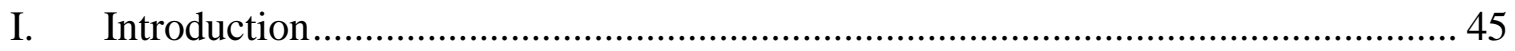

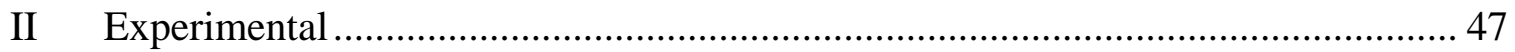

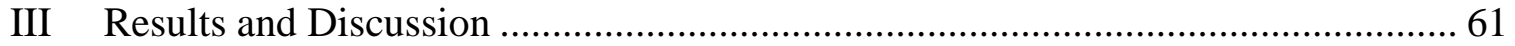

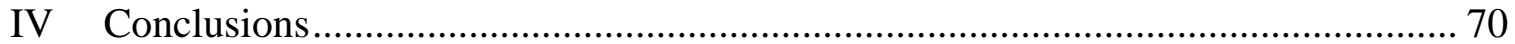

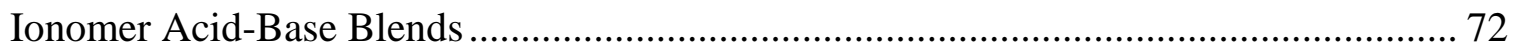

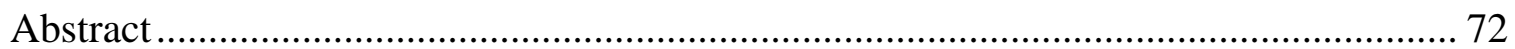

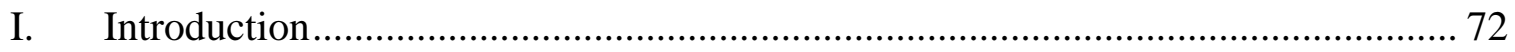

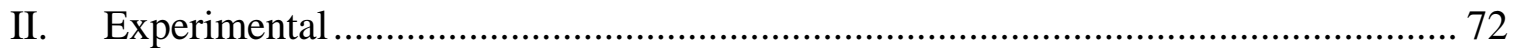

III Results and Discussion .............................................................................. 72

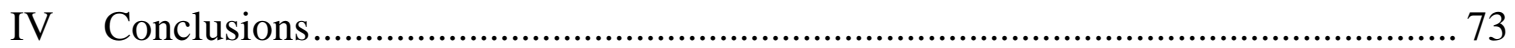




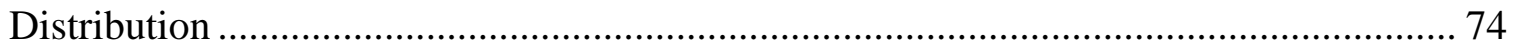

Appendix I: List of Presentations and Publications .................................................... 75 


\section{Table of Figures}

Figure 1 Schematic representation of Nafion ${ }^{\circledR}$ containing a PTFE backbone with a fluorinated pendant side group containing a sulfonic acid moiety.

Figure 2 Schematic representation of a Direct Hydrogen Fuel Cell and a Direct Methanol Fuel Cell operating on hydrogen-oxygen and methanol-oxygen. ............12

Figure 3 Snapshots of the evaporation process for system II (upper panels) and IV (lower panels), listed in Table I, at 25\%, 50\%, and 94\% evaporated solvent. Solvent monomers are colored red, and type 2 and type 3 polymer monomers are colored green and black, respectively. Note that the ordering appears as a result of solvent evaporation. The direction of evaporation is $\mathrm{z}$ and is perpendicular to both $\mathrm{x}$ and $\mathrm{y}$.....

Figure 4 Morphology of the resulting films in the surface plane for mono and polydispersed chain length multiblock copolymers with varying relative stiffnesses. Six cases are shown. Top: $1-1,1-3,3-10$. Bottom: $1-1$ (polydispersed), 1 - 10, 1 - 10 (polydispersed). The transition from lamellar to cylindrical occurs when the difference in stiffness is large enough. In the 1 - 3 case domains begin to form and for the 1-10 case they dominate the structure. The different morphologies found are likely to exhibit different proton conductivity as well as swelling characteristics.

Figure 5 Time evolution of the density profile in the solvent evaporation direction for (a) polymer and (b) solvent during the evaporation process in the homopolymer system. The profiles are at different times and from right to left corresponds to $\mathrm{t} /\left(10^{3}\right)=0,4,10,20,30,40,60,80,100,140,180,220,260,310,360,430$. The substrate is at $\mathrm{z}=0$.

Figure 6 After evaporation of solvent, slices showing the top view of system II (top row) and system IV (bottom row) at heights of 15,20 , and 25 , respectively, from the substrate. The thickness of the films is about 40

Figure 7 Vertical morphology cuts of the yz plane at $\mathrm{x}=25,30$, and 35 for system II (top row) and system IV (bottom row). Note that the right end of the slices is part of the surface of the film.

Figure 8 (a) Polymer and solvent concentration profiles as a function of time starting from $t=0$ and plotted every 2400 and (b) solvent concentration profiles as a function of the scaling variable zt-1/2. The solid line in (b) represents the theoretical curve based on Equation 2 ....

Figure 9 Dependence of diffusion constants on solvent concentration for Ds(c) ( $\boldsymbol{\square})$, Dc(c) $(\boldsymbol{\Delta})$, and $\mathrm{D}(\mathrm{c})(\bullet)$ determined from the concentration profile using Equation 2 while open circles are for $\mathrm{D}(\mathrm{c})$ determined from the Darken Equation 5. The lines are a guide to the eye.

Figure 10 Weight gain in terms of the number of solvent monomers diffused into the polymer at a given time t for system II ( $\square$ ), system III (o), and system IV $(\Delta) \ldots \ldots . .24$

Figure 11 The location of the polymer segment-solvent interface as a function of time for

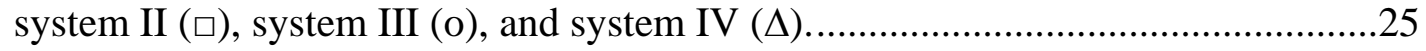

Figure 12 4-Point Membrane Proton Conductivity Cell Conductivity Capability via a Solatron 1260 Impedance Analyzer and Solatron 1287 Potentiostat. 
Figure 13 Impedance response of a typical proton conducting membrane between 100

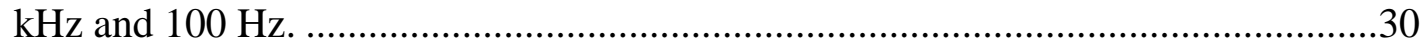

Figure 14 Three-step synthesis of block copolyimides .....................................................31

Figure 15 Three-step synthesis of block copolyimides ........................................................33

Figure 16 IR spectra of random copolyimides. .....................................................................33

Figure 17 TGA of sulfonated copolyimides. The right plot shows a comparison of the acid form of PI55B versus its salt form and the left plot compares the block copolyimides in their acid forms with varying levels of sulfonation.......................34

Figure 18 Water uptake of sulfonated copolyimide films.................................................35

Figure 19 Proton conductivities of sulfonated copolyimide films. .......................................35

Figure 20 Preparation of Sulfonated Polyimides with Six-membered Rings. .........................36

Figure 21 (A) Water Uptake and (B) Conductivity of Polyimide Membranes........................37

Figure 22 Synthesis of PBI and Addition of Sulfopropyl Groups. .......................................38

Figure 23 Synthesis of Monomers for Sulfonated PBI. .....................................................39

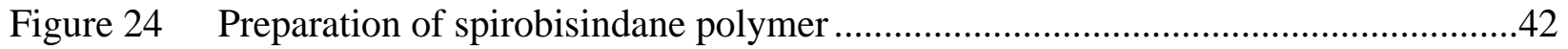

Figure 25 A graph of the time versus the log of permeability. .......................................43

Figure 26 Alternative hydrocarbon based PEMs. .............................................................45

Figure 27 Diels Alder Polymerization of 3,3'-(1,4-phenylene)bis(2,4,5-triphenyl-2,4cyclopentadien-1-one) and 1,4-diethynylbenzene to yield the parent

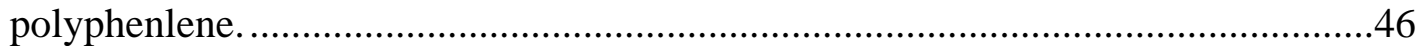

Figure 28 Minimum energy molecular model of repeat unit .............................................46

Figure 29 Conversion of 1,4-bis(2-phenylethynyl)benzene into 2,2'-Diphenyl-1,1'-(1,4phenylene)diethanedione (1-6) followed by the conversion of 2,2'-Diphenyl1,1'-(1,4-phenylene) diethanedione into 3,3'-(1,4-phenylene)-bis(2,4,5triphenyl-2,4-cyclo-pentadien-1-one) (7-9) and its stoichiometric reaction with 1,4-diethynylbenzene to yield the parent polyphenylene (12) ..............................47

Figure 30 Sulfonation of the Diels Alder poly(phenylene) with the maximum theoretical sulfonation level. The theoretical achievable sulfonation level is 6 sulfonic acid groups per repeat unit.......................................................................48

Figure 31 Targeted IEC in the Reaction Mixture versus Actual IEC ..................................50

Figure 32 Proton conductivity of SDAPP samples and Nafion 117 immersed in $30^{\circ} \mathrm{C}$ liquid water as a function of hydration number ................................................51

Figure 33 Relationship between proton conductivity, temperature, and activation energy of SDAPP series versus Nafion117 in deionized water from $30^{\circ} \mathrm{C}$ to $80^{\circ} \mathrm{C}$.............52

Figure 34 Polymer dissolution and conversion into an acidified film. ..................................53

Figure 35 Density of SDAPP as a function of increasing sulfonation level. ..........................54

Figure 36 Normalized FT-IR spectra of IR spectra of Parent polyphenylenes through SDAPP4. Sulfonate group at $1126 \mathrm{~cm}^{-1}$ wave numbers is shown to increase with increasing ion exchange capacity. ..........................................................54

Figure 37 Linear correlation of normalized FT-IR Peak Intensities of sulfonate groups $\left(1126 \mathrm{~cm}^{-1}\right)$ and internal standard in polymer chain $\left(1495 \mathrm{~cm}^{-1}\right)$ to membrane ion exchange capacity.........................................................................55

Figure 38 Thermogravimetric evaluation of SDAPP series including theoretical and experimental observations of complete loss of sulfonic acid groups. ......................56

Figure 39 Temperature at 5\% weight loss in Helium for poly(ether-ether-ketone) (PEEK), sulfonated PEEK (S-PEEK), poly(ether-sulfone) (PES), sulfonated PES (S-PES), polybenzimidazole (PBI), sulfonated PBI (S-PBI), 
polyphenylquinoxaline (PPQ), sulfonated PPQ, polyimide (PI), and sulfonated PI (S-PI), poly(tetrafluoroethylene) (PTFE), and Nafion.

Figure 40 DMTA of wet and dry samples of SDAPP with an IEC of 1.6 versus Nafion112. .57

Figure 41 Cross sectional TEM micrographs of SDAPP versus Nafion117 ............................58

Figure 42 Small and wide-angle X-ray scattering of SDAPP1. Measurements have been carried out at room temperature on a Sintag $\Theta-\Theta$ geometry.....

Figure 43 A) Small angle neutron patterns of a $55 \%$ sulfonated PP membrane dry and swollen at the indicated temperatures. The solid line at low q corresponds to a Guinier fit and the line at high q to a bicontinuous model. B) Outline of Guinier approximation.

Figure 44 SANS data for water swollen SDAPP membrane at $60^{\circ} \mathrm{C}$ at the indicated sulfonation levels. SANS pattern of Nafion under the same conditions are shown for comparison.

Figure 45 CCM based upon SDAPP. Idealized relationship of ionomer content and its effect on proton, electron, water, $\mathrm{O} 2$, and $\mathrm{H} 2$ transport.

Figure 46 Increasing fuel cell performances with increasing SDAPP proton conductivity. Fuel cell conditions were $100{ }^{\circ} \mathrm{C}, 100 \% \mathrm{RH}$, and $5 \mathrm{mg} / \mathrm{cm}^{2}$ of catalyst on each side of the PEM. Electrode ionomer ink was based upon SDAPP4.

Figure 47 Fuel cell performance of SDAPP3 versus Nafion1135. Fuel cell conditions were $80{ }^{\circ} \mathrm{C}, 100 \% \mathrm{RH}$, and $10 \mathrm{mg} / \mathrm{cm}^{2}$ of catalyst on each side of the PEM. Electrode ionomer ink was based upon Nafion1100 for both samples.

Figure 48 Fuel cell performance of SDAPP3 versus Nafion112. Fuel cell conditions were $120^{\circ} \mathrm{C}, 50 \% \mathrm{RH}$, and $0.4 \mathrm{mg} / \mathrm{cm}^{2}$ of catalyst on each side of the PEM.

Figure 49 The membrane electrode assembly (MEA) is one of the key components of a hydrogen fuel cell. The performance is determined by PEM and the catalytic and electrochemical processes within the MEA. Investigation of the PEM, interface, and interaction with catalyst layer on transport

Figure 50 Cyclic voltammagrams showing hydrogen adsorption/desorption of various electrode formulations with Nafion and SDAPPe binders.

Figure 51 Hydrogen fuel cell performance of Nafion 112 versus SDAPP3 (SDAPP3 thickness 3mil) at a cell potential of $0.5 \mathrm{~V}$. Electrode assemblies for Nafion 112 and SDAPP3 are based upon $30 \mathrm{wt} \%$ Nafion based electrodes (left) versus Nafion112.

Figure 52 Polarization curve performance of electrode formulations at $80^{\circ} \mathrm{C}$ and $50 \%$ RH.

Figure 53

Acid-base Interactions in Blend Membranes. .73 


\title{
Advanced Proton-Exchange Materials for Energy Efficient Fuel Cells
}

\author{
Final Report
}

Project Number: 52592

Responsible Project Manager: J.B. Kelley

Principle Investigator: C.J. Cornelius

\section{Executive Summary}

The Advanced Proton-Exchange Materials for Energy Efficient Fuel Cells Laboratory Directed Research and Development (LDRD) project began in October 2002 and ended in September 2005. This LDRD was funded by the Energy, Information, and Infrastructure Surety strategic business unit. The purpose of this LDRD was to initiate the fundamental research necessary for the development of a novel proton-exchange membranes (PEM) to overcome the material and performance limitations of the "state of the art" Nafion that is used in both hydrogen and methanol fuel cells. An atomistic modeling effort was added to this LDRD in order to establish a frame work between predicted morphology and observed PEM morphology in order to relate it to fuel cell performance. Significant progress was made in the area of PEM material design, development, and demonstration during this LDRD. A fundamental understanding involving the role of the structure of the PEM material as a function of sulfonic acid content, polymer topology, chemical composition, molecular weight, and electrode electrolyte ink development was demonstrated during this LDRD. PEM materials based upon random and block polyimides, polybenzimidazoles, polyphenylenes, and blends were created and evaluated for improvements in proton conductivity, reduced swelling, reduced $\mathrm{O}_{2}$ and $\mathrm{H}_{2}$ permeability, and increased thermal stability. Results from this work reveal that the family of polyphenylenes potentially solves several technical challenges associated with obtaining a high temperature PEM membrane. Fuel cell relevant properties such as high proton conductivity (>120 mS/cm), good thermal stability, and mechanical robustness were demonstrated during this LDRD. The successes in this program led to several technical presentations, publications, ongoing technical advances, and external and internal research funding. This report summarizes the technical accomplishments and results of this LDRD. 
In 1839 Grove discovered the first fuel cell by observing the production of electricity from organic chemicals using precious metal electrodes [1,2]. However, it was not until the development of PEM materials that fuel cells began to show their potential as a viable power source $[3,4,5]$. Fuel cells directly convert chemical energy into electrical energy. Typical fuels such as hydrogen, methanol, and ethanol can be directly oxidized and reduced utilizing a Pt or PtRu catalyst to generate power. Unlike batteries, fuel cells can theoretically operate indefinitely by simply supplying more fuel. The efficiency of fuel conversion to power is $40-60 \%$ for fuel cells, while current internal combustion engines are only 20-30\% efficient [6]. Currently, the state of the art PEM material used in fuel cells is Nafion ${ }^{\circledR}$ (DuPont, United States). Nafion ${ }^{\circledR}$ is a polytetrafluoroethylene (PTFE) polymer that is polymerized in the presence of sulfonic acid containing fluorinated $\alpha$-olefin [7,8]. This type of chemistry leads to a random structure of Nafion $^{\circledR}$, which is schematically illustrated in Figure 1 revealing its PTFE backbone, and pendant sulfonic acid group. Nafion $^{\circledR}$ has been demonstrated as an excellent PEM material, its high material cost is a barrier for consideration in many practical proton-exchange membrane fuel cell (PEMFC) applications as well as its extremely high methanol permeability [9,10,11,12]. Although these issue exists, Nafion ${ }^{\circledR}$ is almost exclusively used in Direct Hydrogen and Direct Methanol Fuel Cells (DHFC and DMFC) because of its excellent proton conductivity and chemical inertness. Figure 2 is a schematic represent of a DHFC and DMFC operating on hydrogen and methanol.

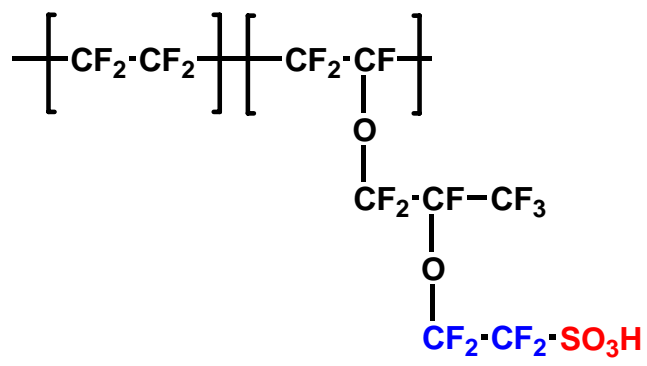

Figure 1 Schematic representation of Nafion ${ }^{\circledR}$ containing a PTFE backbone with a fluorinated pendant side group containing a sulfonic acid moiety.

\footnotetext{
1 Laramie, J.; Dicks A. Fuel Cell Systems Explained, John Wiley and Sons, LTD, Baffins Lane, Chichester, West Sussex, England, 2000

2 Thomas, S.; Zalbowitz, M. “Fuel Cells, Green Power” (web page, August 11, 1999).

http://education.lanl.gov/resources/fuelcells/

3 Stone, C.; Morrison, A.E. Solid State Ionics 2002, 152-153, 1

4 Huff, J.R. Progress in Batteries and Solar Cells 1989, 8, 302

5 Costamagna, P.; Srinivasan, S. J. Power Sources 2001, 102(1-2), 242

6 "Fuel Cells" http://www.yournextcar.org/fuelcells.html

7 Savadogo, O. J. New Mater. Electrochem. Systems. 1998, 1, 47

8 Connolly, D.J.; Gresham, W.F., US Patent 3,282,875 1966

9 Appleby, A.J.; Foulkes, F.R. Fuel Cell Handbook, Van Nostrand Reinhold, New York, 1989

10 Blomen, L.J.M.J.; Mugerwa, M.N. Fuel Cell Systems, Plenum, New York, 1993

11 Ren, X.; Springer, T.E.; Zawodzinski, T.A.; Gottesfeld, S. J. Electrochem. Soc. 2000, 147(2), 466

12 Costamagna, P.; Srinivasan, S. J. Power Sources 2001, 102(1-2), 253
} 
The cost and performance limitations of current perfluorinated polymer electrolyte membranes (PEM) such as Nafion ${ }^{\mathrm{TM}}$ have hindered large-scale commercialization and market penetration of polymer electrolyte membrane fuel cells (PEMFC) in mobile and stationary systems. This has sparked a worldwide research effort to design alternative polymer electrolyte membrane (PEM) materials with high ionic conductivity, thermal stability to allow operation over $100^{\circ} \mathrm{C}$, chemical stability to a strong acid proton conductor and oxidation, good processability, and excellent barrier properties to fuels (e.g. methanol, oxygen, etc.) [13,14]. One common approach has been to sulfonate existing thermoplastics such as polystyrene, polyetherketones, and polyethersulfones $[15,16,17,18,19,20]$. This has generated mostly PEM's with lower costs and improved thermal stability, but generally lower ionic conductivities at comparable ion exchange capacities than Nafion [21]. However, many of these thermoplastics based PEMs are more susceptible to oxidative or acid catalyzed degradation than Nafion [22].

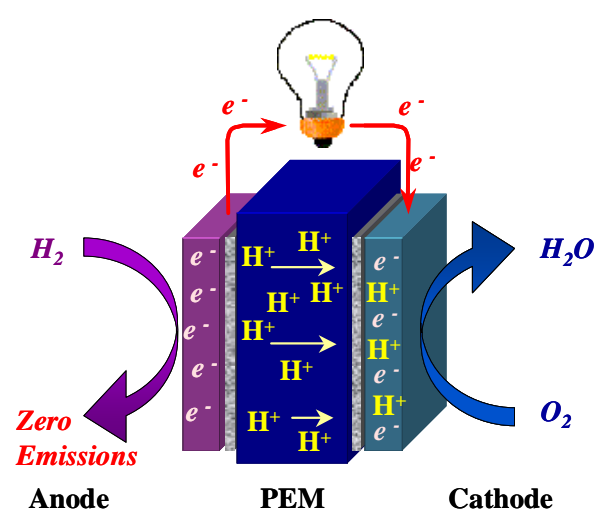

Hydrogen Fuel Cell

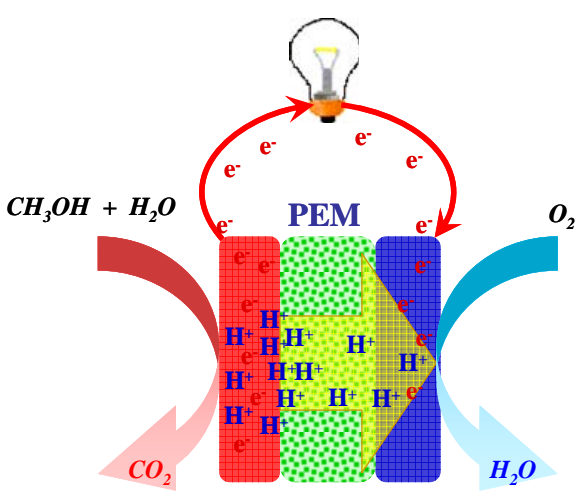

Anode

Figure 2 Schematic representation of a Direct Hydrogen Fuel Cell and a Direct Methanol Fuel Cell operating on hydrogen-oxygen and methanol-oxygen.

13 Roziere, J.; Jones, D. J. Annu. Rev. Mater. Res. 2003, 33, 503

14 Savadogo, O., J. New Mater. Electrochem. Syst., 1998, 1, 47

15 Carretta, N.; Tricoli, V.; Picchioni, F. J. Membr. Sci. 2000, 166, 189

16 Ding, J.; Chuy, C.; Holdcroft, S. Chem. Mater. 2001, 13, 2231

17 Zaidi, S.M.J.; Mikhailenko, S.D.; Robertson, G.P.; Guiver, M.D.; Kaliaguine, S. J. Membr. Sci. 2000, 173, 17

18 Jones, D. J.; Roziere, J. Journal of Membr. Sci., 2001, 185, 41

19 Nolte, R.; Ledjeff, K.; Bauer, M.; Mulhaupt, R. J. Membr. Sci. 1993, 83, 211

20 Wang, F.; Hickner, M.; Kim, Y. S.; Zawodzinski, T. A.; McGrath, J. E. J. Membr. Sci. 2002, 197, 231

21 Kreuer, K. D. J. Membr. Sci. 2001, 185, 29

22 Hubner, G; Roduner, E. J. Mater. Chem., 1999, 9, 409 


\title{
Molecular Simulations of Solvent Evaporation and Interdiffusion in Polymer Films
}

\begin{abstract}
Solvent evaporation from homopolymer and heteropolymer films along with the interdiffusion of solvent into these films is studied by molecular dynamics simulations. Due to the high viscosity of polymer melts, in many cases polymer films are made by first dissolving the polymer in a low viscosity solvent, spreading the solution on a substrate and subsequently evaporating the solvent. Here we study the last part of this process, namely the evaporation of solvent from a polymer film. As the solvent evaporates, the polymer density at the film/vapor interface is found to increase sharply creating a polymer density gradient which acts as a barrier for further solvent evaporation. For both homopolymer and heteropolymer films, the rate of solvent evaporation is found to decrease exponentially as a function of time. For multiblock copolymer films the resulting domain structure is found to be strongly affected by the relative stiffness of the two blocks. The reverse process, namely the interdiffusion of solvent into a polymer film is also studied. For homopolymer films the weight gain by the film scales as $\mathrm{t}^{1 / 2}$, which is expected for Fickian diffusion. The diffusivity $\mathrm{D}(\mathrm{c})$ determined from the onedimensional Fick's diffusion equation agrees well with that calculated from the corrected diffusion constant using the Darken equation. Far above the polymer glass transition temperature, $\mathrm{D}(\mathrm{c})$ is nearly independent of concentration. However, as the temperature decreases $\mathrm{D}(\mathrm{c})$ is found to depend strongly on the state of the polymer and is related to the shape of the solvent concentration profile. Finally the swelling of a multiblock copolymer film in which the stiffer block is below its glass transition temperature is also studied. While the solvent swells only the softer block of the copolymer, the weight gain by the film remains Fickian.
\end{abstract}

\section{Introduction}

Many practical applications and modern technologies rely on the diffusion of small molecule penetrants within or through a polymeric film or membrane. Applications include controlled drug release, food storage, and membrane separations [23,24,25,26,27,28]. In general, the transport properties of penetrants through a polymeric matrix are determined by the chemical and physical properties of both the polymer and the penetrant. The interdiffusion of penetrants into a polymer depends on the penetrant concentration gradient within the system as well as the rate of polymer segmental relaxation. Well above the polymer glass transition the diffusion is usually well described as Fickian or Case I, in which case the mass uptake of the penetrant solvent or the distance covered by the solvent as a function of time increases as $\mathrm{t}^{1 / 2}$. Non-Fickian kinetics is expected when the viscoelastic properties of the polymer become the determining factor. This case is often referred to as Case II diffusion and the mass uptake of solvent is linearly increasing with time.

23 Sonnenburg, J.; Gao J.; and Weiner, J.H. Macromolecules 1990, 23, 4653

24 Müller-Plathe, F. Chem. Phys. Lett. 1996, 252, 419

25 Charati, S.G. and Stern, S.A. Macromolecules 1998, 31, 5529

26 van der Vegt, N.F.A. Macromolecules 2000, 33, 3153

27 Yi, X. and Pellegrino, J. J. Poly. Sci.:B: Poly. Phys. 2002, 40, 980

28 Lim, S.Y.; Tsotsis, T.T.; and Sahimi, M. J. Chem. Phys. 2003, 119, 496 
The interdiffusion of a solvent film placed in contact with one surface of a homopolymer melt film can often be described by the one-dimensional diffusion

$$
\partial \mathrm{c} / \partial \mathrm{t}=\partial / \partial \mathrm{z}(\mathrm{D}(\mathrm{c}) \partial \mathrm{c} / \partial \mathrm{z})
$$

where $\mathrm{c}$ is the solvent concentration in units of mass per unit volume and $\mathrm{D}(\mathrm{c})$ is the diffusivity. This equation assumes that the volume of the medium is not changed by the interdiffusion of the solvent. $D(c)$ is in general dependent on $c$ and except in special cases such as $D(c)=D_{0}$ is independent of solvent concentration, Equation. 1 has to be solved numerically [29]. For constant $\mathrm{D}(\mathrm{c})$, Equation 1 can be solved analytically and the concentration of solvent in the medium as a function of position and time is

$$
c(z, t)=c_{0}\left[1-\operatorname{erf}\left(z / 2\left(D_{0} t\right)^{1 / 2}\right)\right]
$$

where $\mathrm{c}_{0}$ is the equilibrium solvent concentration in the polymer and erf is the error function. This simple functional form of Equation 2 is often used to fit experimental data even if the solvent swells the polymer and $\mathrm{D}$ (c) may not be independent of c. It is important to note that in general the diffusivity $\mathrm{D}(\mathrm{c})$ is not equal to the self or tracer diffusion constant $\mathrm{D}_{\mathrm{s}}(\mathrm{c})$ of the solvent. Only in the limit of low concentration, as discussed below, is $\mathrm{D}(\mathrm{c})=\mathrm{D}_{\mathrm{s}}(\mathrm{c})$.

If the diffusivity $\mathrm{D}(\mathrm{c})$ is only a function of c, a Boltzmann transformation of Equation 1 gives

$$
\partial \mathrm{z} / \partial \mathrm{t}=\mathrm{f}(\mathrm{D}, \mathrm{c}) \mathrm{t}^{1 / 2}
$$

where $f(D, c)$ is a function of $D$ and $c$ only. This equation, regardless of the functional form of $\mathrm{D}(\mathrm{c})$, reflects the square root time dependence that is a fingerprint of Fickian diffusion.

Transport properties of a solvent into a heteropolymer can be more complex $[30,31,32,33]$. For example, copolymers are known to self-assemble into a microdomain structure which can impose spatial constraints on a diffusing solvent and can lead to anisotropic behavior. How this microdomain structure changes in solution is a topic of current interest mainly due to its potential application for nanotechnology. The morphology of the polymer film can be influenced by a number of factors, such as polymer chain length and its chemical structure, block length, temperature, and thermodynamic compatibility of the solvent with the components of the copolymer. For a given copolymer system, a neutral solvent is expected to distribute itself equally between the two microdomains while a slight difference in solvent selectivity between the block of the copolymer can lead to an observable preferential swelling of one component $[34,35]$. Very little is known about the affinity of a solvent in a copolymer with variable stiffness between the block segments. We have recently shown [36] that varying only

29 Crank, J. The Mathematics of Diffusion Oxford University Press, Oxford, 1975

30 Csernica, J.; Baddour, R.F.; and Cohen, R.E. Macromolecules 1987, 20, 2468

31 Lin, H.; Steyerl, A.; Satija, S.K.; Karim, A.; and Russell, T.P. Macromolecules 1995, 28, 1470

32 Zielinski, J.M.; Heuberger, G.; Sillescu, H.; Wiesner, U.; Heuer, A.; Zhang, Y.; and Spiess, H.W.

Macromolecules 1995, 28, 8287

33 Horstmann, M.; Urbani, M.; and Veeman, W.S. Macromolecules 2003, 36, 6797

34 Lodge, T.P.; Hamersky M.W.; Hanley K.J.; and Huang, C. Macromolecules 1997, 30, 6139

35 Miller-Chou, B.A. and Koenig, J.L. Macromolecules 2003, 36, 4851

36 Tsige, M.; Mattsson, T.R.; and Grest, G.S. Macromolecules 2004, 37, 9132 
the stiffness of the block segments of the copolymer can result in rich microdomain structures as shown in Figure 3. As far as we are aware, no systematic study has been carried out to examine the distribution of solvent in copolymers with variable block stiffness, though the single chain behavior in selective solvent have recently been reported [37,38].
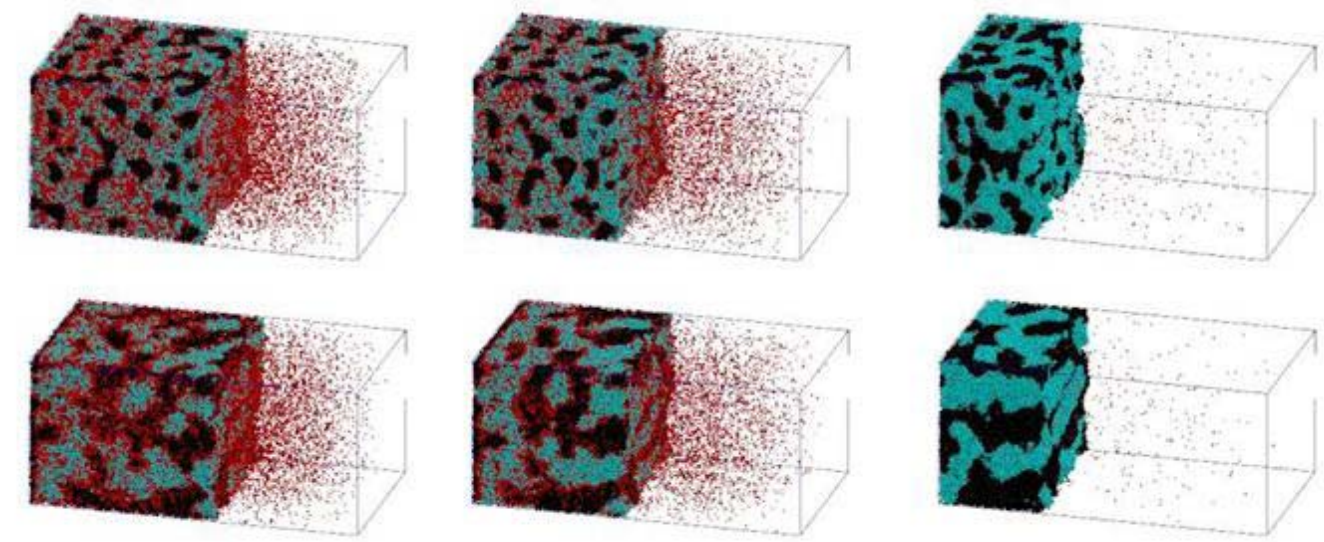

Figure 3 Snapshots of the evaporation process for system II (upper panels) and IV (lower panels), listed in Table I, at 25\%, 50\%, and 94\% evaporated solvent. Solvent monomers are colored red, and type 2 and type 3 polymer monomers are colored green and black, respectively. Note that the ordering appears as a result of solvent evaporation. The direction of evaporation is $\mathrm{z}$ and is perpendicular to both $\mathrm{x}$ and $\mathrm{y}$.

Our main interest is the final morphology as a function of properties of the polymer: for example the stiffness of the different segments. To make connection with the experimental systems discussed above, we study multiblock copolymers in which the two blocks have different stiffness. The stiffness is controlled by the strength of the three body bending angle. In the figures presented here, a bending energy of 1 corresponds to flexible segments while 10 corresponds to stiff segments. Examples of the final, dry, polymer morphology after evaporation for six different systems are shown in Figure 3. We find that it is possible to tune the final morphology from a lamellar phase with large parallel domains to a phase where the stiff segments are contained mainly in cylinders perpendicular to the surface solely by changing the relative stiffness. The lamellar-like structure for the $1-10$ polydispersed case (lowest left in Figure 3) furthermore suggests that the order can be broken by variations in segment length. Experimental realization of the ordered cylindrical phase therefore likely requires very well defined segment lengths, at least in the case of equal amounts of A and B. Simulations where the mole fraction deviates from 1:1 showed that isolated domains of the minority phase form more easily.

37 Polson, J.M. and Zuckermann, M.J. J. Chem. Phys. 2000, 113, 1283

38 Cooke, I.R. and Williams, D.R.M. Macromolecules 2004, 37, 5778 

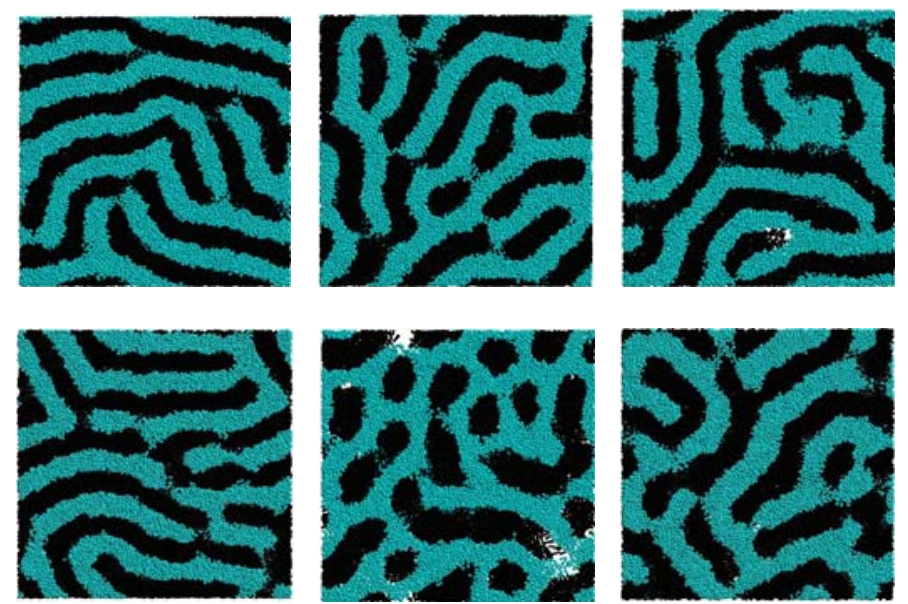

Figure 4 Morphology of the resulting films in the surface plane for mono and polydispersed chain length multiblock copolymers with varying relative stiffnesses. Six cases are shown. Top: $1-1,1-3,3-10$. Bottom: $1-1$ (polydispersed), $1-10,1-10$ (polydispersed). The transition from lamellar to cylindrical occurs when the difference in stiffness is large enough. In the $1-3$ case domains begin to form and for the $1-10$ case they dominate the structure. The different morphologies found are likely to exhibit different proton conductivity as well as swelling characteristics.

Molecular Dynamics (MD) simulations have become a powerful tool for studying polymeric systems. For homopolymers, a variety of methods [39] have now been developed to generate well equilibrated melt configurations which can be used to start a simulation. The same is not the case for all but the simplest heteropolymers. For example for a diblock copolymer system, if the ordered phase is lamellar, then it is straightforward to generate starting states [40] with the correct lamellar spacing. However, if the ordered phase is spherical or cylindrical, there is at present no method which can create an initial starting state with the correct lattice spacing and domain size. The problem is, the structure of the equilibrated heteropolymer film is not generally known a priori. Even if known, as in the case of a diblock copolymer, generating an equilibrated starting configuration is at present an unsolved problem. One way of computationally producing polymer films is to follow the experimental procedure of dissolving the polymer in a solvent and then evaporating the solvent. We followed this procedure, as shown in Figure 3, to generate the initial configuration for studying computationally, the interdiffusion of solvent into heteropolymer films. For comparison we also studied the evaporation from a homopolymer film [41], which somewhat surprisingly has not been well studied experimentally.

This section is organized as follows. In the following section we briefly discuss the model and the force field used to describe our systems. Simulation details about the system setup and size are also discussed. In Section III the results for the evaporation study of solvent from both homoand heteropolymers are presented. Special attention is given to how the evaporation process affects the structure of the film. For the heteropolymer case, emphasis is also given on how differences in block length affect the final morphology of the system. In Section IV the

39 Auhl, R.; Everaers, R.; Grest, G.S.; Kremer, K.; and Plimpton, S.J. J. Chem. Phys. 2003, 119, 12718

40 Murat, M.; Grest, G.S.; and Kremer, K. Macromolecules 1999, 32, 595

41 Tsige, M. and Grest, G.S. Macromolecules 2004, 37, 4333 
interdiffusion results for both homo- and heteropolymers are presented. For the homopolymer case, the relation between various diffusion coefficients is discussed. The main results are summarized in Section V.

\section{Model and Simulations Details}

To represent the polymer chains we used the coarse grained bead-spring model in which the bead size defines the excluded-volume interactions while the springs describe chain connectivity. The homopolymer system is represented by freely jointed bead-spring chains of length $\mathrm{N}$ monomers of mass $\mathrm{m}$, while the block copolymer systems are represented by beadspring chains of different block and chain length consisting of two different species each of the same mass $\mathrm{m}$. In all cases, the solvent is modeled as single monomers of mass $\mathrm{m}$. We denote the solvent monomers as type 1 and the two species of the polymer as type 2 and 3, which corresponds to the softer and stiffer part of the copolymer, respectively.

Nonbonded pairs of monomers of type $\alpha$ and $\beta$ interact through the standard 6-12 Leonard-Jones potential

$$
\begin{array}{cc}
\mathrm{U}_{\mathrm{LJ}}(\mathrm{R})=4 \varepsilon_{\alpha \beta}\left[\left(\mathrm{r} / \sigma_{\alpha \beta}\right)^{12}-\left(\mathrm{r} / \sigma_{\alpha \beta}\right)^{6}-\left(\mathrm{r}_{\mathrm{C}} / \sigma_{\alpha \beta}\right)^{12}+\left(\mathrm{r}_{\mathrm{C}} / \sigma_{\alpha \beta}\right)^{6}\right]+\varepsilon_{\mathrm{LJ}} & \text { for } \mathrm{r} \leq \mathrm{r}_{\mathrm{C}} \\
0 & \text { for } \mathrm{r} \geq \mathrm{r}_{\mathrm{C}}
\end{array}
$$

where $r$ is the distance between monomers and $\varepsilon_{\mathrm{LJ}}$ is a constant added so that the potential is continuous at $r=r_{c}$. Here we take the effective excluded-volume diameter of the beads $\sigma_{\alpha \beta}=\sigma$ for all $\alpha, \beta$ and the cutoff radius $r_{c}=2.5 \sigma$ except between the two different species of the copolymer where the interaction is purely repulsive, $\mathrm{r}_{\mathrm{c}}=2^{1 / 6} \sigma$. The depth of the attractive minimum is set to $\varepsilon_{\alpha \beta}=\varepsilon$ for all $\alpha, \beta$ except in the interdiffusion study of copolymers where $\varepsilon_{33}=2 \varepsilon$ is used in order for the stiff blocks to be below their glass transition temperature.

In addition to the Leonard-Jones interaction between bonded monomers we add a harmonic interaction term known as FENE potential [42,43],

$$
\begin{array}{cl}
U(r)=-0.5 R_{0}^{2} k \ln \left[1-\left(r / R_{0}\right)^{2}\right] & \text { for } r \leq R_{0} \\
\infty & \text { for } r<R_{0}
\end{array}
$$

where as in previous studies $\mathrm{R}_{0}=1.5 \sigma$ and $\mathrm{k}=30 \varepsilon$.

For the block copolymer systems a bending potential is imposed between the three neighboring beads along the same chain.

$$
\mathrm{U}_{\text {bend }}(\theta)=\mathrm{k}_{\theta, \alpha}(1-\backslash \cos \theta)
$$

where $\mathrm{k}_{\theta, \alpha}$ is the elasticity parameter and depends on the type of the central monomer and $\backslash$ theta is the angle formed between two adjacent bonds. The stiffness parameters used in most of the present studies are $\mathrm{k}_{\theta, 1}=3$ for type 2 and $\mathrm{k}_{\theta, 2}=10$ for type 3 .

42 Grest, G.S. and Kremer, K. Phys. Rev. 1986, A33, 3628

43 Kremer, K. and Grest, G.S. J. Chem. Phys. 1990, 92, 5057 
All the simulations were run at a temperature of $T=\varepsilon / \mathrm{k}_{\mathrm{B}}$, where $\mathrm{k}_{\mathrm{B}}$ is Boltzmann constant. For the homopolymer the glass transition temperature for the model is $T_{g}=0.5-0.6 \varepsilon / k_{B}$ [44]. The equations of motion were integrated with a velocity Verlet algorithm with a time step of $\Delta \mathrm{t}=0.01 \tau$ for the evaporation and interdiffusion study and $\Delta \mathrm{t}=0.009 \tau$ for the bulk equilibrium measurement of the self- and corrected diffusion constants in a homopolymer melt. Here $\tau=\sigma(\mathrm{m} / \varepsilon)^{1 / 2}$ is the standard LJ unit of time.

\section{Evaporation}

For both homopolymer and block copolymer systems studied the initial configuration is created by randomly building the polymer chains between two flat walls where beads are initially allowed to overlap and then the overlap removed by applying a soft nonbonded potential. The system is then equilibrated at pressure $\mathrm{P} \sim 0$ and temperature $\mathrm{T}=\varepsilon / \mathrm{k}_{\mathrm{B}}$, by allowing the distance between the two walls to adjust. The monomer-surface interaction potential is given by the 9-3 LJ potential with a cutoff distance of $r_{c}{ }^{w}=2.2 \sigma$ [45]. The surface interaction is chosen to be strong enough that a vapor phase does not form between the polymer and the wall [46]. After equilibration, the top wall is then removed so that the solution is in contact with a vacuum. Periodic boundary conditions are used in the $\mathrm{x}$ - and $\mathrm{y}$-directions, and the solvent evaporates in the z-direction. The evaporated solvent monomers are removed from the system when they reach a specified distance far above the original film. This is done by using the massively parallel grand canonical MD code LADERA [47] which is a hybrid of the massively parallel MD code LAMMPS [48] and a grand canonical Monte Carlo (GCMC) code [49].

The initial configuration of the homopolymer system consists of 600 polymer chains of length $\mathrm{N}=500$ monomers dissolved in 300,000 solvent monomers with $\mathrm{L}_{\mathrm{x}}=\mathrm{L}_{\mathrm{y}}=100 \sigma$. For the case of multi-block copolymers, four systems, listed in Table I, with $\mathrm{L}_{\mathrm{x}}=\mathrm{L}_{\mathrm{y}}=80 \sigma$ were studied. The systems differ in the number and length of the blocks, though in each case the stiffness of the two blocks remains unchanged, namely $k_{\theta, 2}=3$ and $k_{\theta, 3}=10$, except for system I where either $k_{\theta, 2}=1$ or 3 is used. The fraction of each component is equal for all four cases. Additional results for different stiffnesses of the two blocks for the ordered case (system I) can be found in reference. System I is ordered with each block having 10 monomers per block and 10 blocks per chain. For the remaining 3 systems, the block length and number of blocks per chain are chosen randomly from the values listed in the table. The polydispersity index $\mathrm{P}$, measured as the ratio of number- and weight-average degrees of polymerizations of the chains, is also listed in Table I and ranges from 1.0 to 1.27. While the range of block length in each case is small compared to experiment, some differences in these cases can be identified as discussed in Section III. For case I, the total number of polymer monomers is $\mathrm{N}_{\mathrm{p}} \sim 200,000$ dissolved initially in an equal number of solvent monomers $\mathrm{N}_{\mathrm{s}}$. For the remaining three cases, the total number of polymer monomers $\mathrm{N}_{\mathrm{p}} \sim 250,000$ dissolved in $\mathrm{N}_{\mathrm{s}} \sim 250,000$ solvent monomers. Each system is allowed to equilibrate for $\sim 10^{5} \tau$ before solvent is allowed to evaporate.

44 Baljon, A.R.C. and Robbins, M.O. Macromolecules 2001, 34, 4200

45 Sides, S.W.; Grest, G.S.; and Stevens, M.J. Macromolecules 2002, 35, 566

46 Sides, S.W.; Grest, G.S.; and Lacasse, M.D. Phys. Rev. E 1999, 60, 6708

47 Thompson, A.P. and Heffelfinger, G.S. J. Chem. Phys. 1999, 110, 10693

48 Plimpton, S.J. J. Comput. Phys. 1995, 117, 1

49 Heffelfinger, G.S. and Ford, D.M. Mol. Phys. 1998, 94, 659 
Table 1 Parameter for the four multiblock systems studied. Range of block length, number of blocks per chain, and polydispersity index $\mathrm{P}$.

\begin{tabular}{cccc}
\hline System & $\begin{array}{c}\text { Block } \\
\text { Length }\end{array}$ & $\begin{array}{c}\text { Number } \\
\text { of Blocks }\end{array}$ & P \\
\hline I & 10 & 10 & 1.0 \\
II & $10-20$ & $5-20$ & 1.14 \\
III & $30-60$ & $3-12$ & 1.16 \\
IV & $20-100$ & $2-20$ & 1.27 \\
\hline
\end{tabular}

\section{Interdiffusion}

For the interdiffusion of solvent monomers into a polymer melt, the simulated system consists of a polymer melt in contact with solvent monomers only at one side of the rectangular box [50,51]. For the homopolymer melt case, the polymer melt was first equilibrated between two walls at pressure $\mathrm{P} \sim 0$ and then the top of the box was extended and a thick layer of solvent monomers is place in contact with the polymer. The homopolymer melt consisted of 600 chains of length $\mathrm{N}=500$ monomers. The number of solvent monomers was 230,000. For the multiblock copolymer case, the final state of the three random copolymers (systems II-IV) was used as starting states for the interdiffusion study. The only difference from the evaporation is that the interaction $\varepsilon_{33}$ between the stiffer blocks was increased to $\varepsilon_{33}=2 \varepsilon$ so that the film would only swell a finite amount as is typically of many applications such as polymer membranes for fuel cells.

For the homopolymer case, separate simulations of an equilibrated polymer solvent mixture in a cubic simulation cell with periodic boundary conditions in all directions were carried out to compare the diffusivity $\mathrm{D}(\mathrm{c})$ obtained from the Darken equation with that measured from the interdiffusion study using the one-dimensional Fick's model. $\mathrm{M}$ chains of length $N=500$ monomers, where $M=100$ for solvent concentration $\mathrm{c}<0.45 \sigma^{-3}$ and $\mathrm{M}=50$ for $c \geq 0.45 \sigma^{-3}$ were used in these simulations. A pure solvent system of 50,000 monomers was also simulated.

\section{Evaporation}

A typical density profiles of polymer and solvent as a function of time is presented in Figure 5 for solvent evaporating from a homopolymer film. Two important features are observed in the evaporation process. First, the density of the polymer increases to its equilibrium melt density value $\left(\rho \sim 0.8 \sigma^{-3}\right)$ by reducing the film thickness. Second, there is a sharp increase in polymer density at the film/vapor interface which results in a polymer density gradient across this interface. This is in agreement with the prediction of Bornside et al. [52] Using a onedimensional model for the spin coating process they predicted that the region near the free surface becomes polymer rich first due to solvent evaporation. So far, this prediction has not been directly verified experimentally, though Richardson et al. [53] have recently found a

50 Tsige, M. and Grest, G.S. J. Chem. Phys. 2004, 120, 2989

51 Tsige, M. and Grest, G.S. J. Chem. Phys. 2004, 121, 7513

52 Bornside, D.E.; Macosko, C.W.; and Scriven, L.E. J. Appl. Phys. 1989, 66, 5135

53 Richardson, H.; Carelli, C.; Keddie, J.L. and Sferrazza, M. Eur. Phys. J. 2003, 12, 2004 
decrease in the rate of solvent evaporation from a spin cast PMMA thin film. This observation can actually be related to the polymer density gradient as discussed below. de Gennes [54] also pointed out that for glassy polymers this polymer rich region could be under mechanical stress which could lead to cracks in the film. This is not observed in our system which, in the limit of no solvent, is well above the glass transition.

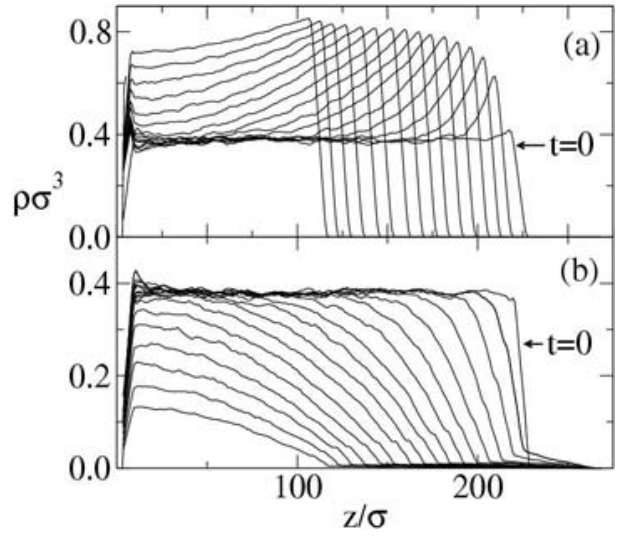

Figure 5 Time evolution of the density profile in the solvent evaporation direction for (a) polymer and (b) solvent during the evaporation process in the homopolymer system. The profiles are at different times and from right to left corresponds to $\mathrm{t} /\left(10^{3} \tau\right)=0,4,10,20,30,40,60,80,100$, $140,180,220,260,310,360,430$. The substrate is at $\mathrm{z}=0$.

The magnitude of the density gradient depends on time and has a counter effect of becoming a barrier to solvent evaporation which in turn results in a solvent density gradient within the system as shown in Figure 5(b). As a result, the concentration of solvent monomers remaining in the film is found to be exponentially decreasing with time in agreement with the experimental observations of Richardson et al. The film thickness is also found to decrease exponentially with time.

The evaporation of solvent from multi-block copolymer films displays similar behavior as that of homopolymers. Results for systems II and IV during the evaporation process are shown in Figure 3. The two important evaporation features, polymer density gradient at the interface and a decrease in film thickness to reach its equilibrium density, observed in homopolymers are also observed for all of the multi-block copolymers systems studied. Previously, we found that at least for the ordered system I, differences in stiffness between the block segments influence the evaporation process considerably. Though the solvent is neutral, its transport property in the systems is found to depend on the relative stiffness between the two blocks. For blocks with the same stiffness, the solvent is equally distributed between the two blocks, while diffusion of solvent is observed exclusively through the softer segments as the relative stiffness between the two increases. However, in order to screen the unfavorable interaction between the two blocks, the solvent also tends to collect in the interfacial region as can be seen in Figure 3. As a result, the rate of solvent evaporation, the width of the polymer/vapor interface, and the final morphologies of the films depend on the stiffness of the block segments. For the various block stiffnesses studied, the same exponential solvent evaporation behavior is observed, but the rate of evaporation is found to decrease as the stiffness of the block segments increased. The interface width, on the other hand, is found to depend on the relative stiffness of the polymer segments. At the end of evaporation, for system I with

54 de Gennes, P.G. Eur. Phys. J. E 2002, 7, 31 
$\mathrm{k}_{\theta, 2}=3$, the morphology is found to be mainly lamellar, while an ordered microphase separated phase with cylindrical features are formed for $\mathrm{k}_{\theta, 2}=1$.

The final morphologies of the polymer films depend on a number of factors, though here we focus on the effect of the block length. In reality, synthesizing perfectly ordered multiblock copolymers is difficult and, therefore, to mimic reality in the simulation the block lengths of the systems studied are chosen randomly from the values given in Table I. The dependence of morphology on block length can be seen from Figures 6 and 7 where the resulting morphologies after evaporation for two ranges of block lengths are shown. As seen in Figure 7 the flexible part of the segment is mainly exposed to the surface since it has a lower surface tension. As expected, the width and the spacing between the two domains increases with increasing block length. For systems II-IV the softer part of the segment percolates while the stiffer one does not.
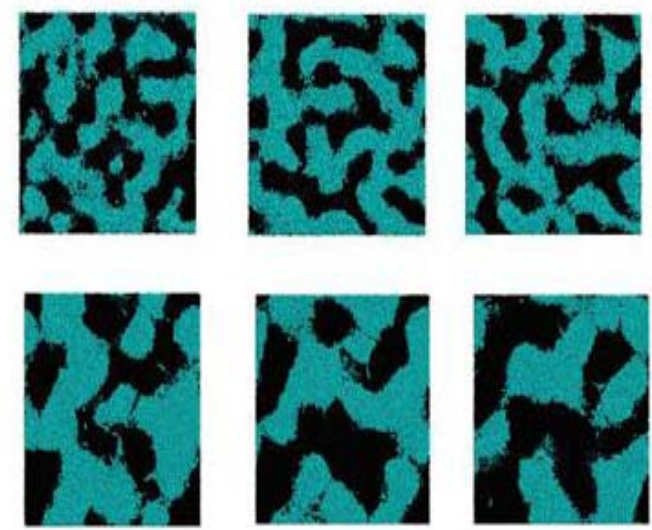

Figure 6 After evaporation of solvent, slices showing the top view of system II (top row) and system IV (bottom row) at heights of $15 \sigma, 20 \sigma$, and $25 \sigma$, respectively, from the substrate. The thickness of the films is about $40 \sigma$.
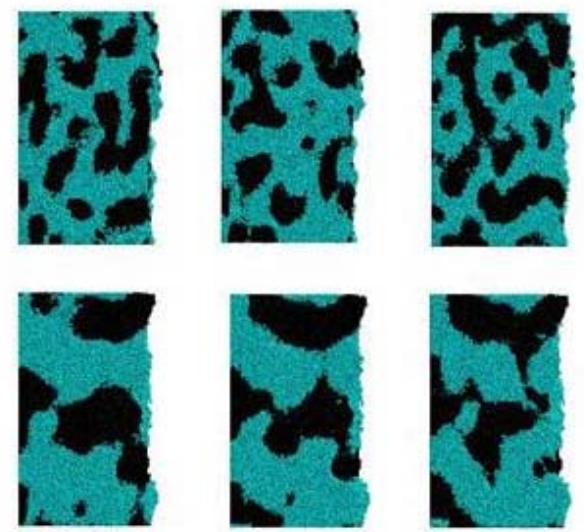

Figure 7 Vertical morphology cuts of the yz plane at $x=25 \sigma, 30 \sigma$, and $35 \sigma$ for system II (top row) and system IV (bottom row). Note that the right end of the slices is part of the surface of the film.

\section{Interdiffusion of solvent into a homopolymer film.}

Consider an equilibrated polymer film placed in contact with a thick layer of solvent. With time the solvent diffuses into the polymer film. In Figure 8(a) the density profile of both polymer and solvent is shown as a function of time for a polymer film which is far above its glass transition temperature. The polymer relaxes as the solvent diffuses into polymer film from the right side, smearing out the boundary. The density profile at different times have the same shape differing slightly only in time scale. The position of the interface is found to increase with $\mathrm{t}^{1 / 2}$ in agreement with Fickian diffusion behavior. This can be further seen by re-plotting the solvent density profile of Figure 7(a) as a function of as shown in Figure 8(b). As expected for Fickian diffusion behavior, the profiles collapse on to a single master curve. In addition, Equation 3 can be integrated to yield the diffusivity at concentration $\mathrm{c}^{\prime}$.

$$
\mathrm{D}\left(\mathrm{c}^{\prime}\right)=-1 / 2[(\partial \mathrm{c} / \partial \eta)]_{\mathrm{c}^{\prime}}{ }^{-1} \int_{0} \mathrm{c}^{\prime} \eta \mathrm{dc}
$$


where $\eta=\mathrm{z} / \mathrm{t}^{1 / 2}$. Thus from the scaled concentration profile one can directly obtain the diffusivity $\mathrm{D}(\mathrm{c})$.
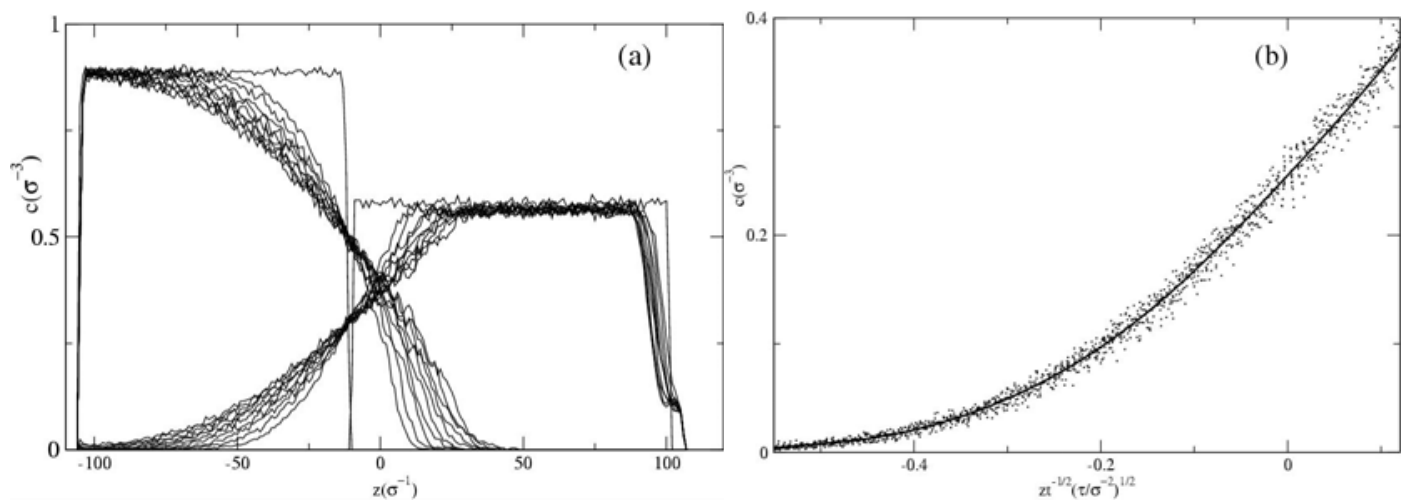

Figure 8 (a) Polymer and solvent concentration profiles as a function of time starting from $\mathrm{t}=0$ and plotted every $2400 \tau$ and (b) solvent concentration profiles as a function of the scaling variable $\mathrm{zt}-1 / 2$. The solid line in (b) represents the theoretical curve based on Equation 2

Applying Equation 4 to the master curve of the solvent concentration profile $c(\eta)$, the diffusivity of the solvent as a function of solvent concentration can be determined. First c( $\eta$ ) was fit to a polynomial function of at least order 5 , i.e. to obtain an optimal fit to the data, and then $c(\eta)$ is integrated analytically to the target concentration using the transformation $\int_{0}^{c^{\prime}} \eta \mathrm{dc}=$ $\int \eta(\partial \mathrm{c} / \partial \eta) \mathrm{d} \eta$. The diffusivity $\mathrm{D}(\mathrm{c})$ calculated by repeating this procedure for different values of solvent concentration is shown in Figure 9 (closed circles). The diffusivity is approximately a constant within the error of the simulation, $\mathrm{D}(\mathrm{c}) \sim 0.033 \pm 0.004 \sigma^{2} / \tau$. This constant value for $\mathrm{D}$ (c) in turn was used in Equation 2 and the calculated concentration profile is shown in Figure 8(b) as solid lines. In the region of interest, the calculated concentration profile fits reasonably well to the simulated concentration profile.

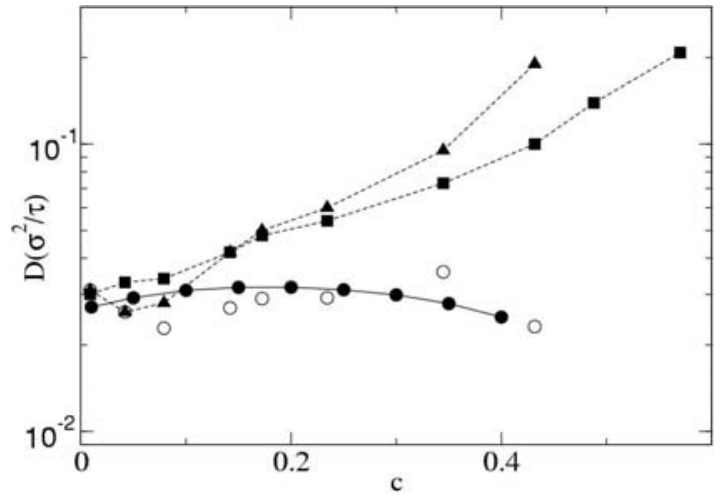

Figure 9 Dependence of diffusion constants on solvent concentration for $\operatorname{Ds}(\mathrm{c})(\boldsymbol{\square})$, Dc(c) ( $\mathbf{\Delta})$, and $\mathrm{D}(\mathrm{c})(\bullet)$ determined from the concentration profile using Equation 2 while open circles are for $\mathrm{D}(\mathrm{c})$ determined from the Darken Equation 5. The lines are a guide to the eye. 
A number of relations between $\mathrm{D}(\mathrm{c})$ and equilibrium diffusion constants have been proposed. The most common is the Darken equation [55,56,57].

$$
\mathrm{D}(\mathrm{c})=\mathrm{D}_{\mathrm{c}}(\mathrm{c})(\partial \ln \mathrm{f} / \partial \ln \mathrm{c})_{\mathrm{T}}
$$

where $D_{c}(c)$ is the corrected diffusivity and is related to molecular mobility and $\boldsymbol{f}$ is the fugacity of the solvent in the polymer. Equation 5 assumes that diffusion is driven by gradients in chemical potential. The corrected diffusion coefficient $D_{c}(c)$ of the solvent in the polymer can be calculated using the Einstein form equation. Note that $D_{c}(c)$ is equal to the self diffusion constant $\mathrm{D}_{\mathrm{s}}(\mathrm{c})$ of the solvent only in the limit the concentration c goes to 0 .

The fugacity $\boldsymbol{f}$ can be determined by applying the particle insertion method and using the grand canonical MD code LADERA [58]. During the course of an equilibrium MD simulation, the energy $\mathrm{E}$ of inserting a solvent particle at random locations is sampled. The excess chemical potential energy $\mu_{\mathrm{e}}$ is computed using

$$
\mu_{\mathrm{e}}=-\mathrm{k}_{\mathrm{B}} \mathrm{T} \ln \left[\exp \left(-\mathrm{E} / \mathrm{k}_{\mathrm{B}} \mathrm{T}\right)\right]
$$

The activity coefficient, $\gamma$, is then computed via $\gamma=\exp \left(\mu_{\mathrm{e}} / \mathrm{k}_{\mathrm{B}} \mathrm{T}\right)$. The thermodynamic factor in Equation 5 can be expressed in terms of the activity coefficient $\gamma$ of the solvent as

$$
\partial \operatorname{lnf} / \partial \operatorname{lnc}=1+\partial \ln \gamma / \partial \operatorname{lnc} .
$$

In the limit of low solvent concentration, $\mathrm{D}(\mathrm{c}) \sim \mathrm{D}_{\mathrm{c}}(\mathrm{c})$ since the thermodynamic factor goes to 1.

The diffusivity $\mathrm{D}(\mathrm{c})$ determined from the Darken equation is compared to that determined directly from the interdiffusion simulations in Figure 9 as a function of concentration. Also shown are the self diffusion $\mathrm{D}_{\mathrm{s}}(\mathrm{c})$ and the corrected diffusion constant $\mathrm{D}_{\mathrm{c}}(\mathrm{c})$. These diffusion constants show an exponential dependence on solvent concentration. However, the fugacity of the solvent was found to decrease monotonically with concentration. This may sound counterintuitive, but since the solvent swells the polymer it is easier to insert solvent monomer as the density of solvent increases. Apart from the scatter in the data due to uncertainty in determining the thermodynamic factor, the diffusivity calculated from the two different approaches show good agreement. At low solvent concentration $\mathrm{D}(0) \approx \mathrm{D}_{\mathrm{c}}(0)=\mathrm{D}_{\mathrm{s}}(0)$, as expected.

Finally, we would like to point out that while the diffusivity shown in Figure 8 is nearly independent of concentration, this is not normally the case. In general D(c) depends strongly on the state of the polymer as we have shown recently. Only far above the glass transition temperature of the homopolymer is $\mathrm{D}(\mathrm{c})$ constant. At lower temperatures, $\mathrm{D}(\mathrm{c})$ becomes concentration dependent as the effective temperature of the polymer melt is reduced towards its glass transition temperature. The behavior of $\mathrm{D}(\mathrm{c})$ and the form of the concentration profile were also found to be related. The shape of the solvent concentration profile is changed from concave to convex as D(c) changed from being a constant to concentration dependent.

55 Darken, L.S. Trans. AIME 1948, 175, 184

56 Maginn, E.J.; Bell, A.T.; and Theodorou, D.N. J. Phys. Chem. 1993, 97, 4173

57 Skoulidas, A.I. and Sholl, D.S. J. Phys. Chem. B 2001, 105, 3151

58 Thompson, A.P. and Heffelfinger, G.S. J. Chem. Phys. 1999, 110, 10693 


\section{Interdiffusion of solvent into a block copolymer film}

Diffusion of solvent into multiblock copolymers strongly depends on the orientation of microdomains to the film surface. Solvent diffusion coefficients were found to be higher for microdomains oriented perpendicular to the film surface than for microdomains oriented parallel to the surface. As shown in Figure 3 the microdomain orientation for the systems used for the interdiffusion study is on the average normal to the interface.

The rate at which the solvent penetrates into the polymer can be determined either taking the location of the polymer-solvent interface or the weight gain by the polymer as a function of time. Figure 10 shows the amount of solvent absorbed by the copolymers films versus $\mathrm{t}^{1 / 2}$. Since the film surfaces after evaporation are somewhat rough, the solvent layer was placed just above the highest point of the polymer film. As a result, the very early time data for the interdiffusion are somewhat ill-defined. However after a short time the solvent fills in the gap between the film and the initial solvent layer. For all the systems, Figure 10 shows approximately linear dependence on $\mathrm{t}^{1 / 2}$ up to the saturation point. This indicates that the diffusion behavior of the solvent in all the systems is Fickian. The rate of solvent absorption, the slope of the curve, of systems III and IV is the same though system IV absorbs less amount of solvent, which is comparable to that of system II, at saturation. Note that the surface area of the film is fixed and is only allowed to expand in the normal to the surface direction. This constraint may place limits on the extent of swelling and may have resulted in an early saturation of the systems than would have been experimentally.

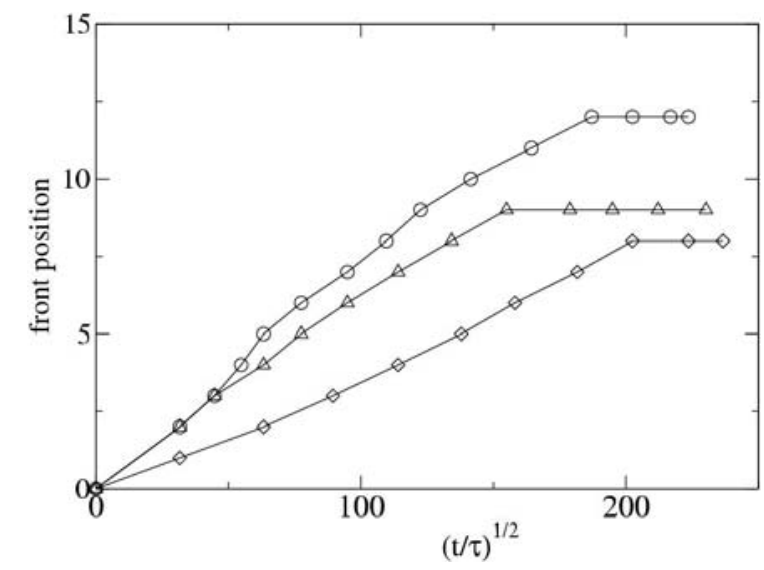

Figure 10 Weight gain in terms of the number of solvent monomers diffused into the polymer at a given time t for system II ( $\square)$, system III $(0)$, and system IV $(\Delta)$.

To further investigate the diffusion behavior of the solvent, the position of the polymersolvent interface as a function of time is shown in Figure 10. Since the flexible part of the segment has lower surface tension, the interface is basically between the flexible block part of the segment and the solvent. The position of the interface, shown in Figure 11, on the average shows a $t^{\wedge} 1 / 2$ dependence in agreement with the homopolymer result and also the Fickian behavior observed by Figure 10. This is because, the solvent swells the flexible block part of the chain and thus the diffusion of solvent mainly takes place through the flexible block segments. 


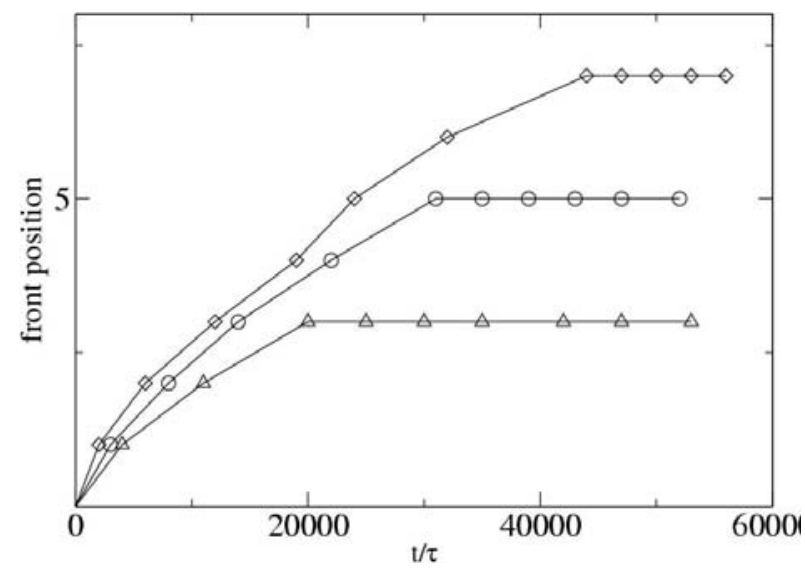

Figure 11 The location of the polymer segment-solvent interface as a function of time for system II $(\square)$, system III (o), and system IV $(\Delta)$

It is important to consider the effect of block connectivity on the motion of the block segments of the copolymers. Since the blocks are covalently bonded their dynamics is constrained as reflected in the dependence of the interface position of the copolymers on the length of the blocks. For system II, which has shorter block segments, the motion of flexible and stiff block segments are highly correlated. That is, in order to swell the flexible segment normal to the surface the stiff segment has to be stretched. However, for system III and IV the flexible part can swell significantly without stretching the stiff block segment.

\section{Conclusions}

Large scale molecular dynamics and grand canonical Monte Carlo simulation techniques were used to study solvent evaporation from homopolymer and heteropolymer films along with the interdiffusion of solvent into this film. As in most cases, where the structure of the film is not know a priori, the model polymer films were produced by dissolving the polymer in a solvent and subsequently evaporating the solvent. This method produces structures that are in local equilibrium as in experiments. As the solvent evaporates, a sharp increase in the polymer density at the film/vapor interface is observed which creates a polymer density gradient that acts as a barrier for further solvent evaporation. For both homopolymer and heteropolymer films, the rate of solvent evaporation was found to be an exponentially decreasing function of time. In addition, for multiblock copolymer films the rate of solvent evaporation, the width of the polymer/vapor interface, and the resulting domain structure were found to be dependent on the stiffness of the block segments. We also showed that the final morphologies of the multiblock films strongly depend on the block length.

The reverse process that is the interdiffusion of solvent into a polymer film was also studied. For homopolymer films the weight gain by the polymer matrix increased as $t^{1 / 2}$ in agreement with Fickian diffusion. The diffusivity $\mathrm{D}(\mathrm{c})$ as a function of concentration was determined from the solvent concentration profile using the one-dimensional Fick's diffusion equation. The dependence of the diffusivity $\mathrm{D}(\mathrm{c})$ on solvent concentration was found to be strongly dependent on the state of the polymer. The diffusivity is approximately a constant for a polymer far above its glass transition temperature, but then becomes concentration dependent as one approaches the glass transition temperature. The behavior of $\mathrm{D}(\mathrm{c})$ and the shape of the solvent concentration profile were found to be directly related. The diffusivity calculated from the solvent concentration profile is in good agreement with the diffusivity calculated from an 
equilibrated solvent-polymer mixture using the Darken equation. For multiblock copolymer films, where the stiffer block is below its glass transition temperature, the solvent swelled the softer block of the segment. In this case, the weight gain by the polymer matrix was found to be in accordance with Fickian diffusion. 


\title{
Sulfonated Random and Block Copolyimides
}

\begin{abstract}
A novel sulfonated copolyimide was prepared from 4,4-oxydianiline, sulfonated 4,4'oxydianiline, and 4,4'-(4,4'-isopropylidenediphenoxy) bis(phthalic anhydride). Both random and block structures of this copolyimide were prepared by varying the timing of monomer addition to the polymerization reaction. The polymers were converted to their acid forms and then cast into films. The degree of sulfonation of the polymers was verified by ${ }^{1} \mathrm{H}$ NMR, FTIR, and nonaqueous titration. The block copolymers showed higher water uptake values and proton conductivities than random copolymers with similar IEC values. These differences became more pronounced as the IEC value was increased.
\end{abstract}

\section{Introduction}

Sulfonated polyimides have attracted much attention for their potential use as proton exchange membranes (PEMs) due to their excellent thermal, chemical, and mechanical stability. Sulfonated polyimides are usually prepared by first synthesizing a parent polyimide that is sulfonated in a subsequent step. The sulfonation step can be performed on a polymer film or it can take place in solution. An alternative to this approach is the preparation of sulfonated polyimides from sulfonated monomers. Using sulfonated monomers allow one to control the degree of sulfonation and the ionic group distribution. Block copolyimides, prepared by utilizing a sequential addition of sulfonated and non-sulfonated monomers, lead to phase-separated membranes with both hydrophilic (sulfonic acid-containing) and hydrophobic (non-sulfonated) domains $[59,60]$.

Perfluorosulfonic acid membranes, such as DuPont's Nafion membrane, which are typically used as polymer electrolytes in PEM fuel cells, are known to have ion-rich domains that form proton transport channels [61]. In this work, a series of sulfonated polyimides have been prepared from dianhydride based on bisphenol-A (BPADA) and a combination of 4,4'oxydianiline (ODA) and oxydianiline disulfonic acid (ODADS). Both random and block copolymers have been prepared in order to study the effect of hydrophilic block size on the formation of proton conducting domains.

\section{Experimental \\ Materials}

All chemicals were purchased from Fisher Scientific except for ODA and 4,4'-(4,4'isopropylidenediphenoxy) bis(phthalic anhydride) (BPADA) which were purchased from Aldrich Chemical Co. NMP and $m$-cresol were distilled under vacuum from $\mathrm{P}_{2} \mathrm{O}_{5}$ and BPADA was recrystallized from a 1:2 mixture of acetic anhydride and toluene. ODADS (in

59 Vallejo, E.; Pourcelly, G.; Gavech, C.; Mercier, R.; Pineri, M.; J. Mem. Sci., 1999, 160, 127

60 Piroux, F.; Espouche, E.; Escoubes, M.; Mercier, R.; Pineri, M. Macromol. Symp., 2002, 188, 61

61 Wang, F.; Hickner, M.; Kim, Y.S.; Zawodzinski, T.A.; McGrath, J.E. J. Mem. Sci., 2002, 197, 231 
triethylammonium salt form) was prepared from 4,4'-oxydianiline by a previously reported method [62].

\section{Synthesis of Random Copolyimides}

The polymerization method for a random copolyimide with 40 mole \% ODADS is given. ODADS (1.7331 g, $4 \mathrm{mmol}$ ), Et $\mathrm{t}_{3} \mathrm{~N}$ (1.62 g, $16 \mathrm{mmol}$ ), and $m$-cresol (40 mL) were charged to a 3necked round-bottom flask equipped with a nitrogen inlet/outlet, vapor trap, and a magnetic stir bar. The flask was heated at $40{ }^{\circ} \mathrm{C}$ until the ODADS was dissolved (about 1h). BPADA (5.2051g, $10 \mathrm{mmol})$, ODA (1.2013g, $6 \mathrm{mmol})$, benzoic acid (1.709g, $14 \mathrm{mmol})$, and $m$-cresol (10 $\mathrm{mL}$ ) were added to the flask and the temperature was increased to $80{ }^{\circ} \mathrm{C}$ for $2 \mathrm{~h}$, and then to 180 ${ }^{\circ} \mathrm{C}$ for $18 \mathrm{~h}$. The reaction mass was cooled to room temperature before pouring it into acetone in a blender. After blending, the mixture was filtered and the solid was Soxhlet extracted with acetone for $18 \mathrm{~h}$.

\section{Synthesis of Block Copolyimides}

The polymerization method for a block copolyimide with 40 mole \% ODADS is given. ODADS (1.7334 g, $4 \mathrm{mmol}$ ), Et ${ }_{3} \mathrm{~N}$ (1.62 g, $16 \mathrm{mmol}$ ), and $m$-cresol (40 mL) were charged to a 3necked round-bottom flask equipped with a nitrogen inlet/outlet, vapor trap, and a magnetic stir bar. The flask was heated at $40{ }^{\circ} \mathrm{C}$ until the ODADS was dissolved (about 1h). BPADA (2.0823g, $4 \mathrm{mmol}$ ) was added and the reaction mass was stirred at $40{ }^{\circ} \mathrm{C}$ for $15 \mathrm{~h}$. A second portion of BPADA (5.2051g, $10 \mathrm{mmol})$, plus ODA (1.2012g, $6 \mathrm{mmol})$, benzoic acid (1.710g, 14 mmol), and $m$-cresol $(10 \mathrm{~mL})$ were added to the flask and the mixture was stirred at $40{ }^{\circ} \mathrm{C}$ for $3 \mathrm{~h}$. The temperature was the increased to $80{ }^{\circ} \mathrm{C}$ for $5 \mathrm{~h}$ and then to $180{ }^{\circ} \mathrm{C}$ for $18 \mathrm{~h}$. The reaction mass was cooled to room temperature before pouring it into acetone in a blender. After blending, the mixture was filtered and the solid was Soxhlet extracted with acetone for $18 \mathrm{~h}$.

\section{Proton Exchange and Film Formation}

Polymer samples (2-3 g in triethylammonium salt form) were dissolved in NMP at room temperature. Concentrated sulfuric acid (1-3 mL, depending on the sulfonation level of the polymer) was added dropwise and the resulting mixtures were stirred at room temperature until all precipitate had dissolved. The polymers were then precipitated in $\mathrm{DI} \mathrm{H}_{2} \mathrm{O}$ in a blender and soxhlet extracted with acetone.

To cast a film, $900 \mathrm{mg}$ of the polymer was dissolved in $10 \mathrm{~mL}$ NMP and filtered onto a clean glass dish with a $9 \mathrm{~cm}$ diameter. The solvent was evaporated under vacuum at $40{ }^{\circ} \mathrm{C}$ for three days. Films were lifted off of the dishes by immersion in $\mathrm{DI} \mathrm{H}_{2} \mathrm{O}$.

\section{Characterization and Measurements}

Infrared (IR) spectra were recorded on a Perkin Elmer Spectrum GX FTIR spectrometer from solution-cast films. ${ }^{1} \mathrm{H}$ NMR spectra were recorded on a Bruker DRX $400 \mathrm{MHz}$ instrument using DMSO- $d_{6}$ as solvent. Gel permeation chromatography (GPC) was performed in a $\mathrm{LiBr} / \mathrm{NMP}$ solvent system at room temperature with a flow rate of $1.0 \mathrm{~mL} / \mathrm{min}$. The weightaverage and number average molecular weights were calculated with respect to polystyrene standards.

62 Fang, J.; Guo, X.; Harada, S.; Watari, T.; Tanaka, K.; Kita, H.; and Okamoto, K. Macromolecules 2002, 35, 9022 
The thermooxidative behavior of both the triethylammonium salt form and acid form of the copolymers was measured on a TA instruments TGA 2050. The samples were dried in the thermogravimetric analysis (TGA) furnace at $200{ }^{\circ} \mathrm{C}$ for $1 \mathrm{~h}$ before evaluation from 60 to $800{ }^{\circ} \mathrm{C}$ in air at a heating rate of $10{ }^{\circ} \mathrm{C} / \mathrm{min}$.

The ion exchange capacities (IECs) of the acid forms of the polymers were determined by nonaqueous potentiometric titration of DMAc solutions with a standard $\mathrm{NaOH}$ solution. Films (approximately $5 \mathrm{~cm} \times 2 \mathrm{~cm}$ ) were soaked in $50 \mathrm{~mL}$ of $1.0 \mathrm{M} \mathrm{Na}_{2} \mathrm{SO}_{4}$ for 24 hours prior to titration. The solution of polymer and $\mathrm{Na}_{2} \mathrm{SO}_{4}$ were then titrated to an endpoint of $\mathrm{pH} 7$ with $0.01 \mathrm{M} \mathrm{NaOH}$. The IEC of the film was computed by

$$
I E C=\frac{v_{\text {base }} *[\mathrm{NaOH}]}{m_{\text {dry }} * 0.001}
$$

where $\mathrm{v}_{\text {base }}$ is the volume of base required to reach the endpoint, $[\mathrm{NaOH}]$ is the concentration of the base, and $\mathrm{m}_{\mathrm{dry}}$ is the mass of the dry polymer. All IEC values reported in this work are the average of three titrations.

Water uptake measurements were carried out by immersing films in $\mathrm{DI}_{2} \mathrm{O}$ at room temperature for 24h. The films were taken out, wiped with tissue paper, and quickly weighed on a microbalance to determine the wet mass of the film $\left(\mathrm{W}_{\text {wet }}\right)$. The films were then dried under $\mathrm{P}_{2} \mathrm{O}_{5}$ and vacuum at room temperature or $120^{\circ} \mathrm{C}$ for $24 \mathrm{~h}$ and weighed again to determine the dry mass of the film $\left(\mathrm{W}_{\mathrm{dry}}\right)$. Water uptake was calculated by the following equation:

$$
\text { Uptake }=\left[\frac{W_{\text {wet }}-W_{d r y}}{W_{d r y}}\right] * 100 \%
$$

Proton conductivity of the membranes was measured by four-probe electrochemical impedance spectroscopy (EIS) using a Solartron 1260 frequency response analyzer coupled with a Solartron 1287 potentiostat. EIS was performed on water-immersed samples by imposing a relatively small (10 $\mathrm{mV}$ amplitude) sinusoidal (AC signal) voltage across the membrane sample at frequencies between $100 \mathrm{kHz}$ and $100 \mathrm{~Hz}$ (scanning from high to low frequencies); and the resultant current response was measured. Due to their brittleness, some of the polyimides were cast on PET film substrates to support them during the conductivity measurements. Membranes supported on PET film substrates gave comparable proton conductivity values and frequency responses to unsupported membranes - the substrates did not affect the conductivity measurements. A schematic diagram of the membrane conductivity cell is shown in Figure 12. The outer electrodes are connected to the working and counter electrodes on the 1287 potentiostat, and the two inner electrodes are connected to the reference electrodes.

EIS was performed by imposing a small sinusoidal (AC signal) voltage, $10 \mathrm{mV}$, across the membrane sample at frequencies between $100 \mathrm{kHz}$ and $100 \mathrm{~Hz}$ (scanning from high to low frequencies), and measuring the resultant current response. From the amplitude and phase lag of the current response, a complex number was computed which is called the impedance composed of a real component, Z', and an imaginary component, Z”. An example of the raw data is shown in Figure 13. 


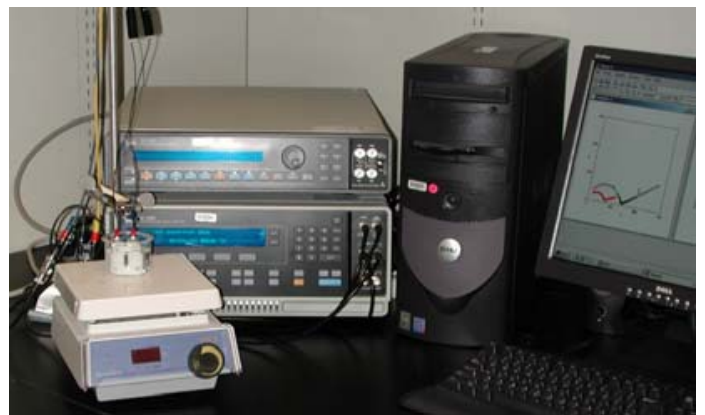

Conductivity Test Equipment
1. Securing screws

2. Teflon blocks

3. Stainless steel electrodes

4. Equilibration windows

5. Membrane sample

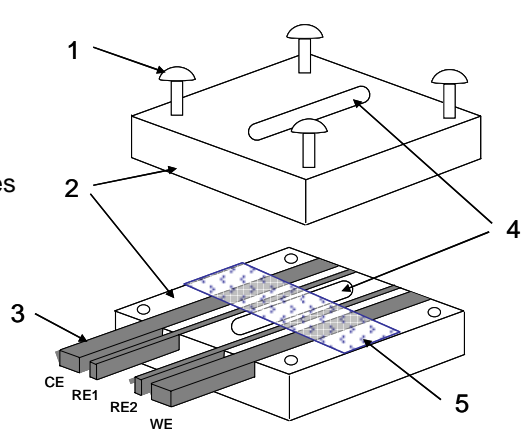

Test Cell

Figure 12 4-Point Membrane Proton Conductivity Cell Conductivity Capability via a Solatron 1260 Impedance Analyzer and Solatron 1287 Potentiostat..

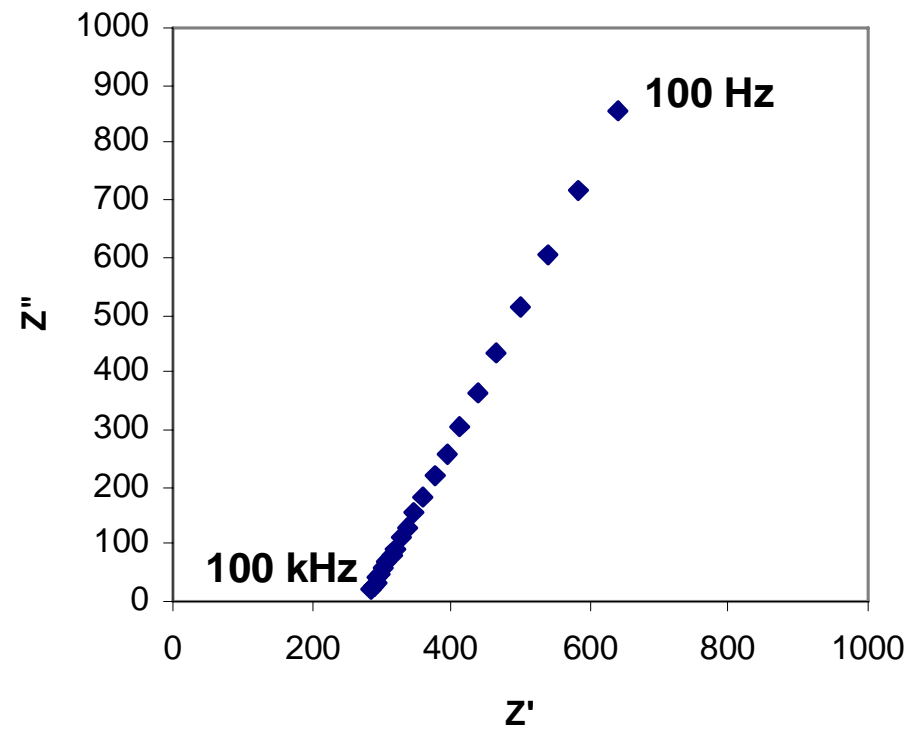

Figure 13 Impedance response of a typical proton conducting membrane between $100 \mathrm{kHz}$ and $100 \mathrm{~Hz}$.

To compute the membrane proton conductivity from the complex impedance response, the impedance line is extrapolated to the $x$-axis. The extrapolated value of the real impedance where the imaginary response is zero $\left(Z^{\prime}\right.$ at $\left.Z^{\prime \prime}=0\right)$ is then taken as the resistance of the membrane and Equation 3 is used to compute the membrane proton conductivity,

$$
\kappa=\frac{\mathrm{L}}{\mathrm{Z}^{\prime} \mathrm{A}}
$$


where $L$ is the length between the sense electrodes, $Z$ ' is the real part of the impedance response (extrapolated to Z" = 0), and A is the area available for proton conduction (width $\mathrm{x}$ thickness). All proton conductivities reported here were measured with the film immersed in liquid water at $30^{\circ} \mathrm{C}$ during the measurement time.

\section{Results and Discussion \\ Random and block copolyimides}

Random and block copolyimides were prepared by a one-pot polycondensation method in NMP solution using benzoic acid as catalyst. The random copolyimides were prepared by a twostep synthesis in which the ODA and ODADS were first allowed to react at low temperature (40$80^{\circ} \mathrm{C}$ ) with one molar equivalent of BPADA to form a random poly(amic acid). In the second step, the temperature was raised to $180{ }^{\circ} \mathrm{C}$ and two equivalents of water per repeat unit were removed as the polyimide formed.
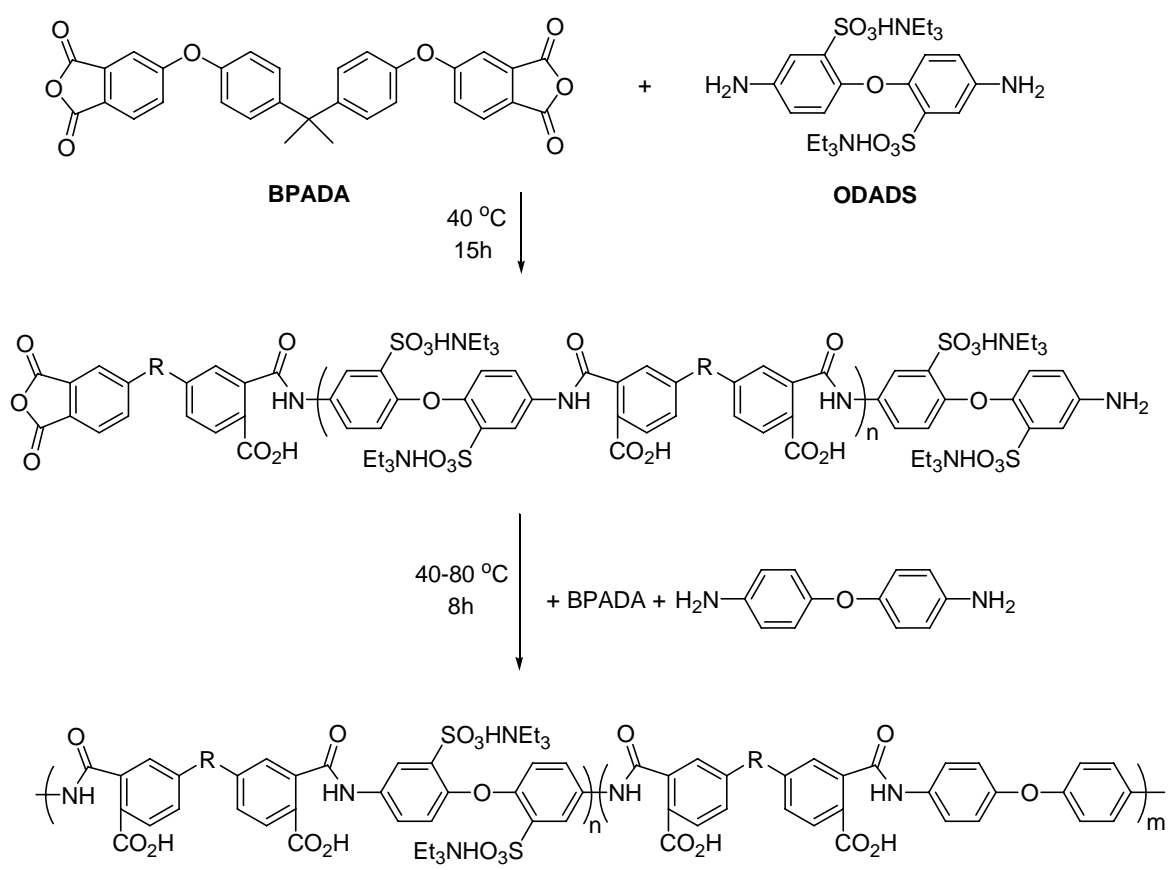

$$
\begin{gathered}
180^{\circ} \mathrm{C} \\
18 \mathrm{~h}
\end{gathered}
$$
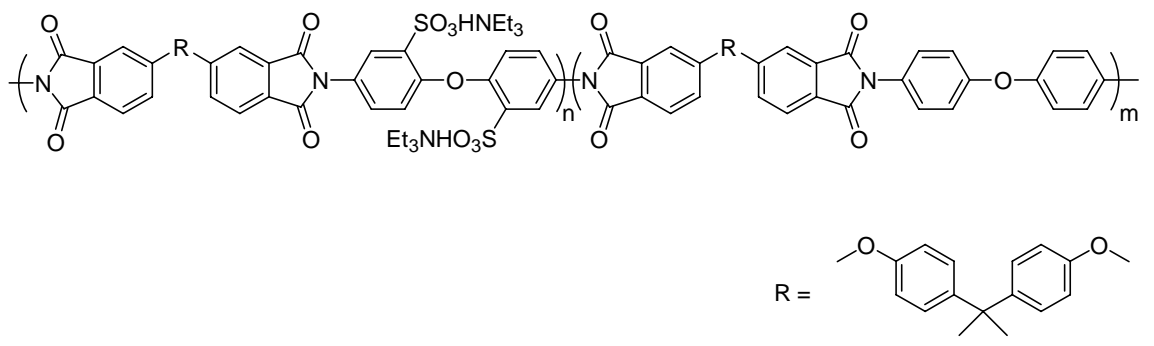

Figure 14 Three-step synthesis of block copolyimides 
The block copolyimides were prepared by a three-step synthesis (Figure 14) in which the ODADS was first allowed to react with one equivalent of BPADA at low temperature $\left(40{ }^{\circ} \mathrm{C}\right)$ to form a poly(amic acid) with exactly two sulfonic acids per repeat unit. In the second step, the ODA was added along with a stoichiometric equivalent of BPADA and the reaction was kept at 40-80 ${ }^{\circ} \mathrm{C}$ as blocks of non-sulfonated poly(amic acid) formed. In the third step, the temperature was raised to $180{ }^{\circ} \mathrm{C}$ and two equivalents of water per repeat unit were removed as the polyimide formed. The sizes of the sulfonated and non-sulfonated blocks were not determined but are presumed to be rather large given the reactivity of the monomers and the fact that equimolar amounts of diamine and dianhydride were added in both the first and second steps.

Random and block copolyimides were obtained by precipitation of the $m$-cresol polymerization solutions into acetone. The residual catalyst and $m$-cresol were removed by Soxhlet extraction with acetone. High molecular weight copolyimdes were obtained over the desired range of compositions. The relative molecular weights were determined by GPC (Table2). The block copolymers have lower molecular weights than their random analogs. This is due to the sequential addition of BPADA in the block copolymer synthesis which effectively doubles the error in the reaction stoichiometry. The polyimides in Table 2 are named such that the numbers in the name reflect the ratio of ODADS to ODA and the final letter indicates random (R) or block (B) structure.

Table 2 Properties of Polyimides.

\begin{tabular}{|c|c|c|c|c|c|}
\hline \multirow[t]{2}{*}{ Polymer } & \multirow[t]{2}{*}{ ODADS:ODA ${ }^{\mathrm{a}}$} & \multirow[t]{2}{*}{$M_{\mathrm{n}}(\mathrm{g} / \mathrm{mol})^{\mathrm{b}}$} & \multirow[t]{2}{*}{ Polydispersity } & \multicolumn{2}{|c|}{ IEC (meq/g) } \\
\hline & & & & Calculated $^{\mathrm{c}}$ & Measured \\
\hline PI28R & $17: 83$ & 86,000 & 2.8 & 0.52 & 0.50 \\
\hline PI46R & $38: 62$ & 72,100 & 1.8 & 0.95 & 0.89 \\
\hline PI55R & $47: 53$ & 76,800 & 2.5 & 1.19 & 1.13 \\
\hline PI28B & $19: 81$ & 44,700 & 2.3 & 0.52 & 0.54 \\
\hline PI46B & $36: 64$ & 26,100 & 1.8 & 0.99 & 0.94 \\
\hline PI55B & $48: 52$ & 22,200 & 1.9 & 1.23 & 1.19 \\
\hline
\end{tabular}

${ }^{1} \mathrm{H}$ NMR was used to confirm the structure of the copolymers and to evaluate the degree of sulfonation (Figure 15). Peak assignments were made based on previously reported assignments for BPADA and ODA repeat units in other polyimides [63,64]. By comparing the integrals of the peaks at $7.95 \mathrm{ppm}$ (proton c) and $7.82 \mathrm{ppm}$ (proton $\mathrm{j}$ ), the ratio of ODADS to ODA in the copolyimides was measured and found to be quite close to the charged monomer ratio (Table 2).

63 Brereton, I.; Devasahayam, S.; Hill, D.J.T. and Whittaker, A.K. Radiation Phys. and Chem., 2004, 69, 65 64 Einsla, B.R. Hong, Y-T.; Kim, Y.S.; Wang, F.; Gunduz, N. and McGrath, J.E. J. Polym. Sci. Part A: Polym. Chem., 2004, 42, 862 
The presence of sulfonic acids was also confirmed by infrared spectroscopy (Figure 16). In particular, the peak at $1030 \mathrm{~cm}^{-1}$ ( $\mathrm{S}=\mathrm{O}$ stretching) increases as the relative amount of ODADS increases. NMR and IR spectra of random and block copolyimides with the same ODADS to ODA ratio were identical.
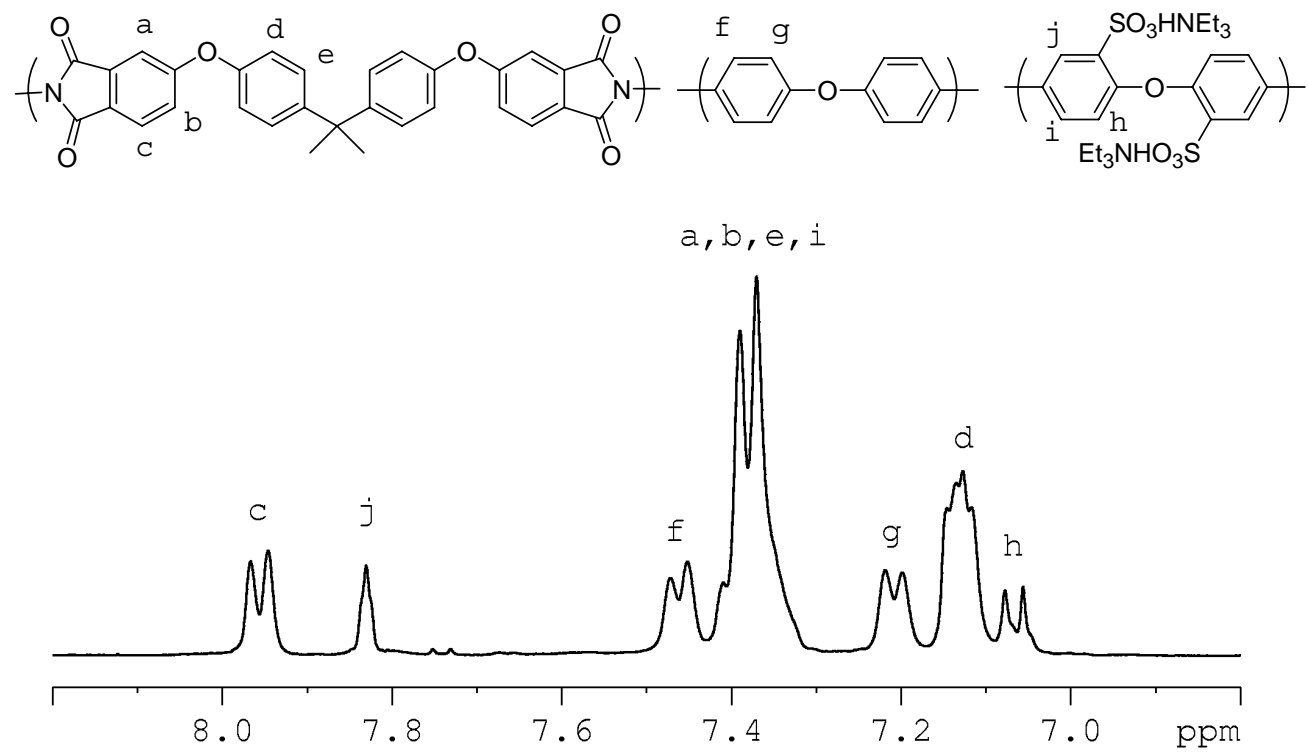

Figure 15 Three-step synthesis of block copolyimides

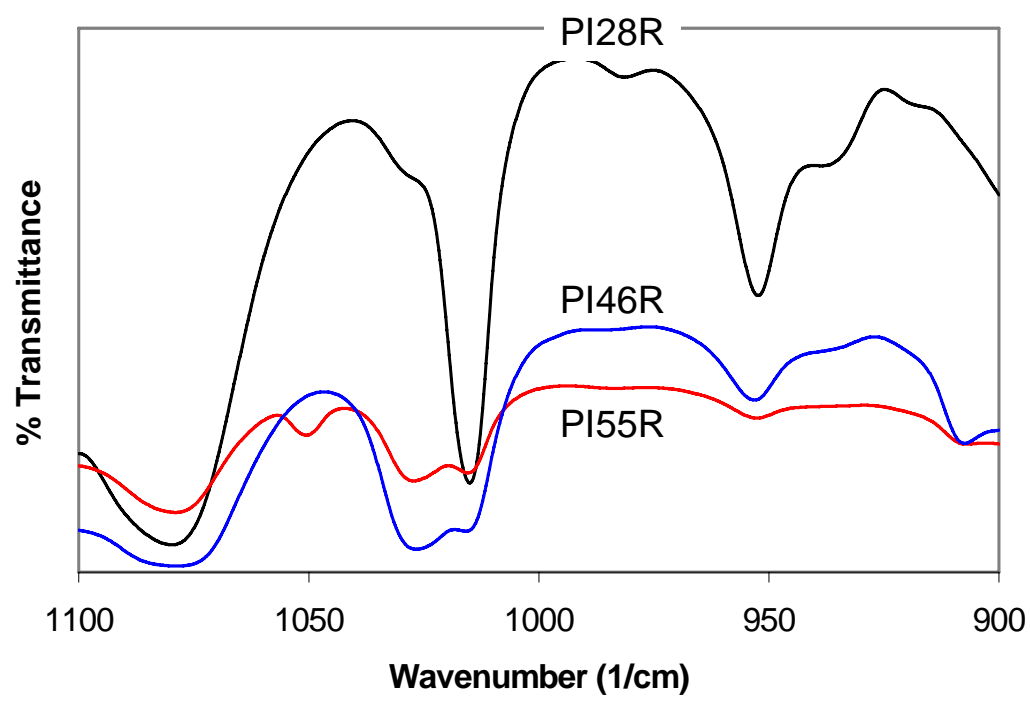

Figure 16 IR spectra of random copolyimides.

Films of the copolyimides in their triethylammonium salt form were slow to convert to their acid forms when treated with aqueous acid so a solution ion exchange technique was 
developed. Solutions of the polymer salts in NMP were treated with $\mathrm{H}_{2} \mathrm{SO}_{4}$ and then precipitated into DI $\mathrm{H}_{2} \mathrm{O}$. Analysis by ${ }^{1} \mathrm{H}$ NMR showed that this treatment succeeded in converting 90-95 \% of the triethylammonium sulfonate groups into sulfonic acid groups. The copolyimides in their acid forms could then be cast into films by slow evaporation of NMP solutions under vacuum at $40{ }^{\circ} \mathrm{C}$. IEC values of these films were determined by nonaqueous titrations and they were all in good agreement with the expected values (Table 2). The calculation to determine the expected IEC values included a correction for the small amount of residual triethylamine present in the films. GPC analysis confirmed that this acidification technique had no significant impact on molecular weight.

The copolyimides were investigated by TGA in both their salt and acid forms. The samples were analyzed between 60 and $800{ }^{\circ} \mathrm{C}$ at a heating rate of $10^{\circ} \mathrm{C} / \mathrm{min}$ in air (Figure 17). All the polymers showed a two-step degradation profile with the first step occurring at around $300{ }^{\circ} \mathrm{C}$ due to desulfonation. The amount of weight lost in this step varied directly with the degree of sulfonation (left). The onset temperature of the first step was slightly higher for the polymers in their salt forms (right). The second step was attributed to degradation of the polymer backbone. TGA analyses of random and block copolyimides with the same ODADS to ODA ratios were not significantly different.
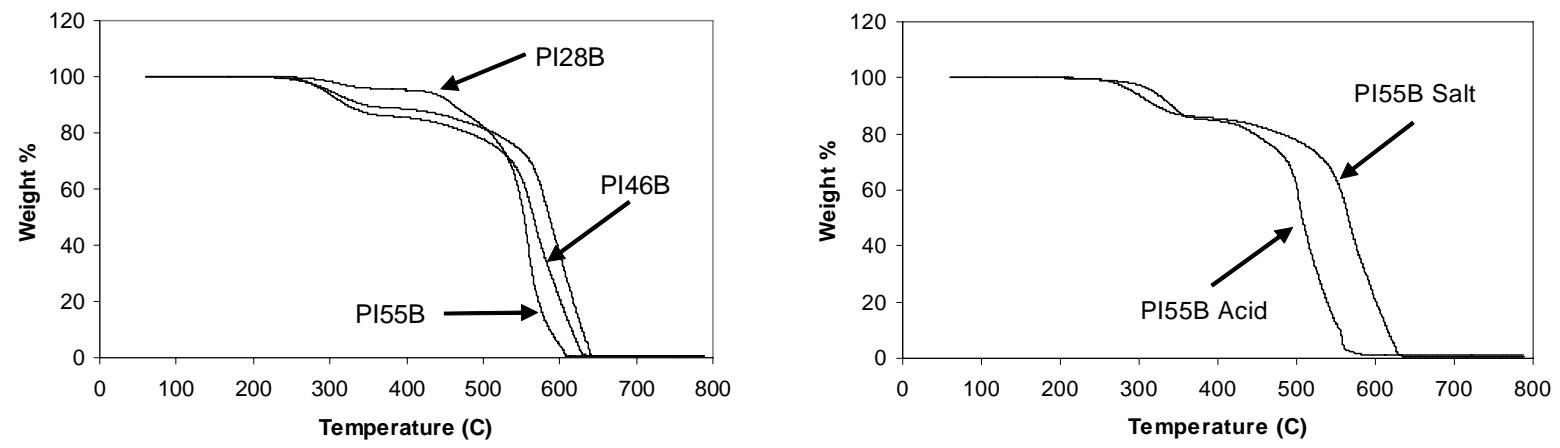

Figure 17 TGA of sulfonated copolyimides. The right plot shows a comparison of the acid form of PI55B versus its salt form and the left plot compares the block copolyimides in their acid forms with varying levels of sulfonation.

The amount of water absorbed by each polyimide film is plotted in Figure 18 as a percentage of the mass of the dry film. As the IEC of the random polyimides increased, the water uptake increased in a linear fashion. The block copolyimides showed a similar relationship at low IEC values, although the amount of water absorbed was greater for the block structures. This can be attributed to larger hydrophilic domains in the block copolymers. At high IEC values, the water uptake in the block copolymers increased sharply, presumably because the hydrophilic domains were so large that they contact one another and formed an interpenetrating network through the film.

The presence of such a hydrophilic network results in ion channels which enhance proton conductivity. Figure 19 shows proton conductivity versus IEC value for the random and block copolyimides. At low IEC values, the conductivities of both the random and block structures 
were rather low. Conductivity increased as the number of sulfonic acid groups increased, but it showed a sharper increase for the block copolyimides than it did for their random analogs. As with water uptake, this difference between random and block copolymers was due to the relative sizes of the hydrophilic domains.

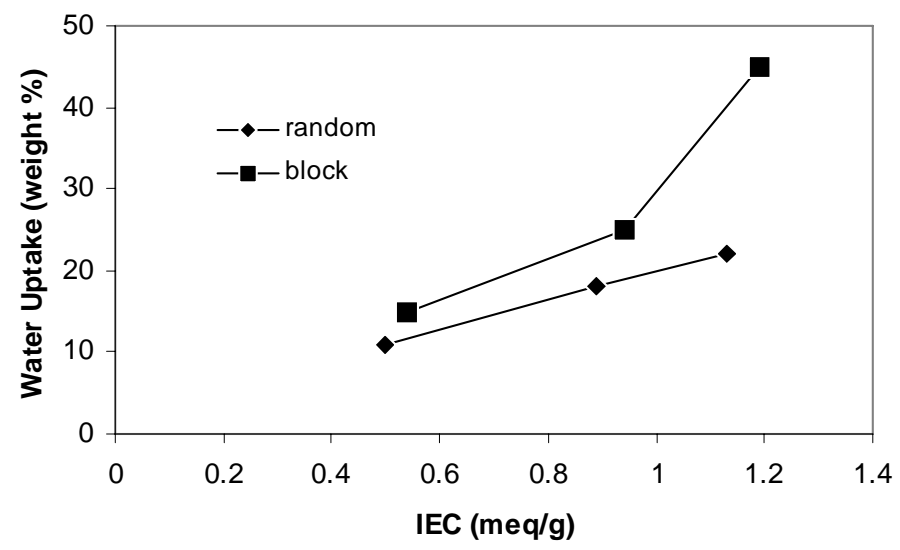

Figure 18 Water uptake of sulfonated copolyimide films.

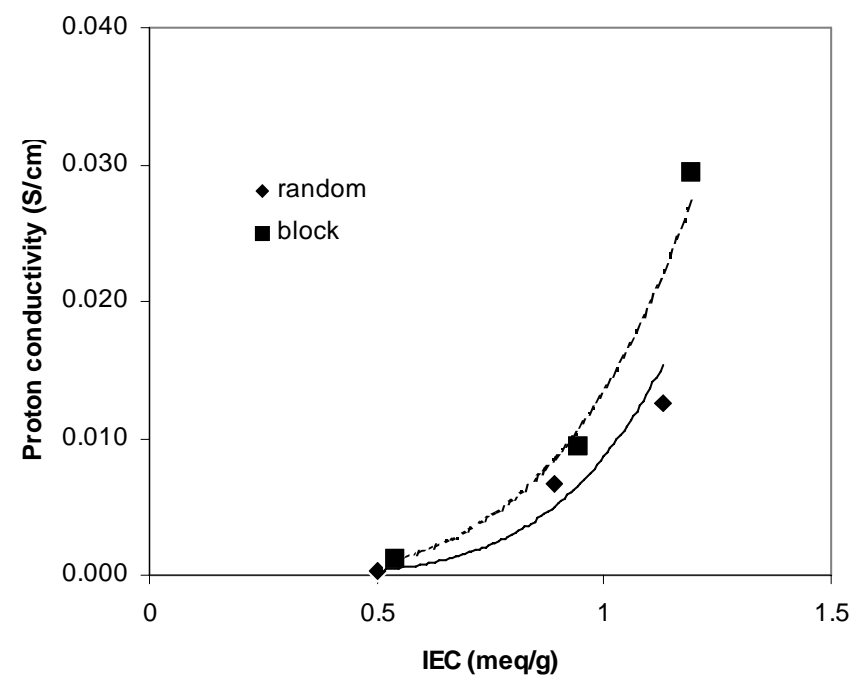

Figure 19 Proton conductivities of sulfonated copolyimide films.

\section{Polyimides based on Six-Membered Rings}

Polyimides based on six-membered rings are known to be more hydrolytically stable than their counterparts with five-membered rings, a series of sulfonated polyimides prepared from naphthalene dianhydride (NDA) were prepared. For the diamine monomer, it was decided that 4,4'-diaminodiphenylsulfone (DPS) and its sulfonated analog, 4,4'-diamino-2,2'disulfodiphenylsulfone (DSDPS), would be used. DSDPS is similar in structure to the ODADS 
monomer used in the previous study but polymers made with DSDPS were predicted to be more hydrophilic due to hydrogen bonding ability of the sulfone group. Sulfones are also electron withdrawing groups (rather than ethers which donate electron density) which should increase the acidity of any attached sulfonic acids by stabilizing the sulfonate anions. These two effects, increased hydrophilicity and increased acidity, should both result in membranes with increased proton conductivity.

The synthesis of DSDPS is not reported in the chemical literature and direct sulfonation of DPS with fuming sulfuric acid gives a product with only about $80 \%$ purity. The impure product isn't soluble in common organic solvents and so purification by recrystallization or chromatography isn't possible. Sublimation was also tried, but it did not yield a pure product. An alternate route for preparing the desired polyimides was therefore implemented. This new route (Figure 20) started with sulfonation of 4,4'-thiodianiline (TDA) using conditions similar to those used to sulfonate ODA. The disulfonated sulfide (DSTDA) could then be used as a monomer to prepare sulfonated polyimides with sulfides in the backbone. This precursor polymer could then be oxidized with hydrogen peroxide to yield the desired polyimide with sulfones in the backbone.
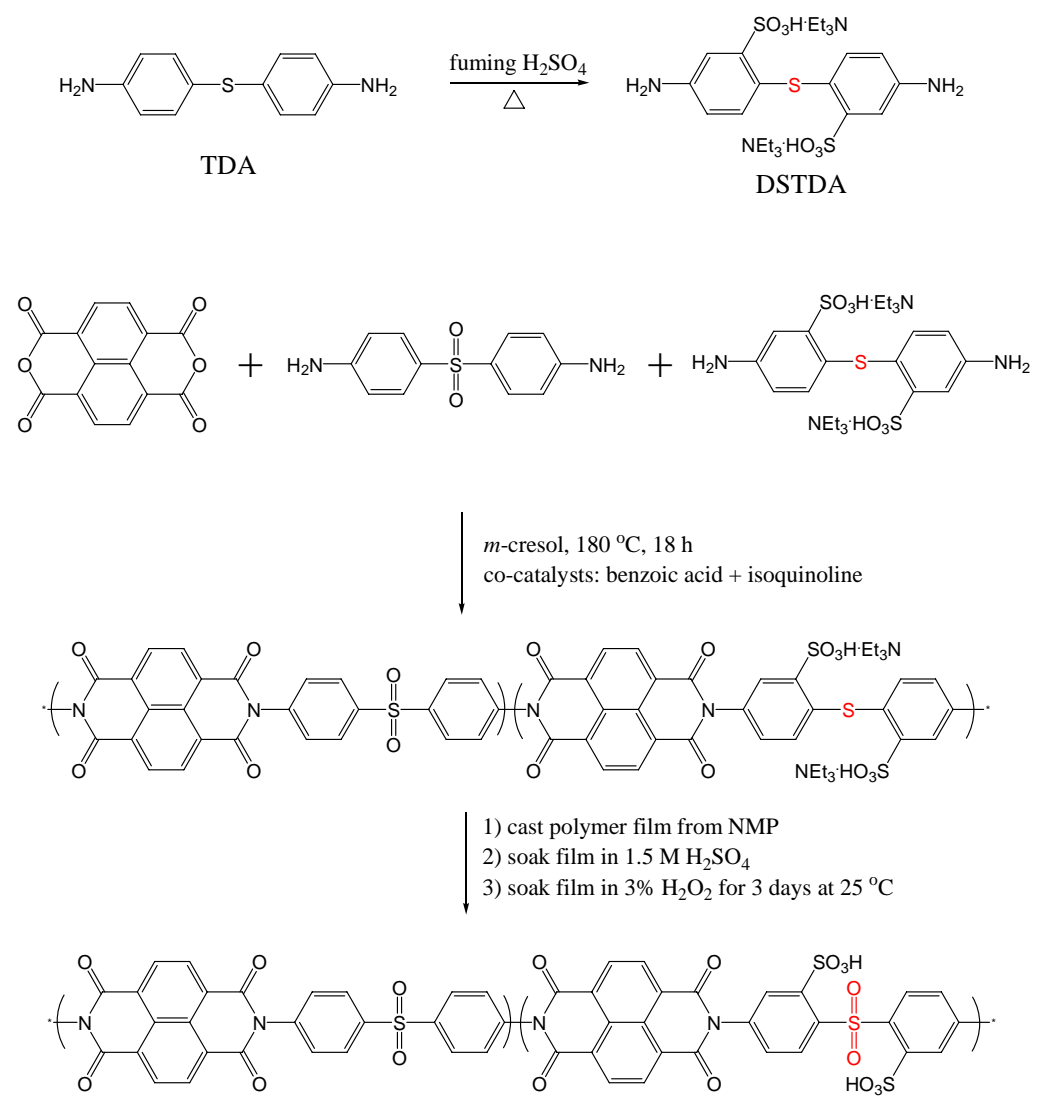

Figure 20 Preparation of Sulfonated Polyimides with Six-membered Rings.

Table 3 lists some of the characterization results for the polymers. Three different precursor polymers were prepared with 30, 50, and 70 mole \% DSTDA. Each of those precursor 
polymers was oxidized and these polymers are named with the suffix -ox in Table 2. The molar ratios of the sulfonated to non-sulfonated monomers were determined my proton NMR and the measurements are all in close agreement with the charged monomer ratios. The ion exchange capacities of the membranes are also in close agreement with the values calculated from the charged monomer ratio.

Table 3 Characterization of Polyimides with Six-membered Rings

\begin{tabular}{lcccc}
\hline Polyimide & \multicolumn{2}{c}{$\begin{array}{c}\text { DSTDA : DPS } \\
\text { molar ratio }\end{array}$} & \multicolumn{2}{c}{$\begin{array}{c}\text { Ion Exchange Capacity } \\
\text { (meq/g) }\end{array}$} \\
& Charged & Measured $^{a}$ & Theoretical $^{\text {Theasured }}{ }^{b}$ \\
\hline DSTDA30 & $30: 70$ & $30: 70$ & 1.16 & 1.11 \\
DSTDA30-ox & $30: 70$ & $29: 71$ & 1.14 & 1.07 \\
DSTDA50 & $50: 50$ & $51: 49$ & 1.84 & 1.89 \\
DSTDA50-ox & $50: 50$ & $51: 49$ & 1.78 & 1.69 \\
DSTDA70 & $70: 30$ & $72: 28$ & 2.57 & 2.49 \\
DSTDA70-ox & $70: 30$ & $72: 28$ & 2.50 & 2.45 \\
\hline${ }^{a}$ Determined by ${ }^{1} \mathrm{H} \mathrm{NMR.}^{b}$ Ion exchange capacity determined by titration of an NMP solution.
\end{tabular}

Figure 21 shows the results of water uptake and conductivity measurements on these membranes. The water uptake increases as the number of sulfonated repeat units increases for each set of polymers and the water uptake also increases for each polymer upon oxidation. The conductivity trends are similar to the water uptake trends so that, as predicted, the polymers with sulfone units in the backbone have higher conductivities than the polymers with sulfide units in the backbone. A general trend with most sulfonated polymers is that conductivity tends to increase as the water uptake increases. Therefore it is difficult to say whether the higher conductivities after oxidation are due to the electron withdrawing effects of the sulfone groups or if they are due to the increased affinity for water. The increases in conductivity are most likely due to a combination of these two effects.

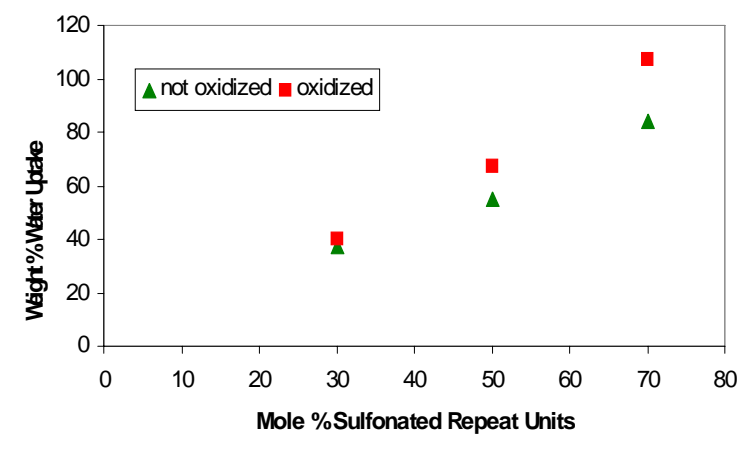

A

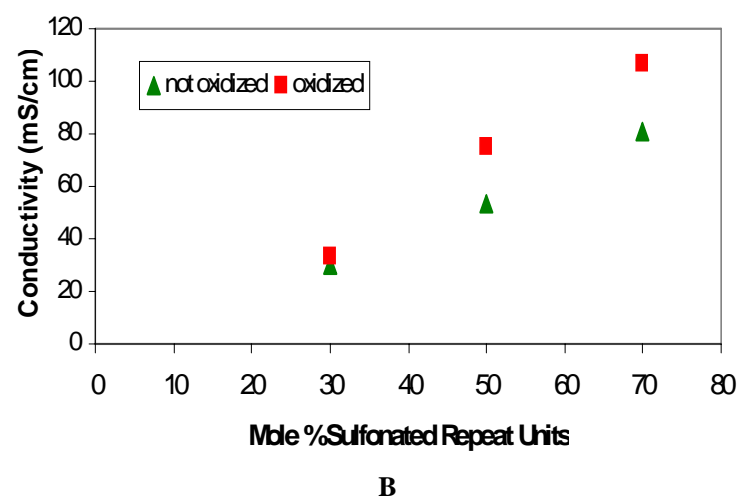

B

Figure 21 (A) Water Uptake and (B) Conductivity of Polyimide Membranes. 
The desired sulfonated polyimides were prepared and cast into membranes and their conductivities were comparable to those of the membranes commonly used in PEM fuel cells. These membranes showed a greater hydrolytic stability than the polyimides with five-membered rings, but they still turned brittle after several days of soaking in water at room temperature. Consequently, they were not able to be used in fuel cell testing.

Poly(2,2'-(m-phenylene)5,5'-bibenzimidazole), PBI, has been studied by several groups for its potential use in proton exchange membranes. PBI has excellent chemical and thermal stability and it can be doped with phosphoric acid to yield membranes with high proton conductivities [65]. Having the acid functionality covalently bonded to the polymer backbone is preferable to doping with a strong acid, however, since a dopant has the potential to leach out of the membrane over time. To that end, PBI with pendant sulfopropyl groups has been prepared (Figure 22) although the conductivities of these membranes are rather low $(1-10 \mathrm{mS} / \mathrm{cm})$ [66]. These sulfopropylated PBI samples were prepared by a reaction between deprotonated PBI and 1,3-propanesultone which results in the random placement of acid groups along the polymer backbone as shown below.

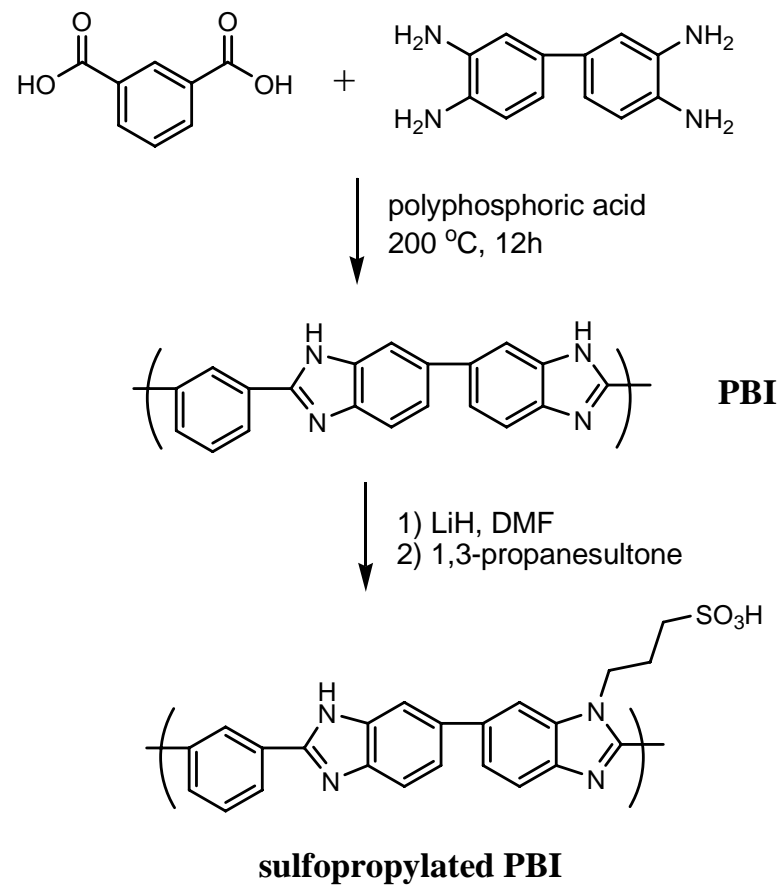

Figure 22 Synthesis of PBI and Addition of Sulfopropyl Groups.

As was demonstrated with the polyimides, sulfonated block copolymers have higher conductivities than their random analogs, so a method for synthesizing PBI with sulfopropylated blocks was devised. The monomer 5-(3-sulfopropoxy) isophthalic acid (5SPIPA) was synthesized as shown in Figure 22. It has been previously reported that synthesis of PBI from 5methoxy isophthalic acid resulted in a low molecular weight polymer due to the electron

65 Litt, M.; Ameri, R.; Wang, Y.; Savinell, R.; Wainwright, J. Mat. Res. Soc. Symp. Proc. 1999, 548, 313

66 Kawahara, M.; Rikukawa, M.; Sanui, K. Polym. Adv. Technol. 2000, 11, 544 
donating effect of the methoxy group, but the same procedure with 4-methoxy isophthalic acid resulted in a polymer with a much higher molecular weight [67]. With this in mind, the monomer 4-(3-sulfopropoxy) isophthalic acid (4SPIPA) was also prepared (Figure 23).<smiles>COC(=O)c1cc(O)cc(C(=O)OC)c1</smiles>

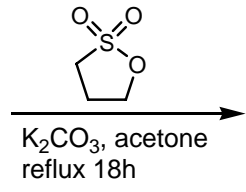<smiles>COC(=O)c1cc(OC)cc(C(=O)OC)c1</smiles>

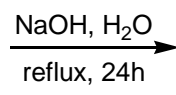<smiles>COc1cc(C(=O)O)cc(C(=O)O)c1</smiles>

5SPIPA<smiles>COC(=O)c1ccc(O)c(C(=O)OC)c1</smiles>

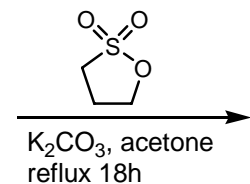<smiles>COC(=O)c1ccc(OC)c(C(=O)OC)c1</smiles>

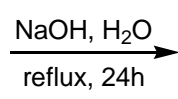

reflux, $24 h$<smiles>COc1ccc(C(=O)O)cc1C(=O)O</smiles>

4SPIPA

Figure 23 Synthesis of Monomers for Sulfonated PBI.

Polymerizations with both 5SPIPA and 4SPIPA in polyphosphoric acid were attempted but when the product polymers were cast into films, the films were too brittle to characterize. This brittleness was almost certainly due to low molecular weights. A second polymerization procedure utilizing a mixture of methanesulfonic acid and phosphorous pentoxide as the solvent was also tried but the resulting polymers were still too brittle to handle.

\section{Conclusions}

A novel sulfonated copolyimide was prepared from ODA, ODADS, and BPADA. Both random and block structures were prepared by varying the timing of monomer addition to the polymerization reaction. A method for converting the salt form of these polymers to their acid form in NMP solution was developed and the resulting polymers were solution cast into films from NMP. The polymer structures were confirmed by NMR and IR spectroscopy. The block copolymers showed higher water uptake and proton conductivity than their random analogs, especially at high IEC values. These differences between random and block structures are due to the presence of large hydrophilic domains in films of the block copolymers. This demonstrated ability to influence film properties by controlling polymer structure will be used in future investigations of other polymer systems.

67 Ueda, M.; Sugita, H. J. Polym. Sci. Polym. Chem. Ed. 1989, 27, 2815 


\title{
Gas Transport in Ladder Polymers
}

\begin{abstract}
An important aspect of creating a high performance fuel cell is controlling the permeability of hydrogen, oxygen, water, and electrons within an electrode membrane assembly (MEA) while simultaneously reducing the interfacial resistance created from bonding the catalyst layer to the PEM. In order to address this challenge, a new family of intrinsically microporous poly(arylene-ether) ladder polymers have been that have exceptionally high oxygen and hydrogen permeability as well as good thermal stability. These materials are based upon 3,3,3',3'-tetramethyl-1,1''-spirobisindane-5,5',6,6'-tetrol (3MSBIT) and 2,3,5,6tetrafluorophthalonitrile (4FPN). Additional studies evaluating the ideal permselectivity for $\mathrm{O}_{2} / \mathrm{N}_{2}, \mathrm{CO}_{2} / \mathrm{CH}_{4}, \mathrm{H}_{2} / \mathrm{CH}_{4}$ reveal that this polymer has properties that exceeds the upper-bound separation characteristics observed for glassy and rubbery polymers. One approach to creating novel polymer electrolyte catalyst materials from this ladder polymer by potentially reducing the polymer's nitriles with $\mathrm{LiAlH}_{4}$ to produce a primary amine that can participate in the nucleophilic attack and ring opening of 1,3-propane sultone. Attempts at reduction the of the nitrile groups and then reacting them with 1,3-propane sultone were unsuccessful but the gas permeabilities of the polymer were above the upper-bound.
\end{abstract}

\section{Introduction}

A desire to lower energy and capital costs for light gas separations (i.e. $\mathrm{H}_{2}$ purification, $\mathrm{O}_{2} / \mathrm{N}_{2}$ separation) has lead to intense development of polymeric membrane materials to accomplish this task. Membranes materials represent an attractive alternative to current technologies, pressure swing adsorption and cryogenics, to further lower production and capital costs for the purification of light gases. The permeability (P) of a gas through a polymeric membrane is dependant on the gases solubility (S) in the polymer and the gases diffusivity (D) through the polymer. The ratio of individual gas permeabilities determines the ideal selectivity for the separation of interest.

$$
\begin{aligned}
& P=D S \\
& \alpha_{A / B}=\frac{P_{A}}{P_{B}}=\left(\frac{D_{A}}{D_{B}}\right)\left(\frac{S_{A}}{S_{B}}\right)
\end{aligned}
$$

A polymers permeability and selectivity for common gases are usually at odds with one another. Typically polymers with high gas permeabilities have poor selectivity and vice versa. Robeson has determined upper bound relationships between permeability and selectivity for several gas pairs.[68] Generally, high $\mathrm{T}_{\mathrm{g}}$ amorphous polymers have offered the best permeability/selectivity combinations for industrially relevant gas separations.[69] The rigid nature of these polymer structures allows a molecular sieving function for gas separation that is not available to rubbery polymer systems.

68 Robeson, L. M. J. Membr. Sci. 1991, 62, 165.

69 Robeson, L. M. Solid State Mater. Sci. 1999, 4, 549. 
There have been a number of investigations to mimic the molecular sieving characteristics of zeolites and carbon molecular sieves by modulating polymer chain packing and mobility. Koros et al have shown permselectivity can be optimized by changing the polymer packing for a series of polypyrrolone ladder-type structures by increasing the sterics of the polymer.[70] Schmidhauser and Koros have shown that incorporating a spirobisindane moiety into the polymer backbone can lead to an increase in permselectivity for certain gas pairs. $[71,72]$ The spirobisindane moiety was shown to inhibit polymer packing and mobility because of its rigid, bulky and highly contorted nature. Recently, McKeown et al built upon this finding by producing a series of ladder polymers based on the spirobisindane moiety.[73,74] In addition to benefits of the spirobisindane ring system mentioned above, intrasegmental polymer mobility is further limited by the ladder structure of the polymer. The contortion and rigidity allow a high degree of void volume to exist. We have prepared one of these ladder polymers and evaluated its permeability and selectivity for use in light gas separations.

\section{Experimental}

All solution NMR spectra were recorded on a Bruker Avance DRX spectrometer. Proton spectra were obtained at an operating frequency of $400 \mathrm{MHz}$. Infrared spectra (FTIR) were obtained using a Perkin Elmer Model 1600 FTIR spectrometer. Thermal analyses were performed on a TA 2910 TGA and a TA 2010 DSC. Size exclusion chromatography was performed using a Polymer Labs PL-GPC210 operating at $40{ }^{\circ} \mathrm{C}$ equipped with RI detection. The mobile phase was THF at a flow rate of $1.00 \mathrm{~mL} / \mathrm{min}$. Separation was affected using two $300 \times 7.5 \mathrm{~mm}$ PLgel $5 \mu \mathrm{m}$ mixed-C columns. Calibration curves were generated using polystyrene standards. Surface area and pore analysis obtained by $\mathrm{N}_{2}$ adsorption at $77 \mathrm{~K}$ using a Quantachrome Autosorb 6B. Membrane permeabilities were obtained using a custom permeation apparatus based on the time lag method. Bulk density measurements were obtained using a Mettler-Toledo XS balance equipped with a density determination kit. The polymer film was weighed in air and in water containing a surfactant to calculate density. Reagents and anhydrous grade solvents (Aldrich, Acros or Fisher) were used as received unless otherwise stated.

\section{Poly(3,3,3',3'-tetramethyl-1,1'-spirobisindane-5,5',6,6'-tetrol-co-2,3,5,6-}

tetraflourophthalonitrile) (1). A mixture of $\mathrm{K}_{2} \mathrm{CO}_{3}$ (6.91 g, $\left.50.0 \mathrm{mmol}\right), 3,3,3$ ',3'-tetramethyl1,1'-spirobisindane-5,5'6,6'-tetrol (3.40 g, $10.0 \mathrm{mmol})$ and 2,3,5,6-tetraflourophthalonitrile (2.00 g, $10.0 \mathrm{mmol}$ ) were stirred in DMF $(50 \mathrm{~mL})$ at $80{ }^{\circ} \mathrm{C}$ for $72 \mathrm{~h}$. The heterogeneous solution was cooled to room temperature and then poured into rapidly stirred $\mathrm{H}_{2} \mathrm{O}(300 \mathrm{~mL})$. The solid was collected by vacuum filtration and washed with water $(2 \times 100 \mathrm{~mL})$ and then $\mathrm{MeOH}(1 \times 100$ $\mathrm{mL})$. The bright yellow solid was taken up in a minimum amount of THF ( 25 mL) and precipitated into rapidly stirring $\mathrm{MeOH}(400 \mathrm{~mL})$. The polymer was collected by vacuum filtration and dried under vacuum $\left(0.1 \mathrm{~mm} \mathrm{Hg} @ 50{ }^{\circ} \mathrm{C}\right)$ to give $4.07 \mathrm{~g}(88 \%)$ of a bright yellow

70 Zimmerman, C. M.; Koros, W. J., J. Polym. Sci., Part B: Polym. Phys. 1999, 37, 1235.

71 Hellums, M. W.; Koros, W. J.; Schmidhauser, J. C. J. Membr. Sci. 1992, 67, 75.

72 Pessan, L. A.; Koros, W. J.; Schmidhauser, J. C.; Richards, W. D. J. Polym. Sci., Part B: Polym. Phys. 1995, 33, 487.

73 Budd, P. M.; Ghanem, B. S.; Makhseed, S.; McKeown, N. B.; Msayib, K. J.; Tattershall, C. E., $2004,2,230$.

74 Budd, P. M.; Msayib, K. J.; Tattershall, C. E.; Ghanem, B. S.; Reynolds, K. J.; McKeown, N. B.; Fritsch, D. J. Membr. Sci. 2005, 251(1-2), 263. 
solid. ${ }^{1} \mathrm{H}$ NMR (400 MHz, $\mathrm{CDCl}_{3}$ ) $\delta$ 6.90-6.70 (br s, 2H), 6.60-6.30 (br s, 2H), 2.70-1.90 (br m, $4 \mathrm{H}), 1.70-0.80$ (br m, 12H). IR (KBr) v 2959, 2235, 1452, 1314, $1011 \mathrm{~cm}^{-1}$. GPC: $\mathrm{M}_{\mathrm{w}}=90,010$; $\mathrm{M}_{\mathrm{n}}=30,800 ; \mathrm{PDI}=2.92$. BET surface area $=750 \mathrm{~m}^{2} / \mathrm{g}$.

Film preparation of spirobisindane polymer. Spiro polymer 3 (550 $\mathrm{mg}$ ) was dissolved in $\mathrm{CH}_{2} \mathrm{Cl}_{2}(15 \mathrm{~mL})$ and filtered ( $2 \mu \mathrm{m}$ glass microfiber). The filtered solution was poured into a flat Petri dish (12 cm dia.) and then placed in a small vacuum desiccator with the gas inlet open to the atmosphere. The solution was allowed to evaporate for 3 days. The dish was removed from the desiccator and, if necessary, the clear yellow was film released from the glass using $\mathrm{H}_{2} \mathrm{O}$.

\section{Results and Discussion}

Spirobisindane polymer was prepared by heating a DMF solution of 3,3,3',3'-tetramethyl1,1'-spirobisindane-5,5'6,6'-tetrol and 2,3,5,6-tetraflourophthalonitrile at $80{ }^{\circ} \mathrm{C}$ for $72 \mathrm{~h}$ in the presence of $\mathrm{K}_{2} \mathrm{CO}_{3}$ (Figure 24). After cooling the solution, polymer was precipitated by pouring into water. The bright yellow polymer was further purified by dissolving in THF and reprecipitating into methanol. Yields of the bright yellow polymer after drying under vacuum were in excess of 85\%. Size exclusion chromatography revealed a molecular weights of $\sim 100,000\left(\mathrm{M}_{\mathrm{w}}\right)$ with PDI's of 3.0-3.5.<smiles>CC(C)(CC1(C)c2cc(O)c(O)cc2CC1(C)C)c1ccc(O)c(O)c1</smiles>

1<smiles>N#Cc1c(F)c(F)c(C#N)c(F)c1F</smiles>

2<smiles>CCOc1cc2c(cc1OCC)CC(C)(C)C2</smiles>

3

Figure 24 Preparation of spirobisindane polymer

Table 4 Single gas permeabilities and ideal selectivities for spiro polymer.

\section{Permeability}

Barrers

\begin{tabular}{lrlllllll}
\hline & & & $\boldsymbol{H e}$ & $\boldsymbol{H}_{2}$ & $\mathbf{C O}_{2}$ & $\boldsymbol{O}_{2}$ & $\boldsymbol{N}_{2}$ & $\boldsymbol{C H}_{4}$ \\
$\mathrm{He}$ & 1016 & $\mathbf{H e}$ & 1.0 & & & & & \\
$\mathrm{H}_{2}$ & 2332 & $\boldsymbol{H}_{2}$ & 0.5 & 1.0 & & & & \\
$\mathrm{CO}_{2}$ & 3496 & $\boldsymbol{C O}_{2}$ & 0.3 & 0.7 & 1.0 & & & \\
$\mathrm{O}_{2}$ & 786 & $\boldsymbol{O}_{2}$ & 1.4 & 3.0 & 4.5 & 1.0 & & \\
$\mathrm{~N}_{2}$ & 238 & $\boldsymbol{N}_{2}$ & 4.5 & 9.8 & 14.7 & 3.3 & 1.0 & \\
$\mathrm{CH}_{4}$ & 360 & $\boldsymbol{C H}_{4}$ & 2.9 & 6.5 & 9.7 & 2.2 & 0.7 & 1.0 \\
\hline
\end{tabular}

Permeabilities are the average of three samples from the same film. The feed pressure was 4 atm for each gas and the temperature was $35^{\circ} \mathrm{C}$. (Barrers, $10^{-10} \mathrm{~cm}^{3}(\mathrm{STP}) \mathrm{cm} /\left(\mathrm{cm}^{2} *_{\mathrm{s}}{ }^{*} \mathrm{mmHg}\right)$ ) 
Free standing films ( $75 \mu \mathrm{m}$ thick) of spirobisindane polymer were prepared by slowly evaporating a $\mathrm{CH}_{2} \mathrm{Cl}_{2}$ solution over a period of three days. The films were optically clear and fluoresced under UV. The time lag method was used to measure single gas permeabilities for helium, hydrogen, carbon dioxide, oxygen, nitrogen and methane at $35^{\circ} \mathrm{C}$ using a 4 atm pressure differential across the membrane (Table 4). Ideal selectivity factors for each gas pair were calculated from the single gas permeabilities. Spirobisindane polymer showed high permeability for each gas, with $\mathrm{CO}_{2}$ having the highest permeability of 3496 Barrers. Our results correlated with previously published data by McKeown et al. Ideal selectivities were particularly good for $\mathrm{O}_{2} / \mathrm{N}_{2}, \mathrm{H}_{2} / \mathrm{CH}_{4}, \mathrm{H}_{2} / \mathrm{N}_{2}$ and $\mathrm{CO}_{2} / \mathrm{CH}_{4}$ with respect to there permeabilities. Each of these gas pairs is at or near the upper bound limit determined by Robeson in 1991.

While initial permeabilities were remarkable, further testing indicated a degradation of gas permeability upon repetitive measurements on a single film (Figure 25). A series of eight permeability measurements were carried out over a period of 2.5 days. Carbon dioxide, hydrogen, oxygen and nitrogen permeabilities all declined approximately 60\%. Helium and methane experienced the least degradation in permeability at $42 \%$ and $49 \%$ respectively. The degradation of permeability was irreversible.

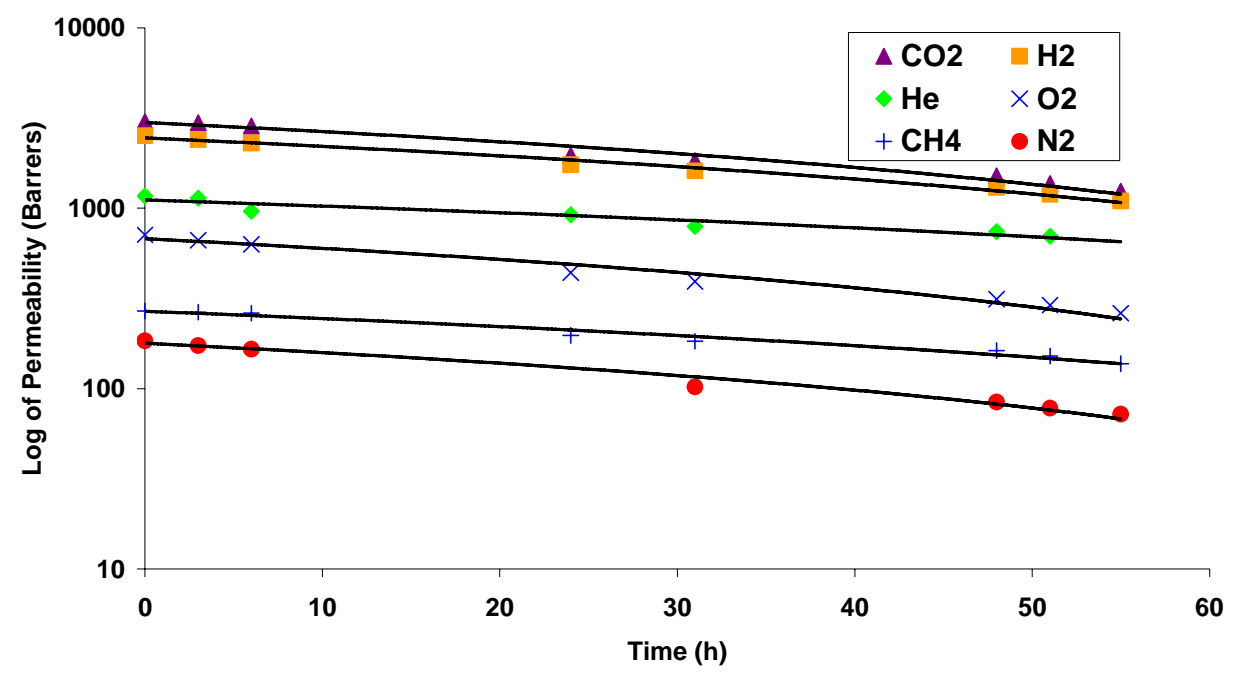

Figure 25 A graph of the time versus the log of permeability.

The decrease in permeability may be a result of a decrease in the free volume of the polymer while in operation. Decreases in the FFV have been modeled and correlated to decreases in gas permeability.[75,76,77,78] This phenomena has been observed with poly(trimethylsilylpropyne) (PTMSP), another high free volume polymer.[79] The fractional

75 Heuchel, M.; Hofmann, D.; Pullumbi, P. Macromolecules 2004, 37, 201.

76 Hofmann, D.; Entrialgo-Castano, M.; Lerbret, A.; Heuchel, M.; Yampolskii, Y. Macromolecules 2003, 36(22), 8528.

77 Park, J.Y. J. Membr. Sci. 1997, 125, 23.

78 Ronova, I.A.; Rozhkov, E.M.; Alentiev, A.Y.; Yampolskii, Y.P. Macromol. Theory Simul. 2003, $12(6), 425$.

79 Nagai, K.; Masuda, T.; Nakagawa, T.; Freeman, B.D.; Pinnau, I. Prog. Polym. Sci. 2001, $26(5), 721$. 
free volume in the polymer film can be indirectly monitored by measuring the bulk density of the film. The bulk density of a spirobisindane polymer film was measured after a series of gas permeability measurement and found to have increased from $1.12 \pm 0.01 \mathrm{~g} / \mathrm{cm}^{3}$ to $1.16 \pm 0.01$ $\mathrm{g} / \mathrm{cm}^{3}$ prior to failure. Using Bondi's group contribution theory [80], the increase in density translates to a $20 \%$ decrease in fractional free volume (FFV) between a new and used polymer film.

Positron annihilation laser spectroscopy (PALS) was carried out to further probe the free volume of the bulk material, an as cast film and a thermally aged film. While PALS does not give a full picture of the FFV, PALS does give an indication of the size and concentration of free volume elements accessible by orthoPostronium (oPs). Table 5 indicates the bulk powder and cast films both have bimodal distributions of free volume elements, which is characterized by the presence of two oPs lifetimes ( $\tau_{3}$ and $\tau_{4}$ ) and intensities $\left(I_{3}\right.$ and $\left.I_{4}\right)$. While bimodal distributions are not typically seen in glassy polymers, they have been found in PTMSP, some silane containing polyolefins and select polyimides.[81] Solution casting of the bulk powder into a film significantly increases the presence of larger pore volumes as evidenced by an increase in $I_{4}$ from 11.6 to $19.1 \%$. In addition there is a decrease in the concentration of smaller pore elements from 9.7 to $5.8 \%$. As the polymer is thermally aged however, the concentration of larger pore elements $\left(I_{4}\right)$ decreases while the smaller pore size distribution remains constant. This result correlates well with the decrease in FFV observed indirectly by density measurements.

Table 5 Comparison of PALS parameters for spriopolymer 1 for bulk powder, initial cast films, and aged samples.

\begin{tabular}{lcccc}
\hline \multicolumn{1}{c}{ Sample } & $\boldsymbol{\tau}_{\mathbf{3}} \mathbf{( n s )}$ & $\mathbf{I}_{\mathbf{3}} \mathbf{( \% )}$ & $\boldsymbol{\tau}_{\mathbf{4}} \mathbf{( n s )}$ & $\mathbf{I}_{\mathbf{4}}(\mathbf{\%})$ \\
\hline Bulk Powder & 1.6 & 9.7 & 4.8 & 11.6 \\
As-Cast Film & 1.9 & 5.8 & 6.1 & 19.1 \\
Aged Film & 1.9 & 5.8 & 6.2 & 17.5 \\
\hline PALS Uncertainty: $\tau_{3}= \pm 0.2 n s, I_{3}= \pm 0.7 \%, \tau_{4}= \pm 0.2$ ns and $I_{4}= \pm 0.8 \%$ &
\end{tabular}

\section{Conclusions}

A highly contorted ladder polymer was prepared and evaluated for gas transport. The membrane permeabilities were consistent with those of a polymer containing large amount of free volume. Permeabilities were high for all gases tested and ideal selectivities were also good, particularly for $\mathrm{O}_{2} / \mathrm{N}_{2}, \mathrm{H}_{2} / \mathrm{CH}_{4}, \mathrm{H}_{2} / \mathrm{N}_{2}$ and $\mathrm{CO}_{2} / \mathrm{CH}_{4}$ separations. However, degradation of gas permeability and an increase in bulk density was observed during extended testing, suggesting a collapse of free volume within the polymer film. PALS and density measurements suggested free volume decreases as the as the polymer aged. Manipulating polymer functionality or structure to stabilize the polymer morphology will be necessary prior to any commercialization for use in light gas separations.

80 Bondi, A. J. Phys. Chem. 1964, 68(3), 441.

81 Nagai, K.; Freeman, B.; Hill, A.J. J. Polym. Sci., Part B: Polym. Phys. 2000, 38, 1222. 


\section{Polyphenylenes}

\section{Abstract}

Utilizing a purely aromatic polymer, such as poly(phenylene)s, provides a route to potentially improve the thermochemical stability of PEMs due to their inherent thermochemical stability. High molecular weights are necessary for these aromatic polymers to ensure polymer chain entanglements that are responsible for producing physically robust PEM films that can be processed into membrane electrode assemblies that survive within a PEMFC. An example of a sulfonated substituted poly(phenylene) is poly(4-phenoxybenzoyl-1,4-phenylene) that has shown relatively high proton conductivities $\left(10^{-2} \mathrm{~S} / \mathrm{cm}\right)$ and good PEM characteristics as well as other hydrocarbon based PEMs shown in Figure 26 [82]. However, achieving high molecular weights based upon this class of polymer is dependent on the pendent group of the aryl halide monomer, which limits sulfonation and broad functionalization [83].

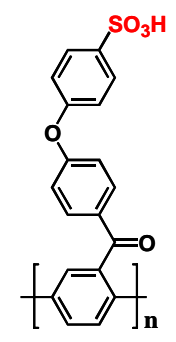

Poly(4-phenoxybenzoyl -1,4-phenylene)

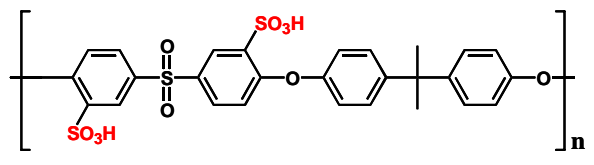

Sulfonated Poly(arylether sulfone)

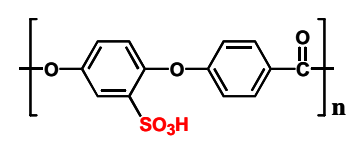

Sulfonated Poly(ether ether ketone)

Figure 26 Alternative hydrocarbon based PEMs.

\section{Introduction}

The subject of this research is the design, synthesis, and physical properties of a sulfonated, highly phenylated poly(phenylene) that provides a very promising solution to achieving PEMs with high molecular weights and overcomes the limitations of sulfonation and broad functionalization (Figure 27). Here we report the first fully aromatic polymer electrolyte that is designed to be processible, thermally and chemically robust, with ionic conductivities rivaling those of Nafion. The backbone polymer, prepared by the Diels-Alder polymerization of 1,4-bis(2,4,5-triphenylcyclopentadienone) benzene with diethynylbenzene, (Figure 27), can be prepared with a wide range of functionalities and configurations that provide an almost unprecedented opportunity to optimize the chemical and physical properties desirable for PEM's [84]. A minimum energy molecular model (Figure 28) of the polymer repeat unit shows a non coplanar phenylene backbone and indicates a rigid rod structure. By themselves, the polymers are insulating and thermally stable to $500^{\circ} \mathrm{C}$, a fact that has made them one of the more important spin-on dielectric materials [85]. Six pendant phenyl groups per repeat unit and the mix of meta

82 Kobayashi, T.; Rikukawa, M.; Sanui, Kohei; Ogata, N. Solid State Ionics, 1998, 106, 219

83 Hagberg, E.C.; Olson, D.A.; Sheares, V.V. Macromol., 2004, 37, 7448

84 Stille, J.K.; Harris, F.W.; Rakutis, R.O.; Mukamal, H. J. Polym. Sci., Part B. 1966, 4, 791

85 Martin, S.J.; Godschalx, J.P.; Mills, M.E.; Shaffer II, E.O.; Townsend, P.H. Adv. Mater., 2000, 12, 1769 
and para configurations imparted by the regiochemistry of the Diels-Alder polymerization make these materials readily soluble in organic solvents and easy processed into thin films. The large number of pendant phenyl groups provides for the facile introduction of up to six sulfonic acid groups per repeat unit, a fact that we use to study the influence of the degree of sulfonation on ionic conductivity, water uptake, and thermal stability.<smiles>CC(C)(C)C(Cl)(Cl)C(Cl)(Cl)C(Cl)(Cl)Cl</smiles><smiles>C=Cc1ccc(C=C)cc1</smiles>

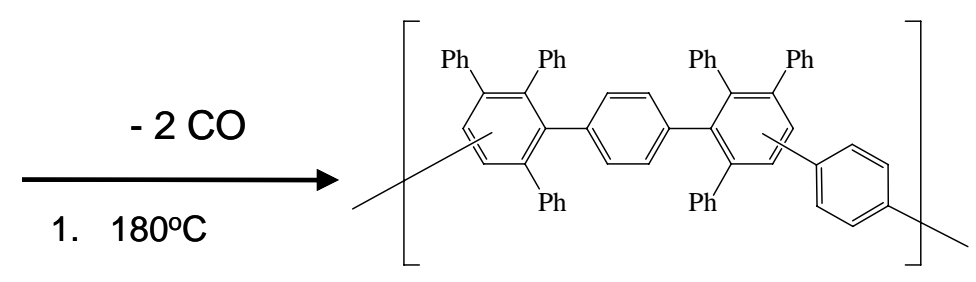

Poly(phenylene)

p-Bis(ethynyl)benzene

Figure 27 Diels Alder Polymerization of 3,3'-(1,4-phenylene)bis(2,4,5triphenyl-2,4-cyclopentadien-1-one) and 1,4-diethynylbenzene to yield the parent polyphenlene.
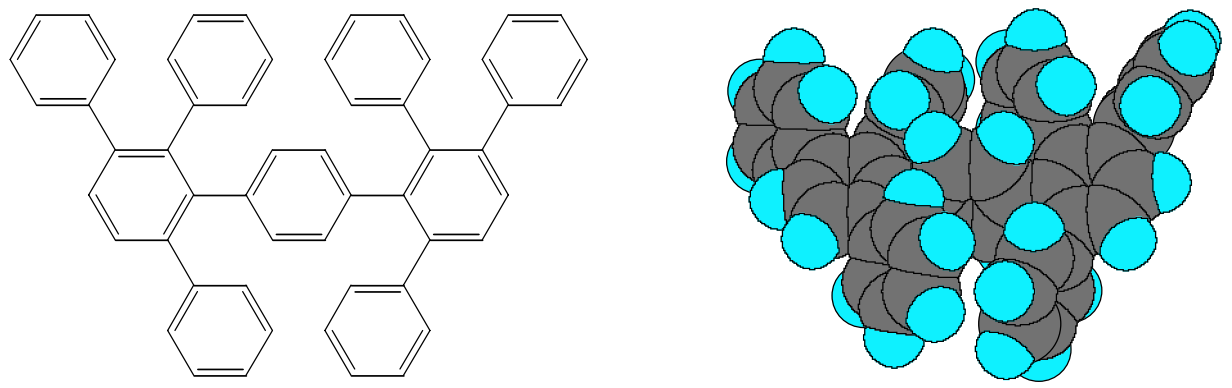

Figure 28 Minimum energy molecular model of repeat unit 


\section{Experimental \\ Materials}

1,4-Bis(2,4,5-triphenylcyclopentadienone) benzene, or bis-tetracyclone, was prepared as described by Noren and Stille (Macromol. Rev., 1971, 5, 385-429). 1,4-Diethynylbenzene was purchased from GFS and sublimed at room temperature before use. Diphenyl ether, chlorosulfonic acid, dimethylacetamide (DMAc) and anhydrous methylene chloride was used as received from Aldrich.

\section{Synthesis of DA Poly(phenylene) [SDAPP0]}

Polymerization of the Diels Alder poly(phenylene)s was performed using a slight modification of the method described in the literature.[86,87] To bistetracyclone (50.0 g; 72.4 mmol) and 1,4-diethynylbenzene (9.13 g; $72.4 \mathrm{mmol})$ in a $500 \mathrm{~mL}$ Schlenk flask, diphenyl ether (250 $\mathrm{mL}$ ) was added and the resulting mixture was frozen in an ice bath. The mixture was freeze-thaw degassed (3X) before heating under argon $(1 \mathrm{~atm})$ at $180{ }^{\circ} \mathrm{C}$ for $24 \mathrm{~h}$. Periodically, carbon monoxide was vented to avoid over-pressurization of the reaction flask. Subsequently, additional diethynylbenzene $(0.10 \mathrm{~g} ; 0.8 \mathrm{mmol})$ was added to the viscous slurry and the mixture was stirred for an additional $12 \mathrm{~h}$ at $180{ }^{\circ} \mathrm{C}$. The reaction vessel was then cooled to room temperature and its contents were diluted with toluene $(300 \mathrm{~mL})$. The polymer was precipitated by dropwise addition of the solution to $1000 \mathrm{~mL}$ of acetone. This dilution in toluene and precipitation in acetone was repeated and the resultant white solid was dried in a vacuum oven for $12 \mathrm{~h}$ at $80{ }^{\circ} \mathrm{C}, 48 \mathrm{~h}$ at $230{ }^{\circ} \mathrm{C}$, and $24 \mathrm{~h}$ at room temperature. A $96 \%$ yield (52g collected) of a tough, yellow solid was obtained. The conversion of the bisethyne to bistetracyclone and final conversion to the parent polymer is shown in Figure 29.
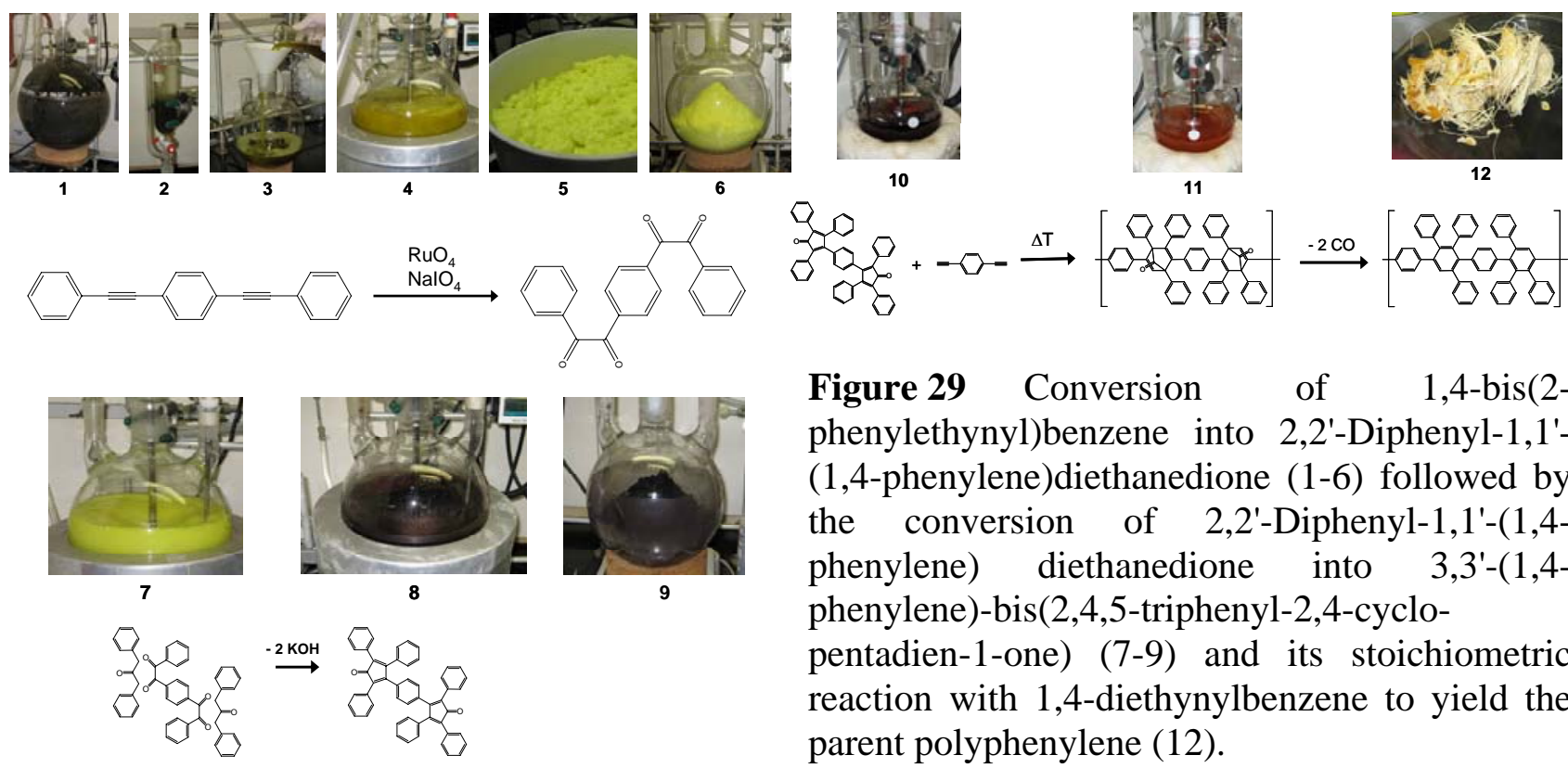

Figure 29 Conversion of 1,4-bis(2phenylethynyl)benzene into 2,2'-Diphenyl-1,1'(1,4-phenylene)diethanedione (1-6) followed by the conversion of 2,2'-Diphenyl-1,1'-(1,4phenylene) diethanedione into 3,3'-(1,4phenylene)-bis(2,4,5-triphenyl-2,4-cyclopentadien-1-one) (7-9) and its stoichiometric reaction with 1,4-diethynylbenzene to yield the parent polyphenylene (12).

86 Olgliaruso, M.A.; Becker, E.I. J. Org. Chem., 1965, 30, 3354

87 Neenan, T.X.; Kumar, U. Macromol., 1995, 28, 124 


\section{Sulfonation of DA Poly(phenylene)}

The repeat unit of SDAPP0 with its six pendent phenyl groups as shown in Figure 30 provides a number of possible sites for sulfonation. However, sulfonation is thought to occur predominantly at the para-positions of the pendant phenyl groups due to their positioning about the sterically congested, con-coplanar, rigid rod backbone (Figure 28) [88]. Therefore, the limits of sulfonation are projected to be between 0 and 6 sulfonic acid groups per repeat unit. By varying the ratio of moles of chlorosulfonic acid to moles of polymer repeat unit charged to the sulfonation reaction, 0.8 to 2.1 sulfonic acid groups per repeat unit were achieved as measured by potentiometric titration.

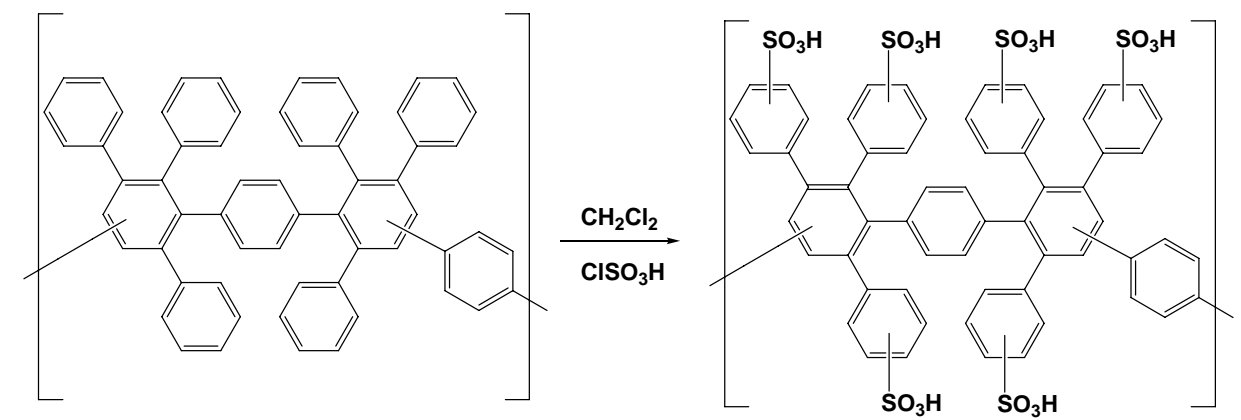

Parent ( SDAPPO )

Sulfonation Level ( 1-6 )

Figure 30 Sulfonation of the Diels Alder poly(phenylene) with the maximum theoretical sulfonation level. The theoretical achievable sulfonation level is 6 sulfonic acid groups per repeat unit.

Our approach to sulfonating SDAPP0 was the creation of a $6 \mathrm{wt} \%$ polymer solution of SDAPP0 and methylene chloride that was subsequently homogeneously sulfonated in situ with chlorosulfonic acid. In a typical sulfonation, SDAPP0 (7.02 g) was added to a flame dried, 500 $\mathrm{mL}$ three-neck, round-bottom flask under argon and dissolved in methylene chloride (6 \% solution by weight). The solution was cooled to $-50{ }^{\circ} \mathrm{C}$ (dry ice/acetonitrile) and chlorosulfonic acid (4.30 g, $36.9 \mathrm{mmol})$ diluted in chloroform $(20 \mathrm{~mL}$ ) was added dropwise though an addition funnel over 15 minutes while being vigorously stirred with a mechanical stirrer under an argon atmosphere. This amount of chlorosulfonic acid gave a 4:1 ratio of acid to polymer repeat unit. Other ratios of sulfonating agent to polymer repeat unit were prepared to attain polymers with various ion exchange capacities, as discussed in the Results and Discussion section. The mixture darkened from bright yellow to black during chlorosulfonic acid addition. After 30 minutes the reaction was warmed to room temperature at which point a dark solid precipitated. The organic solvent was decanted and to the remaining solid was added $300 \mathrm{~mL}$ of a $0.5 \mathrm{M}$ solution of $\mathrm{NaOH}$ that was allowed to react at room temperature for $12 \mathrm{~h}$. The slurry was then heated for $4 \mathrm{~h}$ at 80 ${ }^{\circ} \mathrm{C}$ to ensure sulfonyl chloride conversion. The off-white solid was Soxhlet extracted with deionized water for $48 \mathrm{~h}$ and dried in a vacuum oven at $100{ }^{\circ} \mathrm{C}$ for $48 \mathrm{~h}$ to obtain light yellow solid (9.52 g). ${ }^{1} \mathrm{H}$ NMR (d-DMSO): $\delta$ (ppm) = broad signal 6.35 - 7.22 (peaks at 7.19, 7.09, 6.95,

88 Shifrina, Z.B.; Averina, M.S.; Rusanov, A.L.; Wagner, M.; Mullen, K. Macromol. 2000, 33, 3525 
6.88, 6.64, 6.54). ${ }^{13} \mathrm{C}$ NMR $\left(\mathrm{DMSO}-\mathrm{d}_{6}\right): \delta(\mathrm{ppm})=$ broad signal 138 - 141 (peak at 139) broad signal $131-126$ (peaks at 126.9, 128.7, 129.5, 131.0).

Introduction of increasing numbers of sulfonic acid groups onto polymers improves their ionic conductivity, but also makes the polymers more hydrophilic. In order to have a suitable membrane for PEMFC's, there must be sufficient sulfonic acid groups (meq/g) to provide suitable proton conduction, but few enough to insure that the polymeric film does not lose its mechanical integrity. Table 6 displays the solubility characteristics of the sulfonated samples in a variety of common solvents with respect to the sample's IEC. At every level of sulfonation, the polymer was insoluble in methylene chloride, in contrast to unsulfonated parent polymer. Between IECs of 0.98 and $2.2 \mathrm{meq} / \mathrm{g}$, the samples were soluble in polar aprotic solvents, while remaining insoluble in water. This IEC range is very similar to IEC values studied in other sulfonated aromatic polymers such as sulfonated poly(ether ether ketone). However, when the IEC was increased over $2.2 \mathrm{meq} / \mathrm{g}$ the polymer formed a hydrogel in water eliminating the feasibility of forming a film from these highly sulfonated samples. Table 7 summarizes the ratio of moles of sulfonating agent to polymer repeat unit charged in the reaction and the experimentally determined IEC by titration and Elemental Analysis (EA).

Table 6 Solubility of Sulfonated Diels Alder poly(phenylene) samples (SDAPP) in the sodium salt form

\begin{tabular}{cccccc}
\hline Sample & IEC & $\mathbf{C H}_{\mathbf{2}} \mathbf{C l}_{\mathbf{2}}$ & DMAC & NMP & Water \\
\hline SDAPP0 & 0 & + & - & - & - \\
SDAPP1 & 0.98 & - & + & + & - \\
SDAPP2 & 1.40 & - & + & + & - \\
SDAPP3 & 1.80 & - & + & + & - \\
SDAPP4 & 2.20 & - & + & + & - \\
SDAPP5 & - & - & -+ & -+ & Hydrogel \\
\hline Key: “+”, soluble; “- + swell, “-” insoluble & & &
\end{tabular}

Table 7 Targeted Sulfonation and Experimentally Determined Ion exchange capacity of SDAPP (Sulfonation Stoichiometry)

\begin{tabular}{ccccc}
\hline Sample & $\begin{array}{c}\text { Sulfonation } \\
\text { Stoichiometry }\end{array}$ & $\begin{array}{c}\text { IEC } \\
\text { Experimental }\end{array}$ & $\begin{array}{c}\text { IEC } \\
\text { Elemental Analysis }\end{array}$ & $\begin{array}{c}\text { Sulfonation } \\
\text { Efficiency }^{* *}\end{array}$ \\
\hline SDAPP1 & 1 & 0.98 & 1.18 & 80 \\
SDAPP2 & 2 & 1.40 & 1.55 & 60 \\
SDAPP3 & 3 & 1.80 & 2.14 & 53 \\
SDAPP4 & 4 & 2.20 & 2.64 & 50 \\
\hline
\end{tabular}

* moles of chlorosulfonic acid added per moles of polymer repeat unit in reaction

**\{[Actual Sulfonation] / [Sulfonation Stoichiometry] $\}$ x 100 
A plot of theoretical versus actual sulfonation is shown in Figure 31 in terms of IEC. As expected, the actual sulfonation steadily increased with increasing stoichiometry of chlorosulfonic acid. At low sulfonation levels the sulfonation efficiency was relatively high (80\%), but decreased to 60 to $66 \%$ with increasing concentration of chlorosulfonic acid.

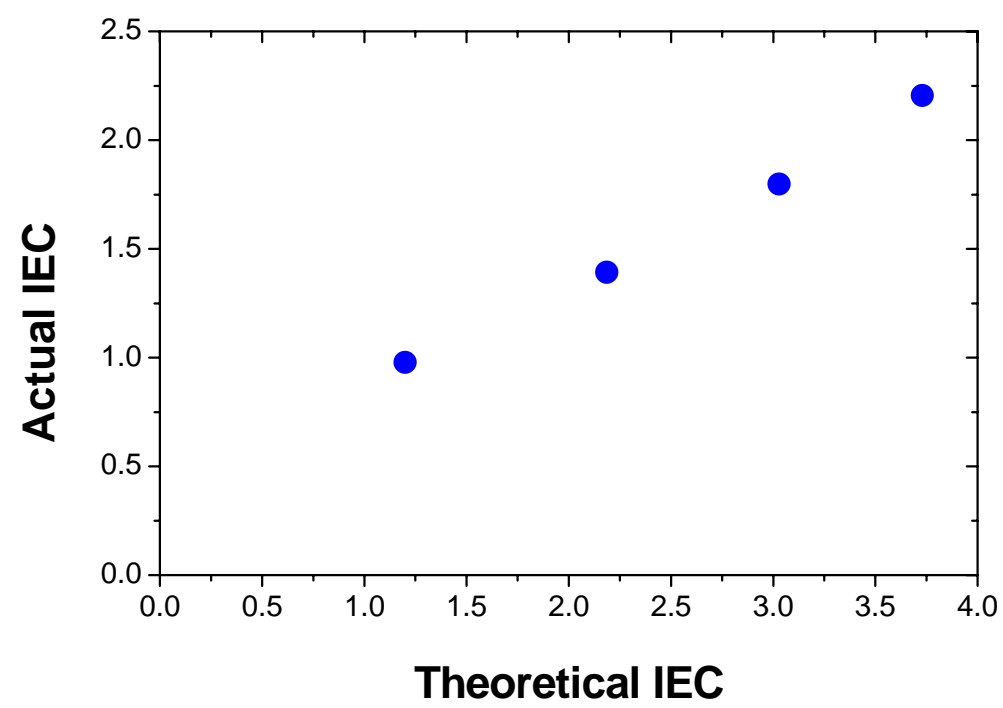

Figure 31 Targeted IEC in the Reaction Mixture versus Actual IEC

\section{Water Uptake and Proton Conductivity of DA Poly(phenylene)}

Electrochemical Impedance Spectroscopy (EIS) was used to collect proton conductivity data for these materials. The instrument and settings used to collect the data were a PAR 273A potentiostat and Schlumberger 1255 High Frequency Analyzer with Z-plot software measuring over a frequency range of $100 \mathrm{kHz}$ to $0.1 \mathrm{~Hz}$ at $0 \mathrm{~V}$ versus an open circuit and a $10 \mathrm{mV}$ amplitude. A series of Nyquist plots were generated based upon this experimental setup represented by real (Z') and imaginary resistance (Z”) in Ohms. The intercept of the X-axis of the imaginary Z” with the real $Z^{\prime}$ in conjunction with the film thickness and electrode area is used to determine the proton conductivity of PEM materials. Measurements were preformed on PEM samples that were allowed to swell and equilibrate in deionized water at $25^{\circ} \mathrm{C}$. Proton conductivity was determined from these samples by quickly removing the swollen films from the water and measuring their resistance. Proton conductivity was determined on films with a nominal thickness of $2.5 \mathrm{mil}$ or $63.5 \mu \mathrm{m}$. Recently, it has been suggested that the temperature (either room temperature or $100{ }^{\circ} \mathrm{C}$ ) used in acid pre-treating films influences the ionic domain microstructure of sulfonated polymers [89]. Sulfonated poly(arylene ether sulfone) copolymer membranes acidified at elevated temperatures were found to imbibe more water and have higher proton conductivities than membranes acidified at room temperature. Since fuel cells typically operate above room temperature all films in this work were pretreated at $100{ }^{\circ} \mathrm{C}$.

89 Kim, Y.S.; Wang, F.; Hickner, M.; McCartney, S.; Hong, Y.T.; Harrion, W.; Zawodzinski, T.A.; McGrath, J.E. J. Polym. Sci. Part B: Polymer Physics, 2003, 41, 2816 
The hydration number $(\lambda)$ is determined from the water mass uptake measurements, IEC of the film sample, mass of water absorbed in into the film $\left(m_{\mathrm{H} 2 \mathrm{O}}=\right.$ wet film minus dry film mass), and $\mathrm{MW}_{\mathrm{H} 2 \mathrm{O}}$ is the molecular weight of water. Equation 1 was used in the determination of the number of water molecules per sulfonic acid group and Figure 32 is a plot of conductivity versus $\lambda$ for SDAPP versus Nafion and Table 8 is a partial summary of the physical property differences between Nafion and SDAPP. The water uptake of SDAPP increased linearly from $21 \%$ to $75 \%$ as the IEC increased from 1.04 to $1.8 \mathrm{meq} / \mathrm{g}$ and increased to $136 \%$ at an IEC of 2.2 .

$$
\lambda=\frac{m_{H 2 O} / M W_{H 2 O}}{m_{d r y} \cdot I E C}
$$

Table 8 IEC, water uptake, hydration number $(\lambda)$, and proton conductivity $(\sigma)$ of SDAPP series and Nafion 117

\begin{tabular}{|c|c|c|c|c|}
\hline & $\begin{array}{c}\text { IEC } \\
\text { (meq/g) }\end{array}$ & $\begin{array}{c}\text { Water Uptake } \\
\text { (wt \%) }\end{array}$ & $\begin{array}{c}\lambda \\
\left(n \mathrm{H}_{2} \mathrm{O} / \mathrm{SO}_{3} \mathrm{H}\right)\end{array}$ & $\begin{array}{c}\sigma \\
(\mathrm{mS} / \mathrm{cm})\end{array}$ \\
\hline SDAPP1 & 1.04 & 21 & 11.2 & 13 \\
\hline SDAPP2 & 1.40 & 36 & 14.3 & 49 \\
\hline SDAPP3 & 1.80 & 75 & 23.1 & 87 \\
\hline SDAPP4 & 2.20 & 137 & 34.6 & 123 \\
\hline Nafion 117 & 0.91 & 36 & 22.0 & 100 \\
\hline
\end{tabular}

Water uptake, $\lambda, \sigma$, and $\Delta H_{f}$ of SDAPP and Nafion 117 evaluated in liquid water at $30^{\circ} \mathrm{C}$

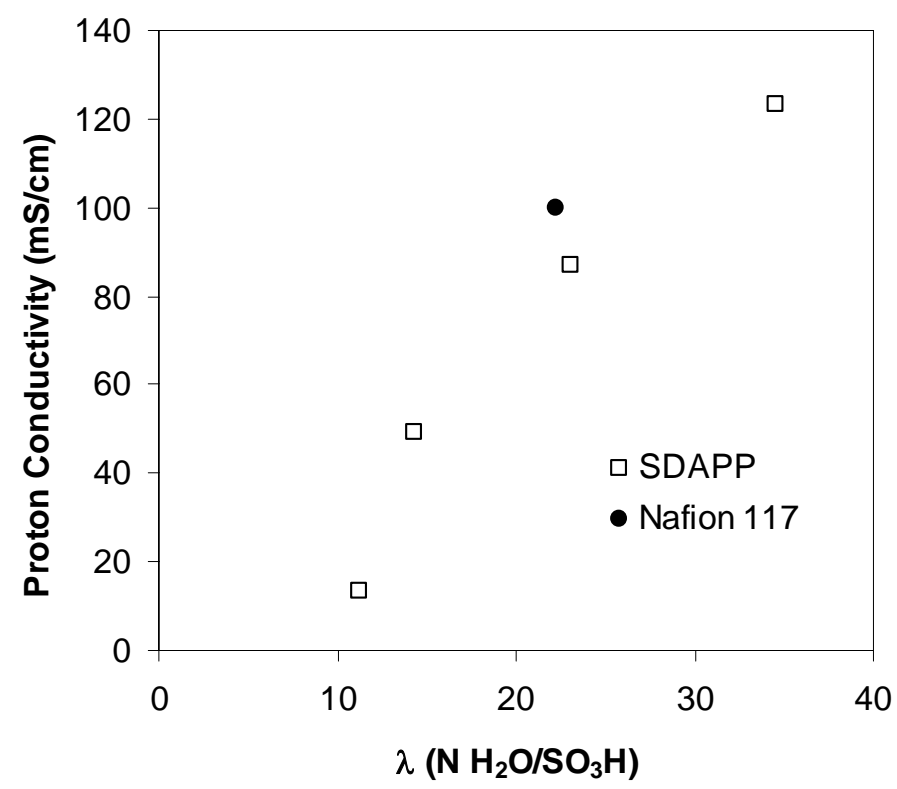

Figure 32 Proton conductivity of SDAPP samples and Nafion 117 immersed in $30^{\circ} \mathrm{C}$ liquid water as a function of hydration number 
The proton conductivity of SDAPP versus Nafion117 as a function of temperature is shown in Figure 33. The results from this study show that it is possible to lower both the activation energy for proton conduction as compared to Nafion, but it is also possible to exceed the proton conductivity of Nafion as demonstrated with SDAPP4. Differences in proton conductivity such as sulfonation method (post vs. monomer), position of sulfonic acid (pendent group vs. backbone), and type of repeat group (phenylene vs. ether-sulfone) will contribute to differences observed in polymer systems. However, this class of poly(phenylene) gives rise to attractive proton conductivities with relatively low water uptake [90].

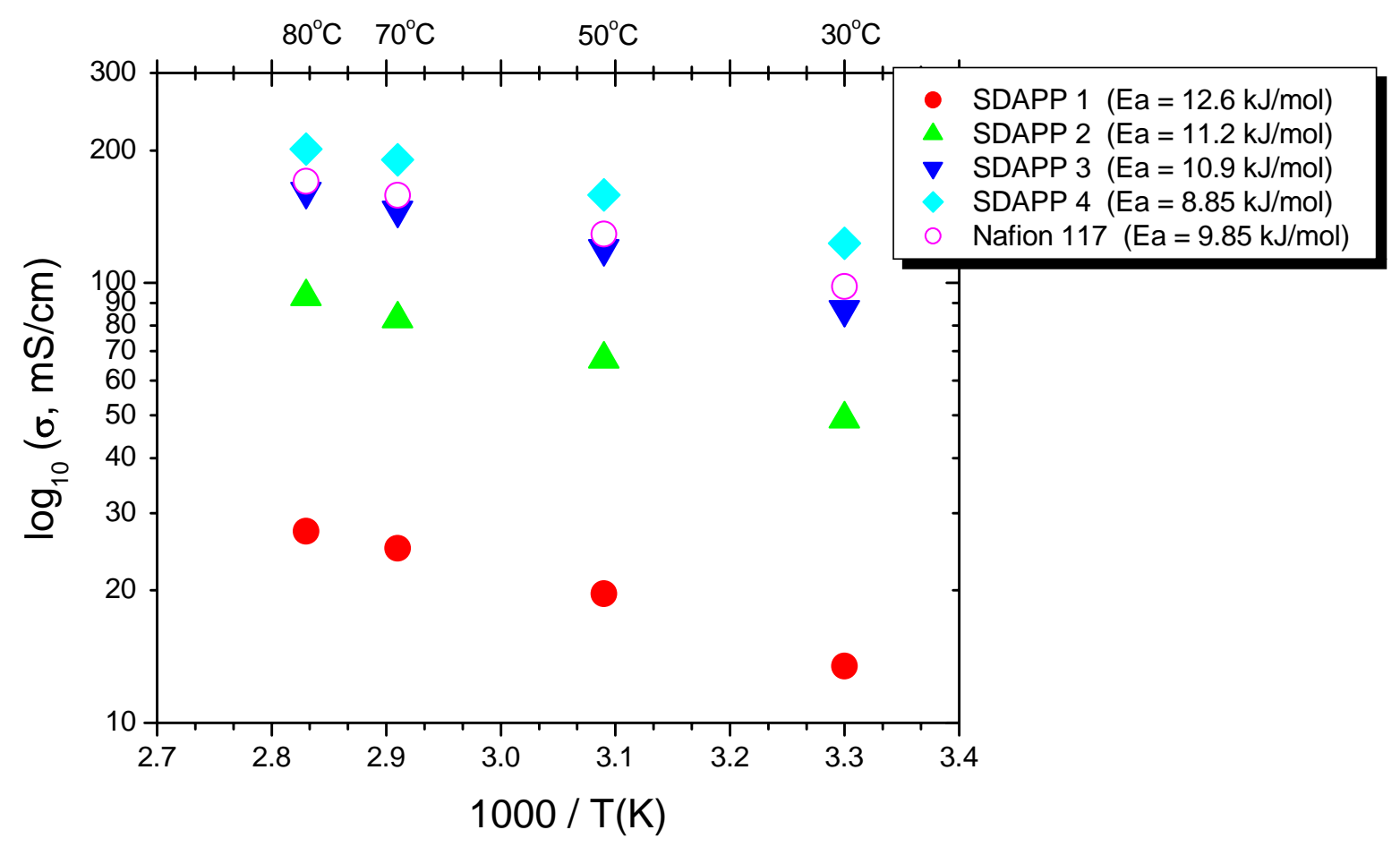

Figure 33 Relationship between proton conductivity, temperature, and activation energy of SDAPP series versus Nafion117 in deionized water from $30^{\circ} \mathrm{C}$ to $80^{\circ} \mathrm{C}$.

\section{Film Formation of DA Poly(phenylene)}

The sodium salt of the sulfonated polymer was dissolved in DMAc (10 wt\% solution) and filtered though a $2 \mu \mathrm{m}$ syringe filter (glass microfiber filter). The solution was cast onto a clean glass plate in an oven at $90{ }^{\circ} \mathrm{C}$ under $\mathrm{N}_{2}$. After $20 \mathrm{~h}$, the film was removed from the glass plate and immersed in de-ionized water $\left(1 \mathrm{~L}, 18 \mathrm{M} \Omega\right.$ ) for one hour at $100{ }^{\circ} \mathrm{C}$ to extract any residual DMAc. The resultant film was then converted into the acid (proton) form by immersion in 2.0 $\mathrm{M} \mathrm{H}_{2} \mathrm{SO}_{4}$ at $100{ }^{\circ} \mathrm{C}$ for one hour. The film was then rinsed thoroughly with de-ionized water and then soaked in de-ionized water $(18 \mathrm{M} \Omega)$ at $100{ }^{\circ} \mathrm{C}$ for another hour to remove any residual acid. The film was stored in de-ionized water until used. A dissolved acid form of the SDAPP polymer is shown in Figure 34 being converted from powder to solution and then cast into a film.

90 Miyatake, K.; Chikashige, Y.; Watanabe, M. Macromol., 2003, 36, 9691 

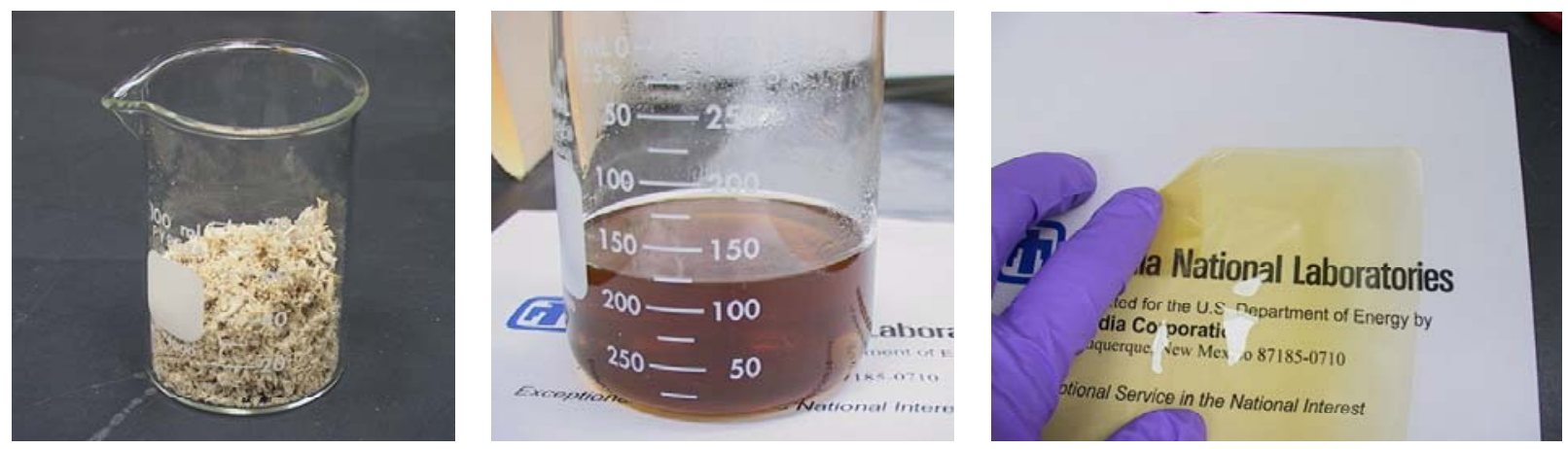

Figure 34 Polymer dissolution and conversion into an acidified film.

\section{Polyphenylene PEM Density}

Density measurement data were based on Archimede's Principle utilizing a Mettler AJ100 analytical balance fitted with a Mettler ME-33360 density determination kit. The Archimede principle is based on the fact that when a solid body is immersed in a liquid it displaces an equivalent mass of liquid. This displaced liquid mass is determined indirectly utilizing this kit, and allows one to calculate the density of the unknown sample based on the difference in its mass when measured in air and a liquid. Equation 2 gives the relationship between predicted density, sample mass, and liquid density. In this equation, the predicted density of the polymer film is represented by $\boldsymbol{\rho}_{\text {film }}$, the masses of the films measured in air and liquid are $\boldsymbol{m}_{\text {air }}$ and $\boldsymbol{m}_{\text {liquid, }}$ and the density of the liquid is $\rho_{\text {liquid. }}$ Octane was employed as the liquid medium and was chosen for these measurements because the polymers were not soluble in it, the solvent has a low surface energy that aided in wetting film samples, and the liquid has a low vapor pressure and negligible toxicity. Prior to making density measurements, films were dried for 24 hours at $120^{\circ} \mathrm{C}$ in a vacuum. The reproducibility in measuring density based on this technique was found to be $0.5 \%$ or $0.004 \mathrm{~g} / \mathrm{ml}$.

$$
\rho_{\text {film }}=\frac{m_{\text {air }}}{m_{\text {air }}-m_{\text {liquid }}} \cdot \rho_{\text {liquid }}
$$

The densities of the SDAPP series were examined utilizing Archimede's Principle to study the role of density and increasing IEC. A linear relationship between increasing sulfonation level and density was observed for the SDAPP series as shown in Figure 35. This linear increase in mass per unit volume or density with increasing sulfonic acid concentration or IEC was anticipated and could be used to assist in the characterization of the IEC. Interestingly, the linear relationship between increasing acid concentration and conductivity that is observed for many acids is also observed for these SDAPP materials and additional work with other ionomers displaying this relationship may be useful in understanding the role of proton conductivity and IEC on an IEC density basis. 


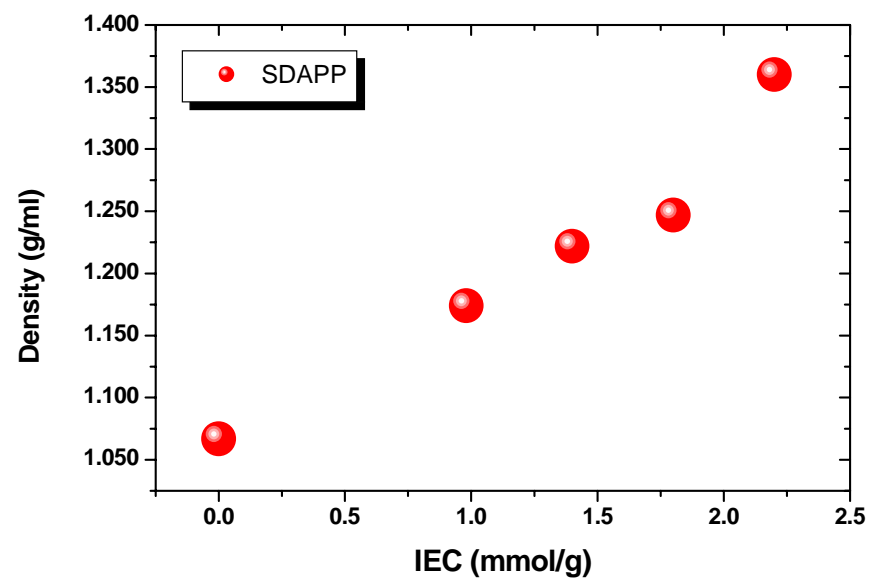

Figure 35 Density of SDAPP as a function of increasing sulfonation level.

\section{FTIR of DA Poly(phenylene) and SDAPP}

FTIR spectra of polymer powders/KBr pellets were collected using a Perkin-Elmer System 2000 spectrometer. Spectroscopic evidence of sulfonation of the base polymer was provided with the presence of infrared absorptions characteristic of aryl sulfonic acid groups. In Figure 36, the IR spectra of SDAPP0 through SDAPP4 are plotted. The infrared spectra of ppoly(phenylenes) contain two single bands, 770-730 $\mathrm{cm}^{-1}$ and $710-690 \mathrm{~cm}^{-1}$, which correspond to the out-of-plane vibrations of the five adjacent aromatic hydrogen-carbon bonds of the pendant phenyl groups[91]. In the unsulfonated polymer, these strong absorptions occur at 758 and 696 $\mathrm{cm}^{-1}$ respectively. The intensities of these peaks in SDAPP are diminished, Figure 36, which suggests that sulfonation is occurring predominately on the pendent phenyl groups due to the conversion of mono-substituted phenyl rings to di-substituted.

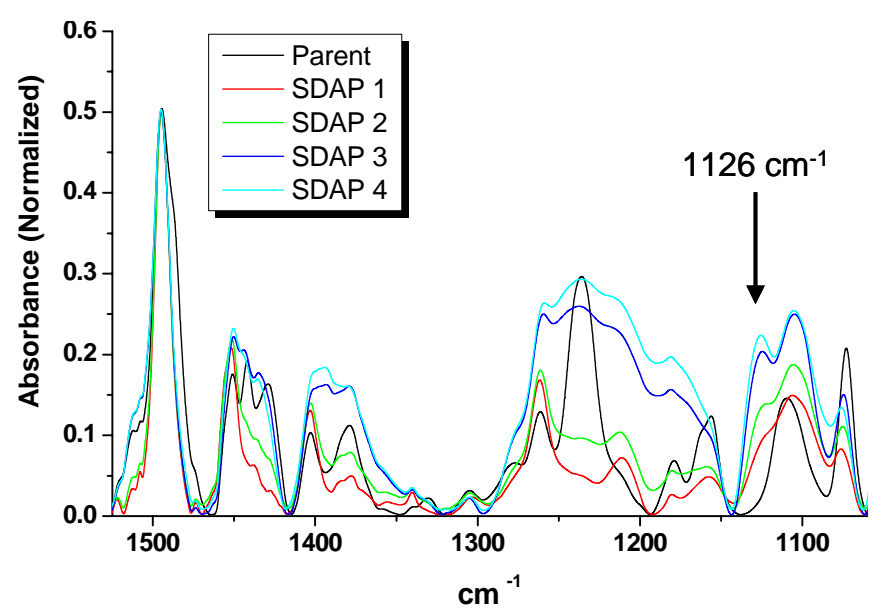

Figure 36 Normalized FT-IR spectra of IR spectra of Parent polyphenylenes through SDAPP4. Sulfonate group at $1126 \mathrm{~cm}^{-1}$ wave numbers is shown to increase with increasing ion exchange capacity.

91 Noren, G.K.; Stille, J.K. Macromol. Rev., 1971, 5, 385 
The asymmetric and symmetric sulfonate stretching frequencies adsorptions, 1126 and $1036 \mathrm{~cm}^{-1}$ respectively, increased in intensity with sulfonation level. The aromatic in-plane skeletal deformation at $1495 \mathrm{~cm}^{-1}$, present in both unsulfonated and sulfonated polyphenylene was used as an internal standard to quantify the amount of sulfonic acid groups in each sample [92]. The ratio of the intensity of the absorption peaks at 1126 and $1495 \mathrm{~cm}^{-1}$ was plotted versus IEC and resulted in a near linear correlation, Figure 37, providing additional evidence for incorporation of sulfonic acid units on the backbone of the polymer in addition to IEC.

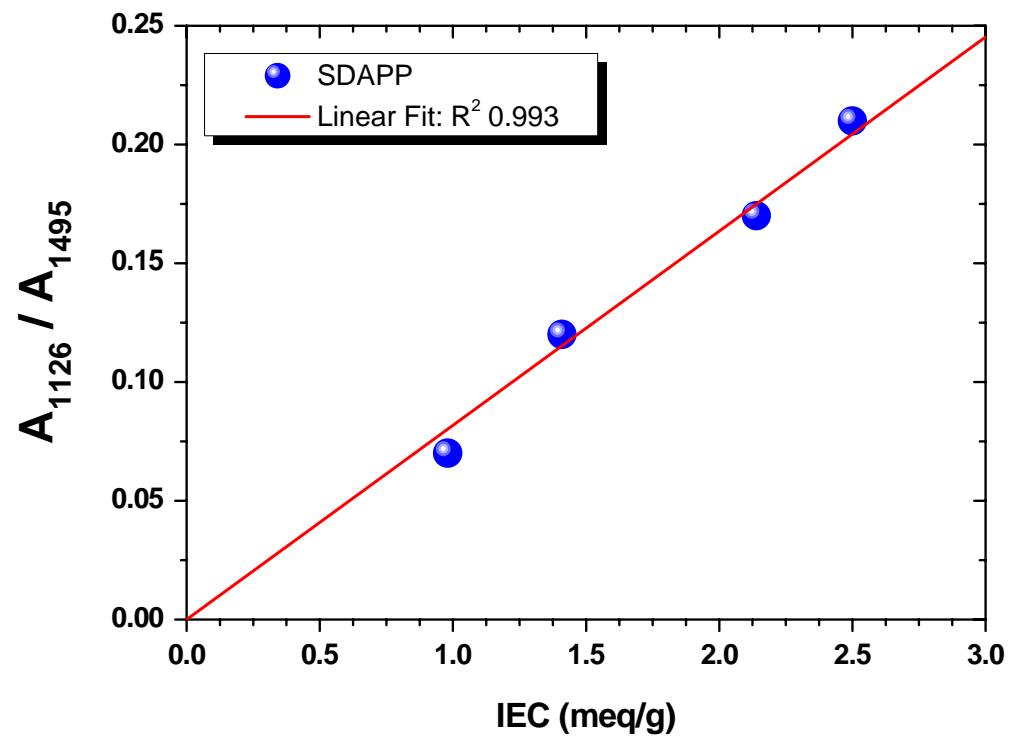

Figure 37 Linear correlation of normalized FT-IR Peak Intensities of sulfonate groups $\left(1126 \mathrm{~cm}^{-1}\right)$ and internal standard in polymer chain $\left(1495 \mathrm{~cm}^{-1}\right)$ to membrane ion exchange capacity.

\section{Thermal Stability of DA Poly(phenylene) and SDAPP}

Thermogravimetric analysis (TGA) under nitrogen was carried out on a Perkin Elmer TGA-7 at a heating rate of $10{ }^{\circ} \mathrm{C} / \mathrm{min}$. All samples were heated in the TGA furnace at $110{ }^{\circ} \mathrm{C}$ under dry nitrogen for 30 min to remove water before the full scan from $50{ }^{\circ} \mathrm{C}$ to $950{ }^{\circ} \mathrm{C}$ was performed. TGA analysis of SDAPP0 under nitrogen revealed a $5 \%$ weight loss occurring at $660{ }^{\circ} \mathrm{C}$. SDAPP in the acid form displayed a three-stage weight loss pattern (Figure 38). Although the sulfonated polymers were dried at $110{ }^{\circ} \mathrm{C}$ for $30 \mathrm{~min}$. immediately prior to the analyses, the samples showed an initial weight loss between $0.5-1.0 \%$ due to the loss of water. As the sulfonation level increased from 1.04 to $2.2 \mathrm{meq} / \mathrm{g}$, the second decomposition temperature (at $5 \%$ weight loss) decreased from 442 to $363{ }^{\circ} \mathrm{C}$. SDAPP2 lost $13.6 \%$ of its mass (after absorbed water loss), which is close to the theoretical value of $11.2 \%$ after SO3 cleavage. These results suggest the second weight loss (after water loss) in SDAPP is attributed to the loss of sulfonic acid groups, which typically range from 285 - $426{ }^{\circ} \mathrm{C}$ in highly phenylated arylenesulfonic polymers, while the third transition was associated with backbone degradation [93].

92 Novak, B.M.; Wallow, T.I. J. Am. Chem. Soc., 1991, 91, 1513

93 Miyatake, K.; Hay, A. S. J. Polym. Sci. Part A. Poly. Chem. 2001, 39, 3211-3217 


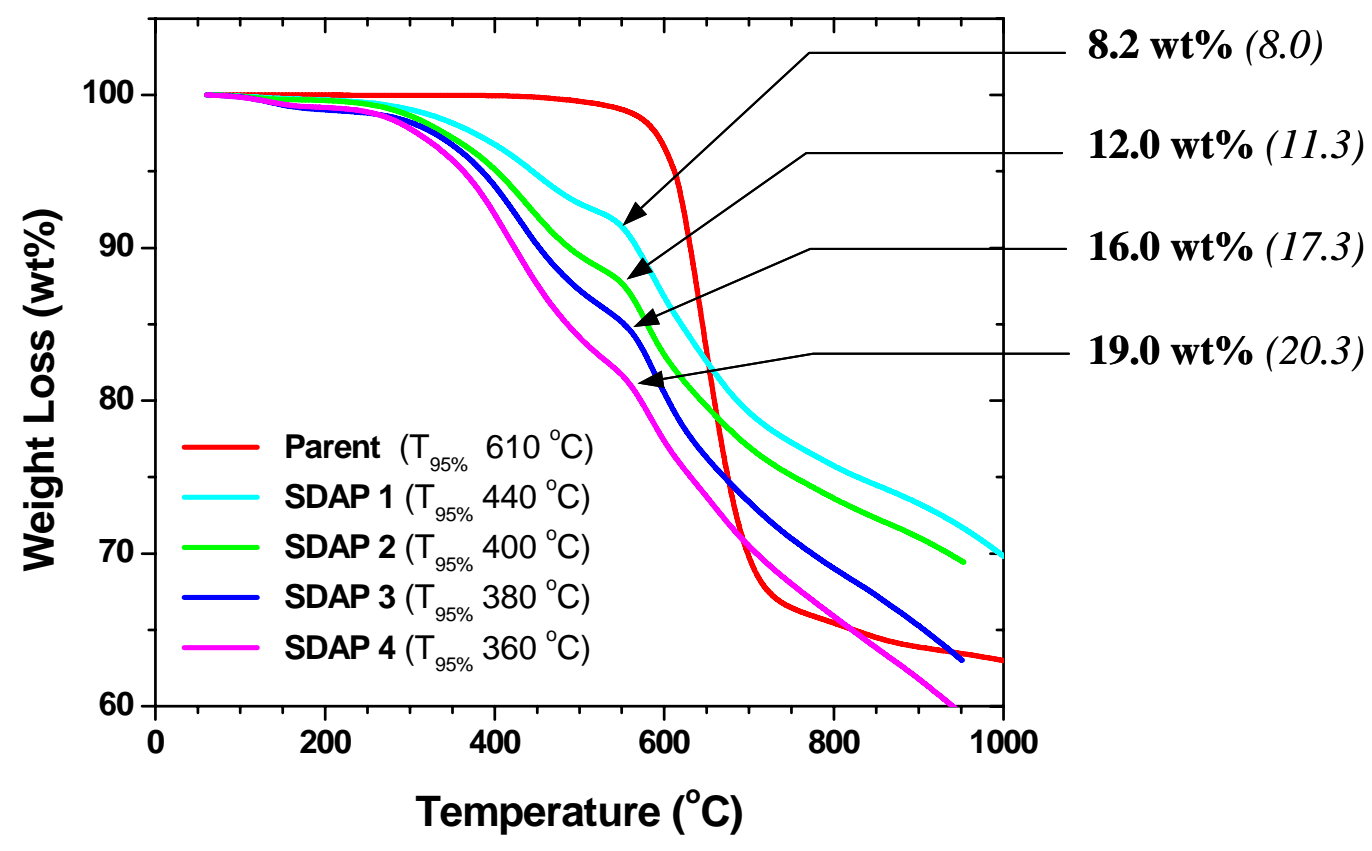

Figure 38 Thermogravimetric evaluation of SDAPP series including theoretical and experimental observations of complete loss of sulfonic acid groups.

PEM lifetime studies at elevated temperatures and development of PEM materials that allow low humidity fuel cell operation is a critical step towards the development of a high temperature non-Nafion hydrocarbon PEM. These studies are necessary in order to develop more thermally and chemically robust materials by studying the failure modes of PEM materials that occur at elevated temperatures. At elevated temperatures it is expected that the PEM and MEA will have higher oxygen and hydrogen permeability with increasing temperature. One technical problem associated with these gases permeating across the MEA from cathode to anode and vise versa is the generation of "hot spots", which leads to holes in the MEA resulting in premature fuel cell failure. Additional material problems with high temperature operation include accelerated physical aging and chemical degradation leading to loss in physical properties and inherent proton conductivity. It has also been observed by several researchers that desulfonation and crosslinking of sulfonic acid groups occur in the PEM material with increasing temperature, which will lead to embrittlement and lose of proton conductivity in the PEM. Such performance loses are unacceptable in a working fuel cell, and understanding how to extend the life of these high temperature PEM materials is critical to the development of a viable material. The thermal stability as determined by the decomposition characteristics of a series of alternative PEM materials are shown in Figure 39 relative to Nafion and their unsulfonated parent [94].

94 Kopitzke, R.W.; Linkous, C.A.; Nelson, G.L. Poly. Degrad. \& Stability 2000, 67(2), 335. 


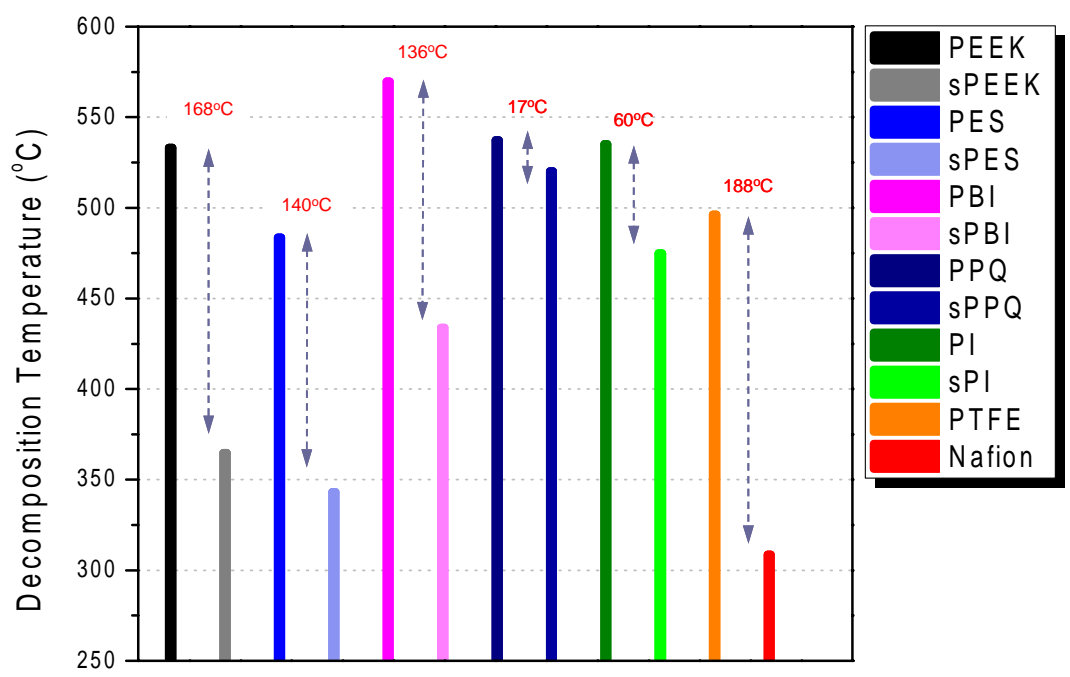

Figure 39 Temperature at 5\% weight loss in Helium for poly(ether-etherketone) (PEEK), sulfonated PEEK (S-PEEK), poly(ether-sulfone) (PES), sulfonated PES (S-PES), polybenzimidazole (PBI), sulfonated PBI (S-PBI), polyphenylquinoxaline (PPQ), sulfonated PPQ, polyimide (PI), and sulfonated PI (S-PI), poly(tetrafluoroethylene) (PTFE), and Nafion.

\section{Mechanical Properties}

In order to substantiate the physical properties of the SDAPP materials, Giner Electrochemical Systems was contracted to evaluate samples with an IEC of $1.6 \mathrm{meq} / \mathrm{g}$; some of the data is reported below. Dynamic mechanical analysis of the SDAPP films showed a higher moduli that Nafion112 under both wet and dry states (Figure 40).

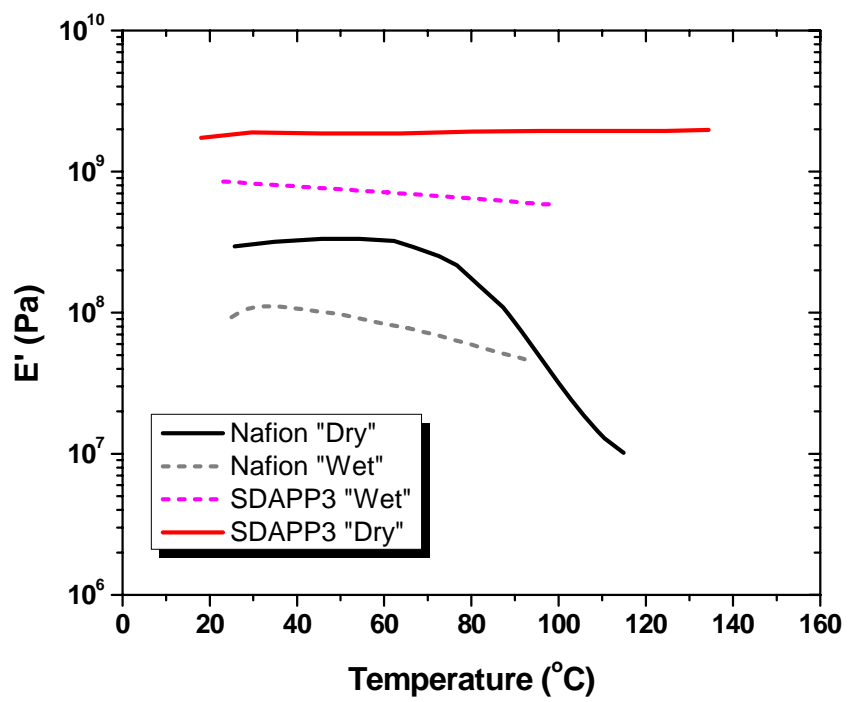

Figure 40 DMTA of wet and dry samples of SDAPP with an IEC of 1.6 versus Nafion112. 
The SDAPP material did substantially uptake water at fully humidified conditions, however the dimensional changes were minimal. Additional wet-dry cycles of the material are believed to be superior to other hydrocarbon based PEMs but additional work is necessary to evaluate this property. Although, the first generation SDAPP materials have promising physical properties there are areas that need improvement.

\section{Morphology of SDAPP via TEM and SANS}

SDAPP membranes were imbibed with lead acetate and imaged with TEM in the dry state in order to appreciate the ordering and relative sizes of the sulfonic acid domains and this technique does not give a directly determine the size of the hydrated domains. The TEM images of the course morphology of SDAPP and Nafion are shown in Figure 41.

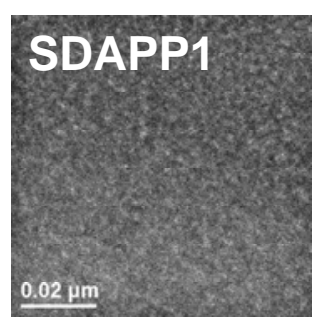

Figure 41
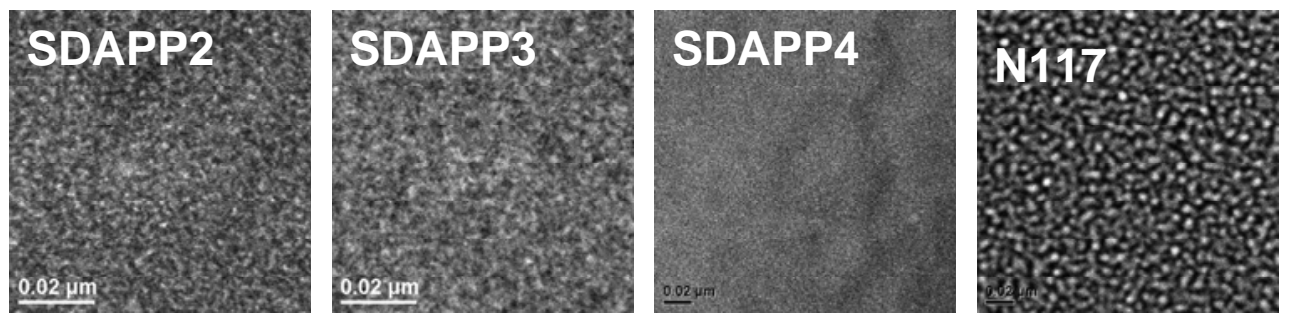

Cross sectional TEM micrographs of SDAPP versus Nafion117

It is clear from these micrographs that some level of phase separation exists within the structures of Nafion and SDAPP. Black regions within the TEM image are associated with the hydrophilic domains due to the interaction of the lead acetate with the sulfonic acid groups and hydrophobic domains are white regions due to the lack of association between polymer and lead acetate. The bicontinuous domains suggested in these TEM images invokes the concept of a highly phase separated material where the sulfonic acid groups self assemble within the hydrophilic domains. While the phase separation in SDAPP materials is not as distinct as Nafion into hydrophilic and hydrophobic domain structures, there does appear to be a noticeable systematic increase in light to dark colored regions from SDAPP1 to SDAPP3 that is reasonable based on the increasing ion exchange capacity. SDAPP4 seems to be more homogeneous, which may suggest a better degree of distribution of volume fractions of hydrophilic and hydrophobic regions within SDAPP4. Again, the TEM images are only a coarse indicator of the relative size of the hydrophilic domains in the hydrated.

\section{Structural Characterization}

In order to increase our understanding of the performance of the SDAPP materials as it relates to fuel cell performance wide angle x-ray scattering (WAXS), small angle x-ray scattering (SAXS) and small angle neutron scattering (SANS) were completed in collaboration with Clemson University. Because of the repeat unit of the SDAPP polymer it is expected to display rigid rod behavior due to the backbone of the polymer (no flexible linkages). Understanding some of the structural aspects of this polymer is important to realizing its potential and also understanding its limitations.

Studies were carried out on SDAPP with IEC capacity ranging from 1 to 2.4, which corresponds to sulfonation levels from $10 \%$ to $55 \%$. Neutron and $\mathrm{x}$-ray scattering have 
investigated the structure of the SDAPP membranes with different sulfonation levels. Combination of both techniques allows probing of multi length scales from angstroms to nanometers. Further information has been obtained from atomic force microscopy. Shown in Figure 42 are representative x-ray patterns of dry and water-swollen membranes. The dry film appears to be amorphous, which is consistent with literature and our measurements of the parent SDAPP0 with DSC and DMTA. Three broad lines are resolved at average distances of 3.0A.

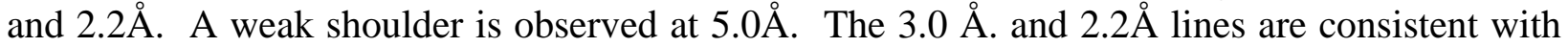
intra molecular dimensions. As the membrane swells with $\mathrm{D}_{2} \mathrm{O}$, three lines at 4.8, 3.7 $\AA$ appear. The line at $2.2 \AA$ becomes less visible as hydration takes place. Adding water allows stacking of some of the aromatic parts. A $3.8 \AA$ line often corresponds to $\pi-\pi$ distance of hinder aromatic rings. No clear periodicities have been detected at the SAX regime.

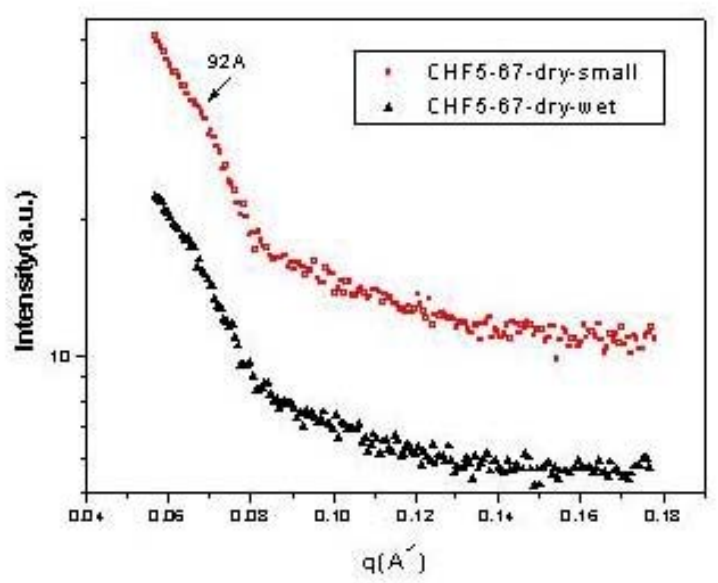

SAXS

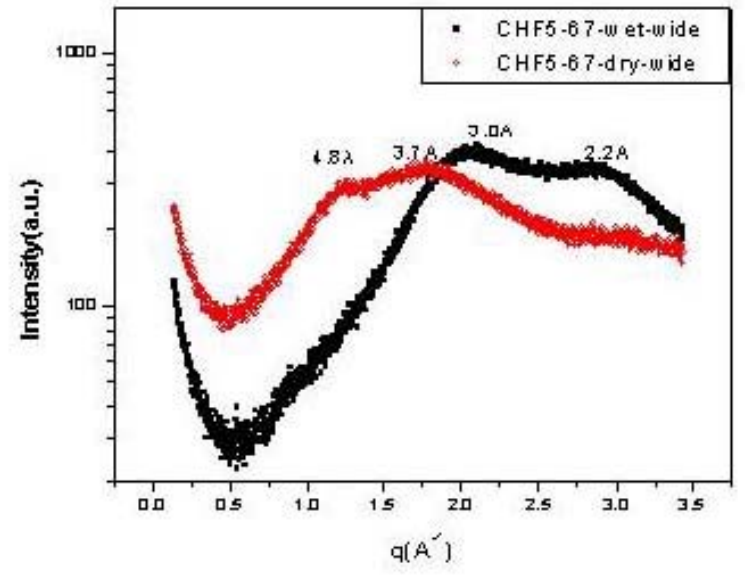

WAXS

Figure 42 Small and wide-angle X-ray scattering of SDAPP1. Measurements have been carried out at room temperature on a Sintag $\Theta-\Theta$ geometry.

Probing the nanometer dimension by SANS data covers dimensions of 2-250 nm directly and extrapolation can be made to larger dimensions. These are the dimensions that correspond to the ionic peak and the matrix signature in Nafion. Figure 43-A is the SANS data for SDAPP4 (55\% sulfonated) both in the dry state and water-swollen states at room temperature and elevated temperatures. In contrast to Nafion, the dry film does not exhibit any signal at the measured range of $53 \AA$ as observed in Nafion. The lack of signal is indicative of a different structure in the dry membrane of SDAPP polymers as compared to Nafion. Since the backbone of this polymer is much stiffer than the backbone on a perfluorinated hydrocarbon, the chains cannot fold to allow the formation of ionic clusters or well defined hydrophilic and hydrophobic parts in the dry state, which accounts for the inability to observe an ionic peak in the dry state. 

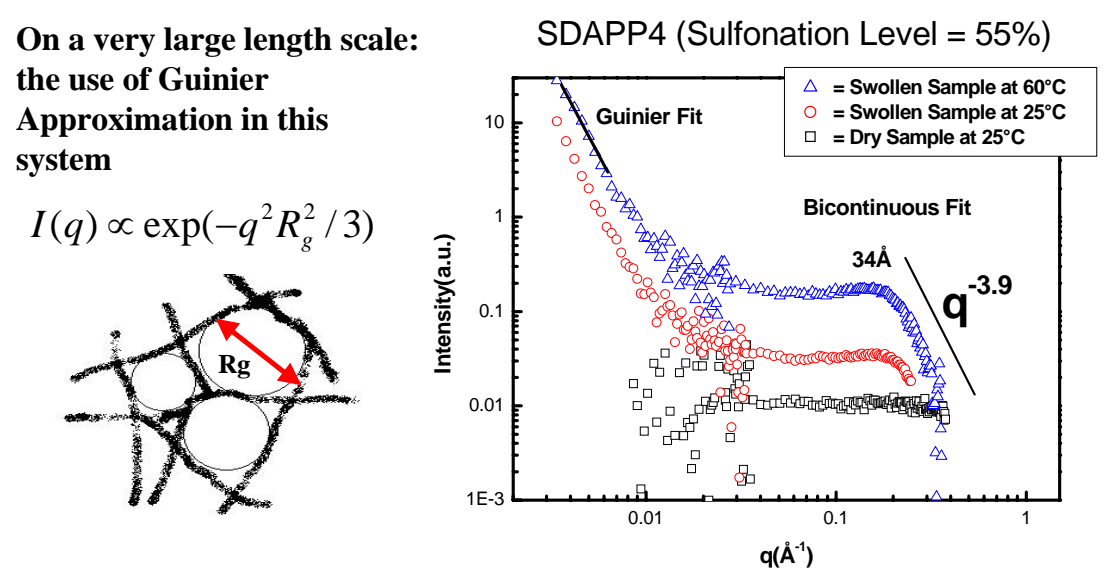

Figure 43 A) Small angle neutron patterns of a $55 \%$ sulfonated PP membrane dry and swollen at the indicated temperatures. The solid line at low q corresponds to a Guinier fit and the line at high $q$ to a bicontinuous model. B) Outline of Guinier approximation.

However, when the samples are allowed to soak in $\mathrm{D}_{2} \mathrm{O}$ at $25{ }^{\circ} \mathrm{C}$ for an hour, a signal develops at low q. In parallel, a peak develops at $\sim 34 \AA$. The signal at low q is attributed to a sparse network. A Guineir approximation introduced in Figure 43-B has been used to analyze this regime. The network is described by a series of balls that define the mesh size. The peak at $34 \AA$ has been fit to a bicontinuous model of Equation 3. The specific structure within this network is still under study. Water swollen Nafion exhibits a bicontinuous network of hydrophilic and hydrophobic domains. In the present system, the chemical structure results in a much more rigid framework.

$$
\begin{aligned}
& S(q)=\frac{k T}{a_{2}+c_{1} q^{2}+c_{2} q^{4}} \\
& d=2 \pi\left[\frac{1}{2}\left(\frac{a_{2}}{c_{2}}\right)^{\frac{1}{2}}-\frac{c_{1}}{4 c_{2}}\right]^{-\frac{1}{2}} \quad \zeta=\left[\frac{1}{2}\left(\frac{a_{2}}{c_{2}}\right)^{\frac{1}{2}}-\frac{c_{1}}{4 c_{2}}\right]^{-\frac{1}{2}}
\end{aligned}
$$

While the signal at low angle is only slightly dependent on ionic strength, the peak at $34 \AA$ becomes more pronounced as the ionic strength of the polymer increases, as shown in Figure 44. Also, with increasing ionic strength, the slope of the I(q) at high q approaches more the $\mathrm{q}^{-4}$. This is an indication that with increasing ionic strength the interface between the solvent and the polymer becomes more defined and the slope of -4 suggests that the SDAPP becomes bicontinuous systems at higher sulfonation levels. In contrast to the large ionic cluster of $53 \AA$ observed for Nafion, the smaller $34 \AA$ ionic cluster associated with the SDAPP series may account for the lower crossover characteristics as compared to Nafion. Further studies need to be completed to understand the role of decreasing ionic domain size as it relates to transport phenomena and fuel cell performance. 


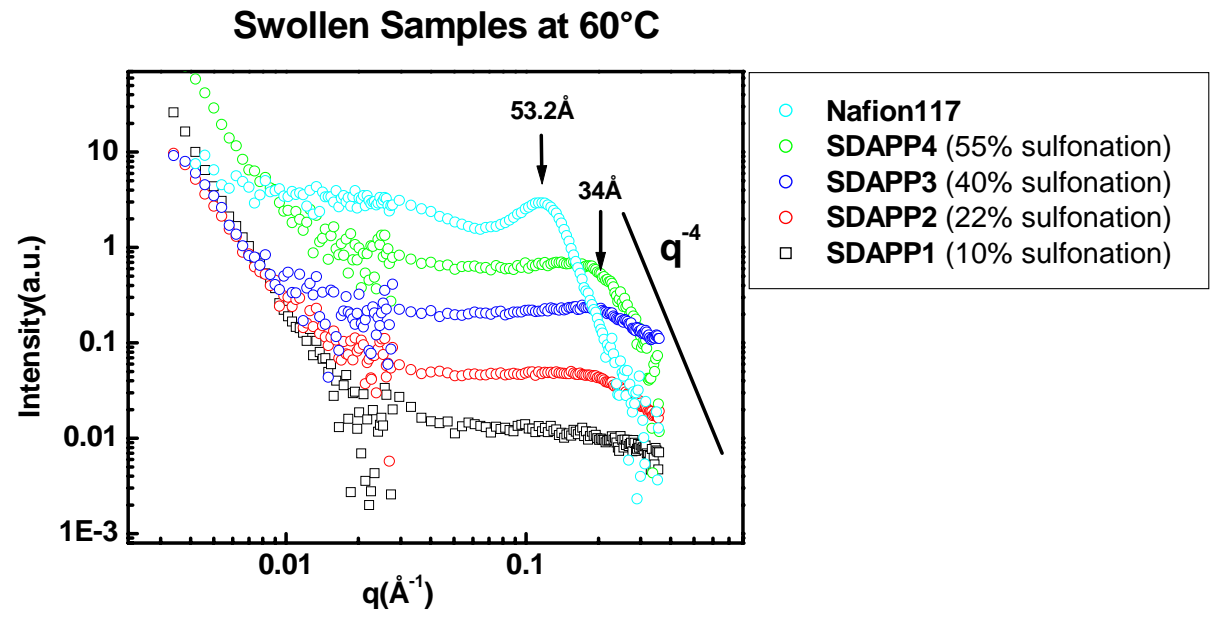

Figure 44 SANS data for water swollen SDAPP membrane at $60^{\circ} \mathrm{C}$ at the indicated sulfonation levels. SANS pattern of Nafion under the same conditions are shown for comparison.

\section{Results and Discussion}

The Catalyst Coated Membrane (CCM) or Membrane Electrode Assembly (MEA) forms a bond between the PEM and electrode that represents the heart of a PEM fuel cell (PEMFC). Figure 45 illustrates the two components of an electrocatalyst layer and the PEM with transport of $\mathrm{O}_{2}, \mathrm{H}_{2}$, water, electrons, and protons through the catalyst layer and PEM.
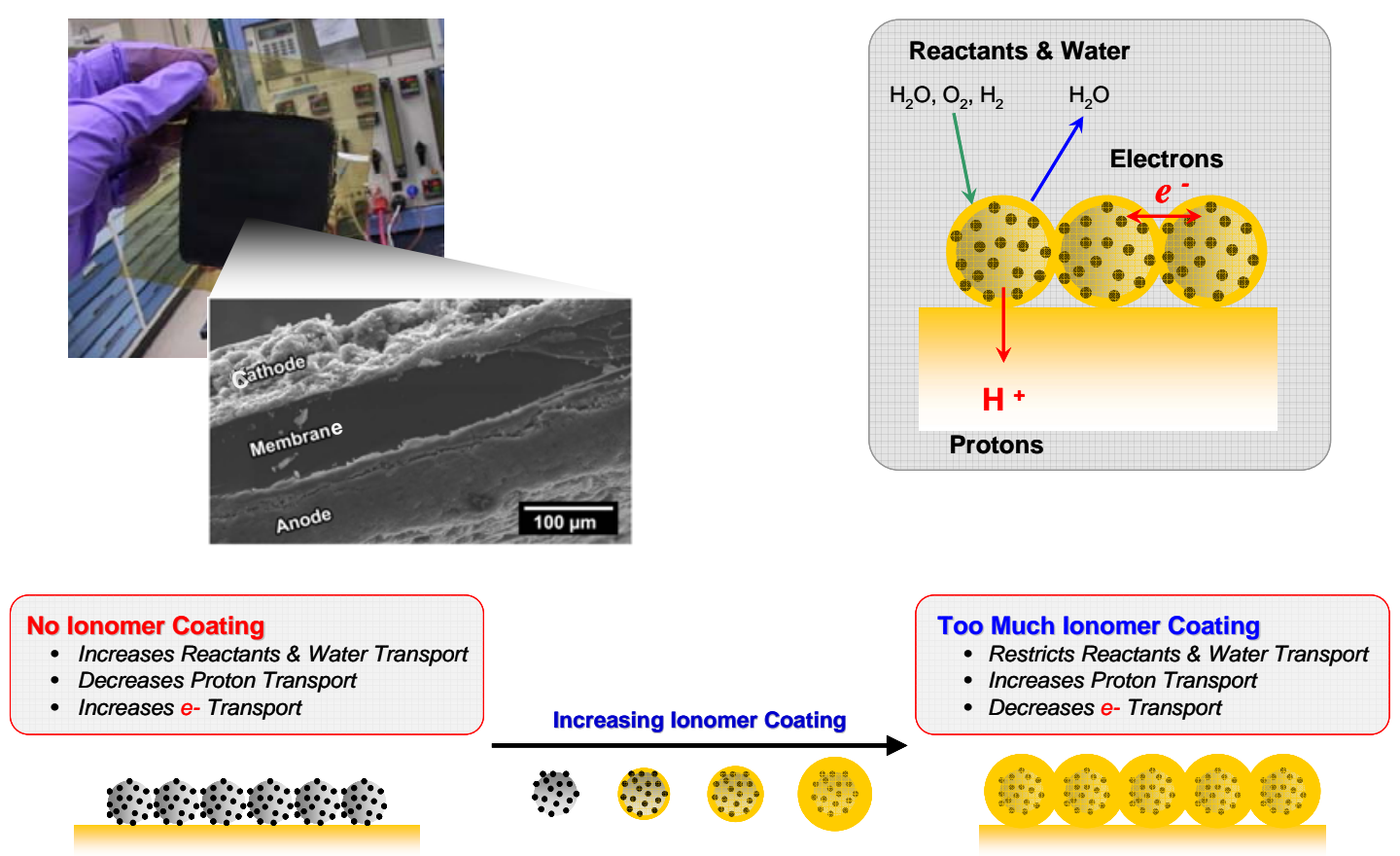

Figure 45 CCM based upon SDAPP. Idealized relationship of ionomer content and its effect on proton, electron, water, O2, and $\mathrm{H} 2$ transport. 
The electrocatalyst in the catalyst layer, most commonly platinum or a platinum alloy, facilitates both the oxidation of hydrogen into protons $\left(\mathrm{H}^{+}\right)$and electrons, and the reduction of oxygen to water. The protons are transported though the PEM where they recombine with electrons and oxygen at the cathode to form water. An interface is formed when a CCM is made from a liquid dispersion of ionomer and electrocatalyst that is applied to a PEM surface by painting or hot pressing.[95,96] Meager fuel cell performance is observed in many non-Nafion alternative PEM materials due to poor interfacial bonding and high interfacial resistance due to bonding dissimilar ionomers in the membrane and electrocatalyst layer. While a PEM must have good proton conductivity, it is also equally important that the interface between the electrocatalyst layer and the PEM have minimal resistance to proton transport. Figure 45 reveals the fundamental complexities of transport within not only the polymer electrolyte membrane as protons are transported from the anode to the cathode, but also in the electrocatalyst layers as protons, electrons, water, and reactant gases move in and out of the nanocomposite catalyst layers. Such a complex multi-phase system is dependent on ion and water transport within the PEM, and transport of ions, electrons, water, and gases within the nanocomposite catalyst layers. Furthermore, research should not only focus on understanding ion transport, but the state-ofwater in the PEM, transport within the electrocatalyst layer, electrocatalyst activity, and interfacial phenomena associated with the bonding of electrodes to the PEM. Understanding the basic thermodynamics and kinetics of wetting, spreading, interface evolution, and the final adhesive bond formed between the catalyst layer and the PEM's heterogeneous surface is a critical aspect for fuel cell development. Designing alternative PEM materials that have adequate water, proton, and reactant gas transport is critical to the development of alternative CCM materials for fuel cell usage.

\section{Hydrogen Fuel Cell}

The hydrogen fuel cell performance of the SDAPP series of materials was investigated to evaluate its potential as a fuel cell membrane. In order to evaluate the potential of the SDAPP materials it was necessary to form a membrane electrode assembly (MEA). MEA's were formed based on standard ink hand painting techniques developed at Los Alamos National Laboratory. This process involves creating a colloidal suspension of Pt/Pt-Alloy catalyst in water, isopropanol, and Nafion 1100 solution. The final target composition was $10 \mathrm{wt} \%$ ionomer in the cathode and $15 \mathrm{wt} \%$ ionomer in the anode with the remaining component being the Pt/Pt-Alloy catalyst (HISPEC Pt/Ru black anode, HISPEC 1000 Pt black cathode). Electrodes were applied to the PEM by painting multiple layers of the catalyst ink suspension with a paintbrush to achieve the target catalyst loading. The final MEA is then assembled into a Fuel Cell technologies $5 \mathrm{~cm}^{2}$ test cell and tested using ETEK LT-1400W 18 mil thick gas diffusion layers at the anode and cathodes. A 120A Fuel Cell technologies Test unit equipped with high frequency impedance was used to evaluate all samples. This test unit has the capability to measure the bulk proton conductivity of the PEM, follow changes in high frequency resistance (HFR) due to membrane dry out, electrode failure, and assess the role interfacial resistance due to pore adherence between the PEM and electrode composite.

Figures 46 demonstrates the performance of the SDAPP series as a function of conductivity at $100{ }^{\circ} \mathrm{C}$ at $100 \%$ relative humidity with pure hydrogen and oxygen flowing at 500 SCCM with a backpressure of 20 psig on the cathode and anode. Figure 46 shows the

95 Grot, W.G. US Patent 5,547,911, 1996

96 Kocha, S.S. Principles of MEA preparation in Handbook of Fuel Cells. Vol.3. Ed. Vielstich, W.; Gasteiger, H.; Lamm., A., John Wiley \& Sons, 2003, p. 538. 
relationship of increasing conductivity of the SDAPP materials as it relates single cell fuel cell performance. As shown in this figure a large HFR $\left(0.82 \Omega * \mathrm{~cm}^{2}\right)$ is observed for SDAPP1 that quickly increases with increasing current density. This behavior is attributed to membrane dehydration due to electro-osmotic drag that also results in a loss in proton conductivity. Overall, this sample has an inadequate concentration of sulfonic acid groups necessary for good proton conductivity and fuel cell performance. Increasing the concentration of sulfonic acid groups from an IEC of 1.04 to 1.4 results in a dramatic increase in fuel cell performance as demonstrated with SDAPP2 $\left(350 \mathrm{~mW} / \mathrm{cm}^{2}\right)$ versus SDAPP1 $\left(175 \mathrm{~mW} / \mathrm{cm}^{2}\right)$. This increase in IEC also results in a significantly low HFR $\left(0.15 \Omega * \mathrm{~cm}^{2}\right)$ that is constant throughout the fuel cell test. This performance improvement is attributed to the increase in proton conductive carriers (sulfonic acid groups) and better electrode adherence to the PEM. Maximum fuel cell performance was observed for SDAPP4 that also had a low HFR throughout the test (0.15 $\Omega^{*} \mathrm{~cm}^{2}$ ). The power density of this sample reached $980 \mathrm{~mW} / \mathrm{cm}^{2}$ at $2900 \mathrm{~mA} / \mathrm{cm}^{2}$, which is 2.8 times greater than SDAPP2 and 5.6 times greater than SDAPP1. This dramatic improvement in fuel cell performance resulting from increasing the IEC from 1.04 to 1.8 appears to suggest a percolation effect with regard to performance. In fact the transition appears to be centered between an IEC of 1.4 and 1.8. While SDAPP4 was not tested, it is expected to result in further fuel cell power density improvements over SDAPP3. However, SDAPP4 increased fuel cell performance may not be attractive due to the tradeoff in increased swelling and future studies will evaluate this transition region as it relates to membrane mechanical integrity and fuel cell performance.

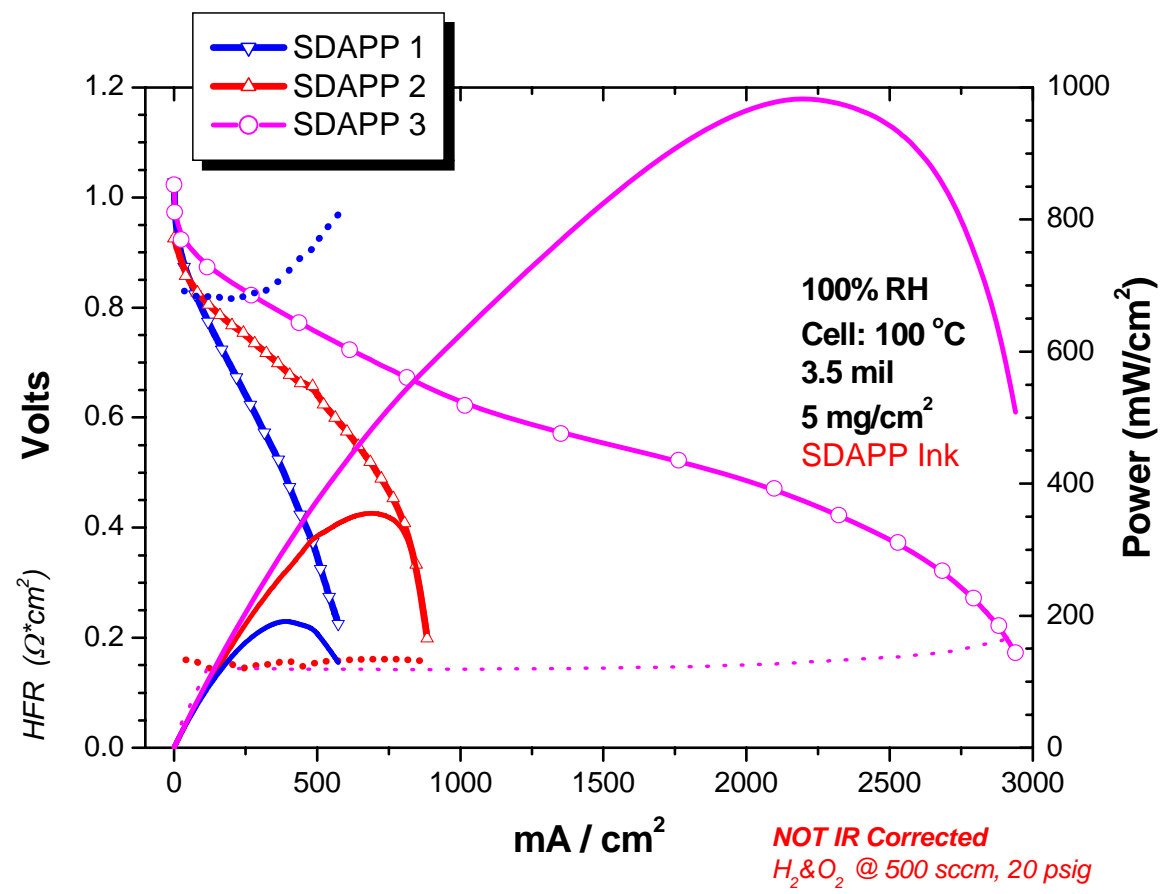

Figure 46 Increasing fuel cell performances with increasing SDAPP proton conductivity. Fuel cell conditions were $100{ }^{\circ} \mathrm{C}, 100 \% \mathrm{RH}$, and $5 \mathrm{mg} / \mathrm{cm}^{2}$ of catalyst on each side of the PEM. Electrode ionomer ink was based upon SDAPP4. 
Figure 47 is a comparison of the SDAPP3 versus Nafion1135 of equivalent thickness (3.5mil) and identical catalyst loading $\left(10 \mathrm{mg} / \mathrm{cm}^{2}\right)$, application technique, and Nafion1100 in the electrode. Fuel cell operating conditions were $80{ }^{\circ} \mathrm{C}$ at $100 \%$ relative humidity with pure hydrogen and oxygen flowing at 300 SCCM for the Nafion sample and 500 SCCM the SDAPP3 sample with a backpressure of 20 psig on the cathode and anode for both samples. SDAPP3 was observed to be capable of achieving a higher current density than Nafion1135 $\left(2100 \mathrm{~mA} / \mathrm{cm}^{2}\right.$ versus $2400 \mathrm{~mA} / \mathrm{cm}^{2}$ ). Also observed for the SDAPP3 sample was a relatively low and constant HFR $\left(0.10 \Omega^{*} \mathrm{~cm}^{2}\right)$ with increasing current density while in contrast to this behavior Nafion1135 had an increasing HFR with increasing current density. This decrease in proton conductivity with increasing current density for Nafion 1135 is why its peak power is only $800 \mathrm{~mW} / \mathrm{cm}^{2}$ versus $1100 \mathrm{~mW} / \mathrm{cm}^{2}$ observed for SDAPP3. Preliminary experiments measuring the electro-osmotic drag of SDAPP3 revealed that this sample has a lower electro-osmotic drag than Nafion (1.5 versus 3.0), but further studies need to be carried out in this area. However, a lower electroosmotic drag would explain the observations made in this polarization curve regarding the different responses in HFR response of both samples.

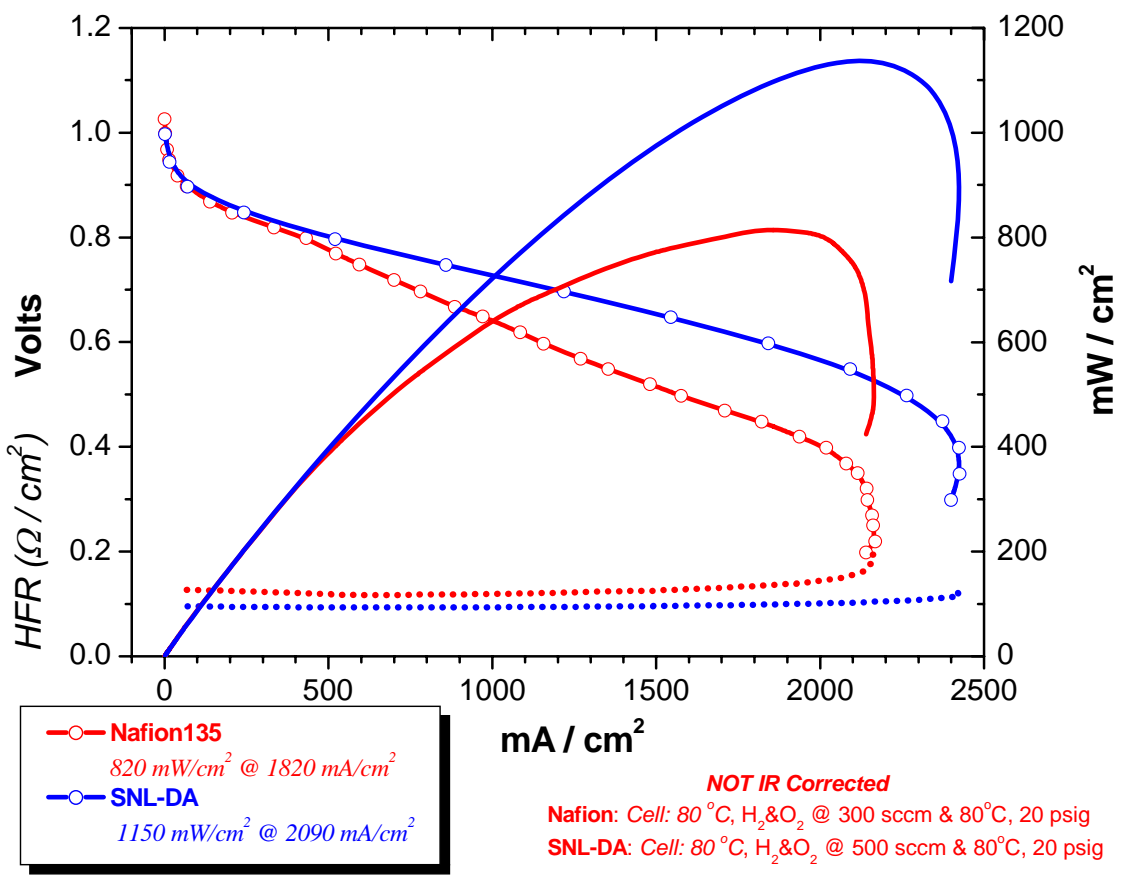

Figure 47 Fuel cell performance of SDAPP3 versus Nafion1135. Fuel cell conditions were $80{ }^{\circ} \mathrm{C}, 100 \% \mathrm{RH}$, and $10 \mathrm{mg} / \mathrm{cm}^{2}$ of catalyst on each side of the PEM. Electrode ionomer ink was based upon Nafion1100 for both samples.

The high temperature performance of SDAPP3 was evaluated versus Nafion112 to test is potential as a high temperature fuel cell membrane. The film thickness of SDAPP3 and Nafion112 were 3 mil and 2 mil respectively as measured in the dry state for both samples. A catalyst loading of $0.4 \mathrm{mg} / \mathrm{cm}^{2}$ was applied to both the anode and cathode by hand painting as previously described utilizing DeNora $20 \mathrm{wt} \% \mathrm{Pt}$ on XC-72 for both the anode and cathode electrodes. Fuel cell operating conditions were $120^{\circ} \mathrm{C}$ at $50 \%$ relative humidity with pure hydrogen flowing at 250 SCCM and air flowing at 500 SCCM throughout the test. The SDAPP 
MEA had an ether version of SDAPP in the electrode while Nafion1100 was used with the Nafion112 MEA. The results of this study are shown in Figure 48 and show that the performance of SDAPP3 is promising when compared to Nafion, which is also thinner than the SDAPP3 MEA sample. Even though the Nafion sample is 50\% thinner than the SDAPP3 MEA, which should result in better performance at higher currents, the thicker SDAPP3 sample still out performed the Nafion112 MEA. While this result shows promise for the SDAPP materials, significant work needs to be completed to optimize the electrode structure and evaluate the role of thickness on the fuel cell performance at these very challenging fuel cell conditions. Based upon these results further work is warranted examining the potential of these materials as a replacement for Nafion.

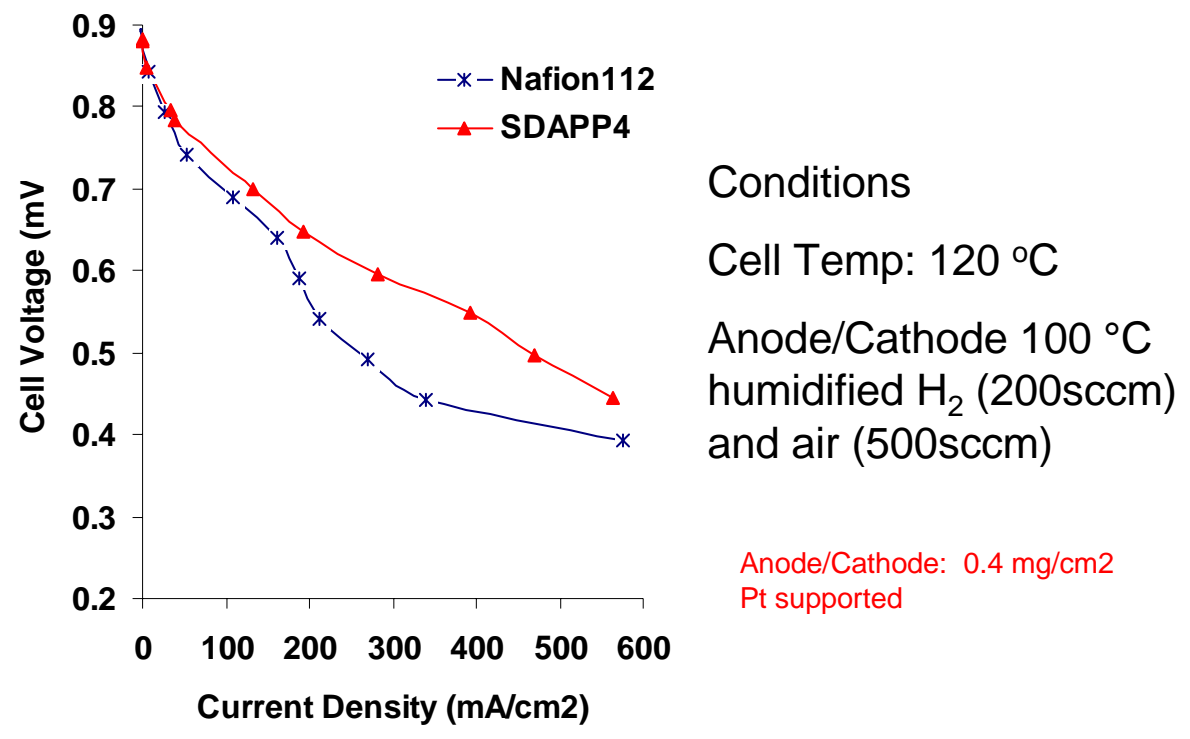

Figure 48 Fuel cell performance of SDAPP3 versus Nafion112. Fuel cell conditions were $120^{\circ} \mathrm{C}, 50 \% \mathrm{RH}$, and $0.4 \mathrm{mg} / \mathrm{cm}^{2}$ of catalyst on each side of the PEM.

\section{Hydrogen Fuel Cell Performance with SDAPP Electrodes}

Alternative hydrocarbon-based proton exchange membranes (PEM) have demonstrated promising properties for high temperature and low relative humidity operation. While high conductivity at low relative humidity in these materials remains a challenge, their outstanding thermal and mechanical properties have warranted many fuel cell performance studies of these Nafion replacements. In fuel cell performance testing, there are many instances of hydrocarbon membranes showing decreased performance from what could be expected from ex-site membrane tests. This decreased membrane electrode assembly (MEA) performance of hydrocarbon membranes is due in many cases to interfacial resistance problems at the interface between traditional Nafion-based electrodes and the hydrocarbon membrane. The complexities of this system are illustrated in Figure 49 showing how the MEA is an essential component within a hydrogen fuel between PEM, interface, and interaction with catalyst layer on transport and fuel cell performance. 

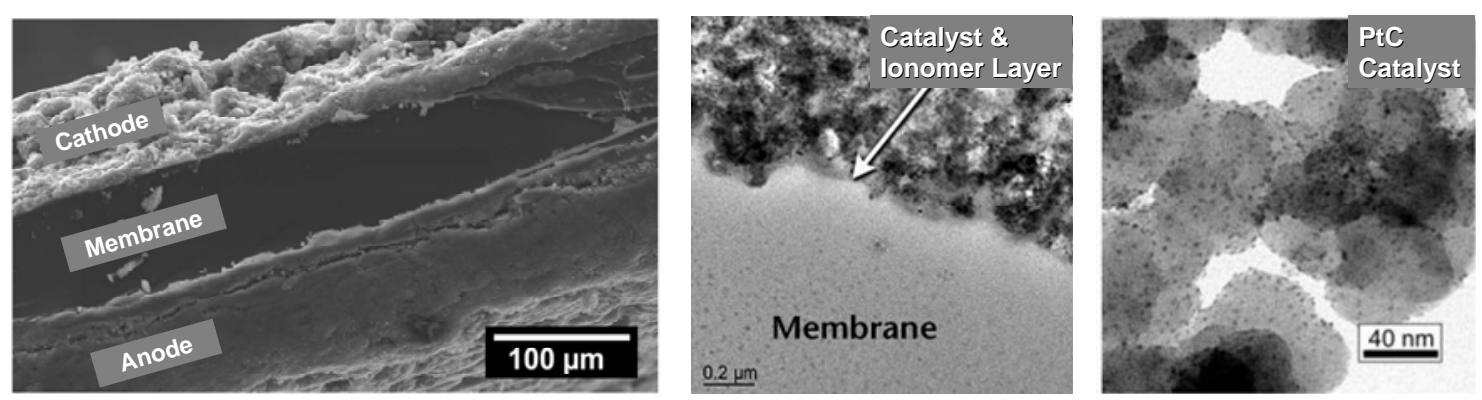

Figure 49 The membrane electrode assembly (MEA) is one of the key components of a hydrogen fuel cell. The performance is determined by PEM and the catalytic and electrochemical processes within the MEA. Investigation of the PEM, interface, and interaction with catalyst layer on transport

\section{Porosity of SDAPP Electrodes}

In the design and performance analysis of new electrodes, there are a multitude of factors that must be taken into account (Figure 45). The electrode must have sufficient proton and electron conduction, there must be adequate void space (open pores - Figure 49) for gas transport to the three-phase reaction interface, and the polymer used in the electrode must have high hydrogen and oxygen solubility and transport so as to not induce mass transport losses. Engineering the three-phase reaction interface is critical to creating high performance electrodes with an alternative electrolyte electrode to meet the standard set by Nafion electrodes.

In order to ensure that the SDAPPe electrode had sufficient pore space for gas phase transport into the three-phase reaction interface, the BET surface areas were measured for each electrode formulation. Results from this work revealed that the surface area of the SDAPPe electrode structures increased with decreasing polymer weight \% demonstrating that an open electrode structure can be achieved with the use of SDAPPe by changing the amount of polymer. This result eliminated concerns regarding the inability of forming an open electrode structure which is necessary for water and gas transport. The data in Table 9 clearly shows that the SDAPPe-based electrode have high BET surface areas and most likely has sufficient pore space for gas phase transport in the electrode structure. This will be an important parameter for optimization of novel hydrocarbon-based electrodes.

Table 9 Measured BET surface areas for electrode formulations, computed ECA surface area determined by $\mathrm{H}_{2}$ adsorpotion/desoprtion via cyclic voltammetry, and Tafel slope (mV/dec) for Nafion and SDAPPe-based electrodes.

\begin{tabular}{lccccccc}
\hline & & & & \multicolumn{4}{c}{ Tafel Slopes } \\
& Wt\% & $\begin{array}{c}\text { BET } \\
m^{2} / g\end{array}$ & $\begin{array}{c}\text { ECA } \\
\left(m^{2} * P t\right) /(m g * P t)\end{array}$ & \multicolumn{2}{c}{$100 \% \mathrm{RH}$} & \multicolumn{2}{c}{$50 \% \mathrm{RH}$} \\
& & & & $O_{2}$ & Air & $O_{2}$ & Air \\
\hline SDAPPe & 30 & 85 & 16 & 63 & 68 & 83 & 79 \\
SDAPPe & 15 & 131 & 22 & 65 & 79 & 105 & 115 \\
SDAPPe & 7 & 135 & - & - & - & - & - \\
Nafion & 30 & 70 & 24 & 59 & 51 & 87 & 83 \\
\hline
\end{tabular}


The electrochemically active area (ECA) for each electrode formulation is summarized in Table 9. At $30 \mathrm{wt} \%$ SDAPPe within the electrode structure an ECA of $16\left(\mathrm{~m}^{2} * \mathrm{Pt}\right) /(\mathrm{mg} * \mathrm{Pt})$ for SDAPPe is observed which is a lower ECA than Nafion at $24\left(\mathrm{~m}^{2} * \mathrm{Pt}\right) /(\mathrm{mg} * \mathrm{Pt})$. An increase in ECA was observed when the amount of SDAPPe was decreased in order reduce the film thickness coating the catalyst and to expose more of the Pt catalyst surface area for SDAPPebased electrodes. An increase in the ECA to $22\left(\mathrm{~m}^{2} * \mathrm{Pt}\right) /(\mathrm{mg} * \mathrm{Pt})$ at $15 \mathrm{wt} \%$ SDAPPe binder was achieved which is approximately the same as the Nafion-based electrode. The $\mathrm{H}_{2}$ adsoption/desorption cyclic voltammetry performed on the Nafion and SDAPPe electrodes in order to determine the ECA of the active platinum surface area is shown in Figure 50. The ECA was determined by integrating the area under the $\mathrm{H}_{2}$ adsorption/desorption curves.

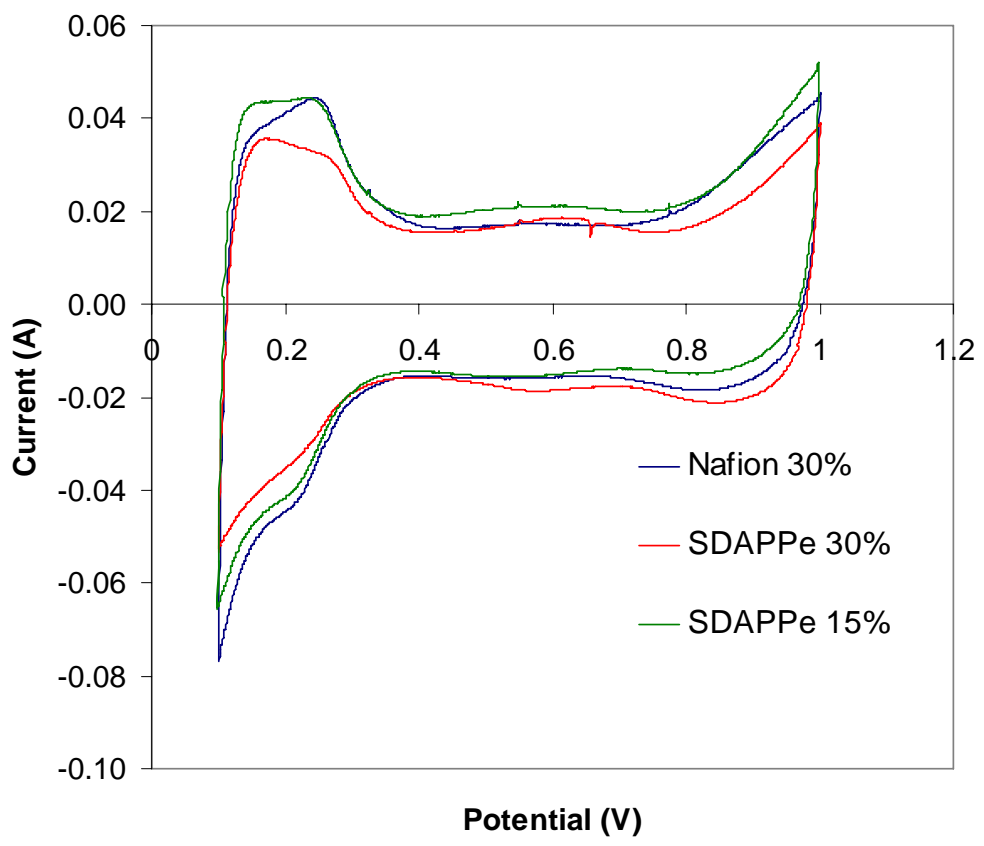

Figure 50 Cyclic voltammagrams showing hydrogen adsorption/desorption of various electrode formulations with Nafion and SDAPPe binders.

The Tafel slopes for various electrode formulations were measured in order to investigate changes in the intrinsic catalytic activity of the Nafion and SDAPPe-based electrodes are summarized in Table 9. Initial results in this area indicate that the intrinsic catalytic activity of SDAPPe based electrodes may be sufficient for use within a $\mathrm{H}_{2}$ fuel cell. At $50 \% \mathrm{RH}$, the Nafion and SDAPPe $30 \mathrm{wt} \%$ electrodes show approximately equivalent Tafel slopes, but there is some increase observed in the Tafel slope when the amount of SDAPPe polymer in the electrode was decreased to $15 \mathrm{wt} \%$. The results from this effort suggest that there is an optimum in SDAPPe loading within the electrode structure and future work is being done to optimize this structure based upon polymer structure.

In order to demonstrate the true potential of hydrocarbon membranes, electrodes that are compatible with the novel membrane were constructed to explore the relationship in fuel cell 
performance. This effort has demonstrated that SDAPP-based electrodes in conjunction with SDAPP membranes are a promising area for alternative PEMs. Having similar polymers in both the electrodes and the membrane will promote low interfacial resistance and durable MEAs. Two varieties of membrane were utilized in this study, Nafion 112 and SDAPP4 (IEC 2.2 $\mathrm{meq} / \mathrm{g}$ ). To these membranes, either Nafion or SDAPP ether (SDAPPe) based electrodes were applied. The electrodes were hand painted from water-alcohol solutions onto the membranes at $60^{\circ} \mathrm{C}$. Target loadings in all cases were $0.4 \mathrm{mg} \mathrm{Pt} / \mathrm{cm}^{2}$ for both the anode and cathode. E-TEK catalyst 20\% Pt on XC-72 was used in all cases and the MEA active area was $5 \mathrm{~cm}^{2}$. Carbon paper GDLs with integral microporous layers were utilized.

One of the benefits of SDAPP membranes over Nafion is that of higher temperature and lower relative humidity performance. A series of $\mathrm{H}_{2}$ polarization curves were taken at $60^{\circ} \mathrm{C}$, $80^{\circ} \mathrm{C}, 100^{\circ} \mathrm{C}$ and $120^{\circ} \mathrm{C}$ at $100 \%, 75 \%, 50 \%$, and $25 \% \mathrm{RH}$. The $\mathrm{H}_{2}$ fuel cell performance of N112 versus SDAPP4 with $30 \mathrm{wt} \%$ Nafion based electrodes is shown in Figure 51 . The results of this test show that Nafion $\mathrm{H}_{2}$ fuel cell performance peaks at $80^{\circ} \mathrm{C}$ and $100 \% \mathrm{RH}$, which are standard conditions for many reports in the literature. However, Nafion's $\mathrm{H}_{2}$ fuel cell performance declines as the temperature and $\mathrm{RH}$ go above $80{ }^{\circ} \mathrm{C}$ or below $100 \% \mathrm{RH}$. The performance of SDAPP4 with Nafion $30 \mathrm{wt} \%$ electrodes were tested under the same conditions for both higher temperature and lower $\mathrm{RH} \mathrm{H}_{2}$ fuel cell performance as compared to Nafion112. The peak in $\mathrm{H}_{2}$ fuel cell performance for SDAPP4 is at $110^{\circ} \mathrm{C}$ and $75 \% \mathrm{RH}$, which is a significant improvement over standard Nafion. Additionally, the performance at both $75 \%$ and $50 \% \mathrm{RH}$ were greater than that at $100 \% \mathrm{RH}$, which demonstrates the potential of SDAPP4 as a high temperature and low humidity membrane.
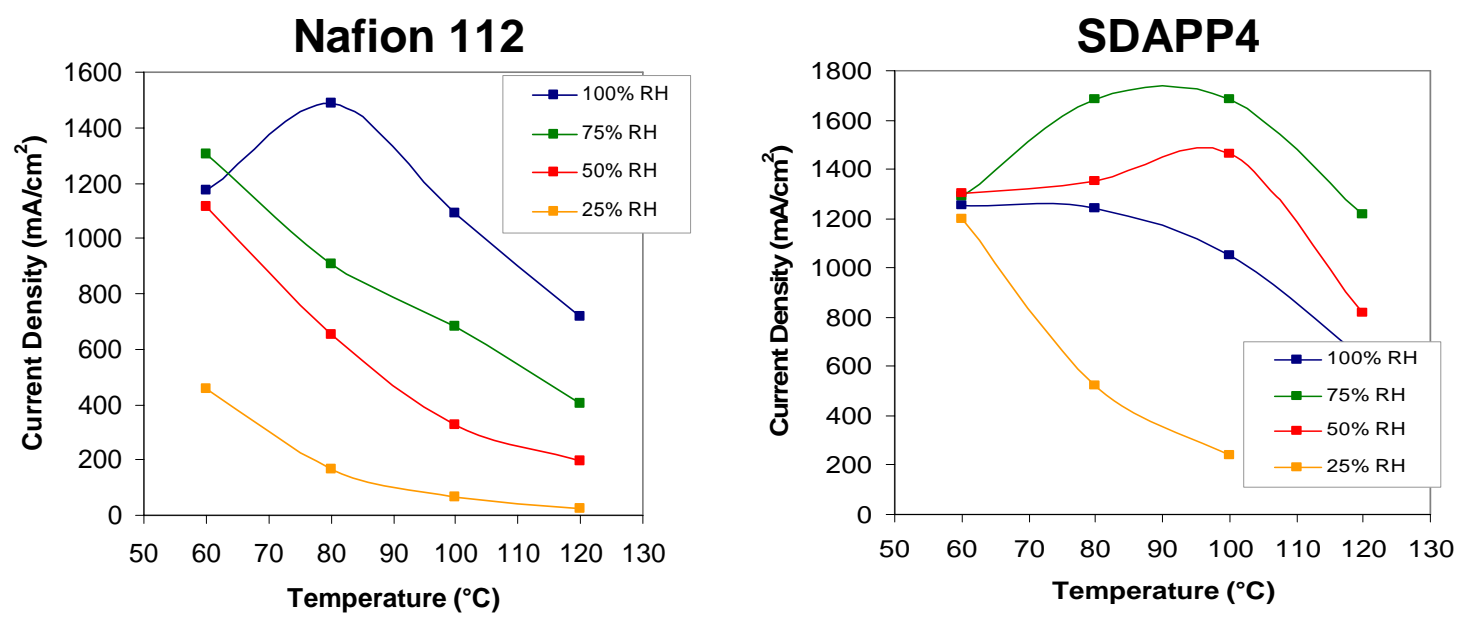

Figure 51 Hydrogen fuel cell performance of Nafion 112 versus SDAPP3 (SDAPP3 thickness 3mil) at a cell potential of $0.5 \mathrm{~V}$. Electrode assemblies for Nafion 112 and SDAPP3 are based upon $30 \mathrm{wt} \%$ Nafion based electrodes (left) versus Nafion112.

The $\mathrm{H}_{2}$ fuel cell performance of a series of SDAPP4 membranes with SDAPPe and Nafion electrodes are summarized in Figure 52. SDAPP4 membranes with Nafion electrodes outperformed the standard N112 with Nafion electrodes as observed in a $\mathrm{H}_{2}$ fuel cell. The $\mathrm{H}_{2}$ 
fuel cell performance of 15 and $7 \mathrm{wt} \%$ SDAPPe electrodes on SDAPP4 membranes are nearly equal to the standard Nafion system, while the $30 \mathrm{wt} \%$ electrode showed very poor performance. It is thought that the SDAPPe electrodes suffer from mass transport resistance at the three-phase interface due to low $\mathrm{O}_{2}$ permeability which is eliminated by elevating the temperature that increases $\mathrm{O}_{2}$ permeability. In the agglomerate catalyst model, a thin layer of polymer covers the platinum electrocatalyst. The oxygen can diffuse to the agglomerate through the open pores in the electrocatalyst layer which is a rapid process, but must then be transport through the thin polymer layer that covers the catalytic sites. The oxygen permeability of SDAPPe is less than Nafion, therefore, there are local mass transport limitations where SDAPPe covers the catalyst particles. To mitigate these losses, a more permeable polymer must be used in place of SDAPPe. The opportunity to increase the oxygen permeability of the SDAPP polymer is possible due to the wide range of chemical functionalities available to the SDAPP family. Table 10 shows a series of SDAPP variants and their corresponding hydrogen and oxygen permeabilities.

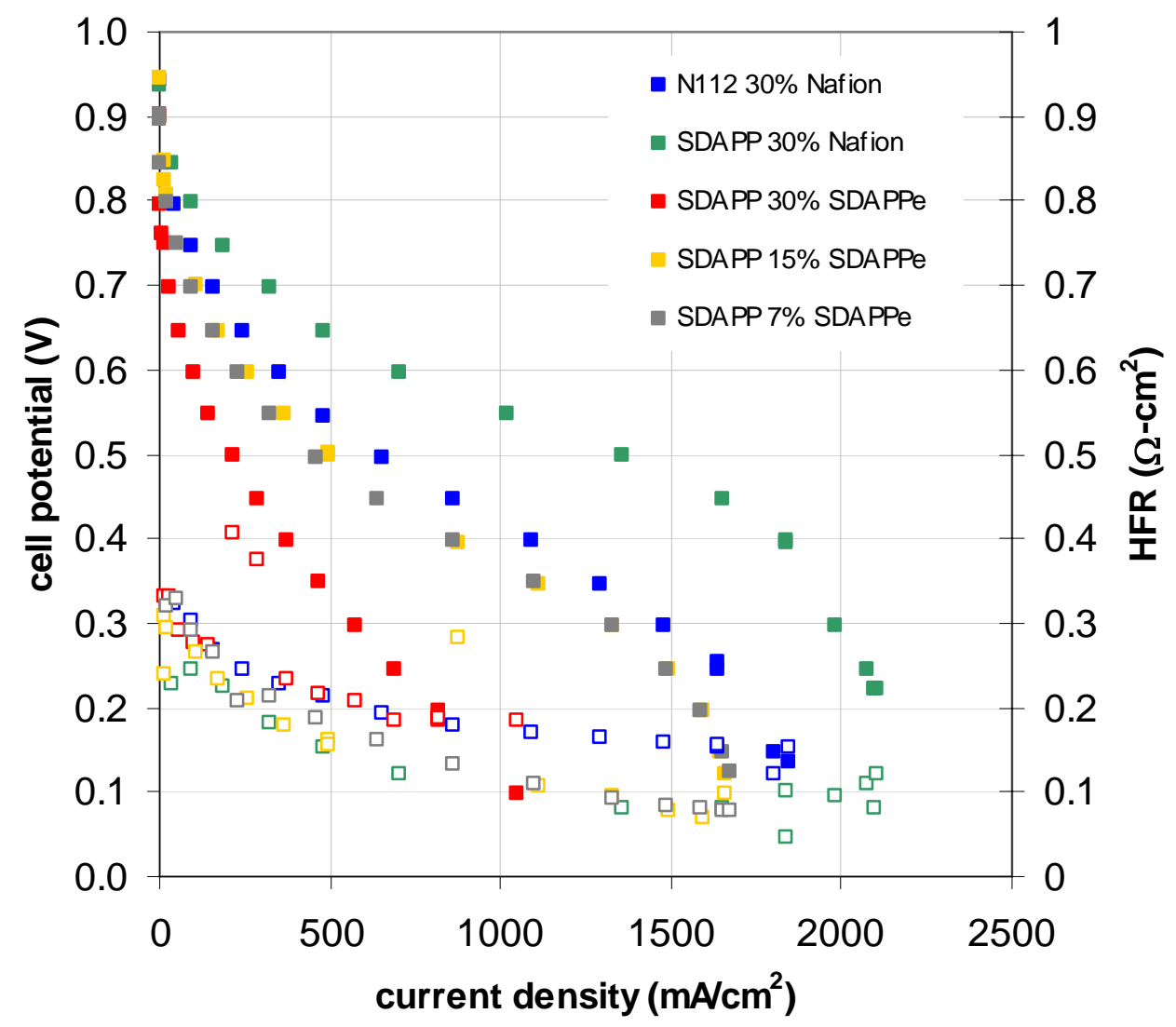

Figure 52 Polarization curve performance of electrode formulations at $80^{\circ} \mathrm{C}$ and $50 \% \mathrm{RH}$.

As can be seen from the table, the SDAPPe variant (analogous to the thioether DA polymer shown in the third row from the top) has the lowest permeability of the group. This analysis was performed after the SDAPPe electrode work commenced. The work on novel electrodes has now moved onto looking at the fluorinated SDAPP versions as electrode binders. These 
polymers should have increased permeabilities over SDAPPe and not show mass transport losses in their polarization performance.

Table 10 Relative $\mathrm{H}_{2}$ and $\mathrm{O}_{2}$ permeabilities of SDAPP variant polymers.

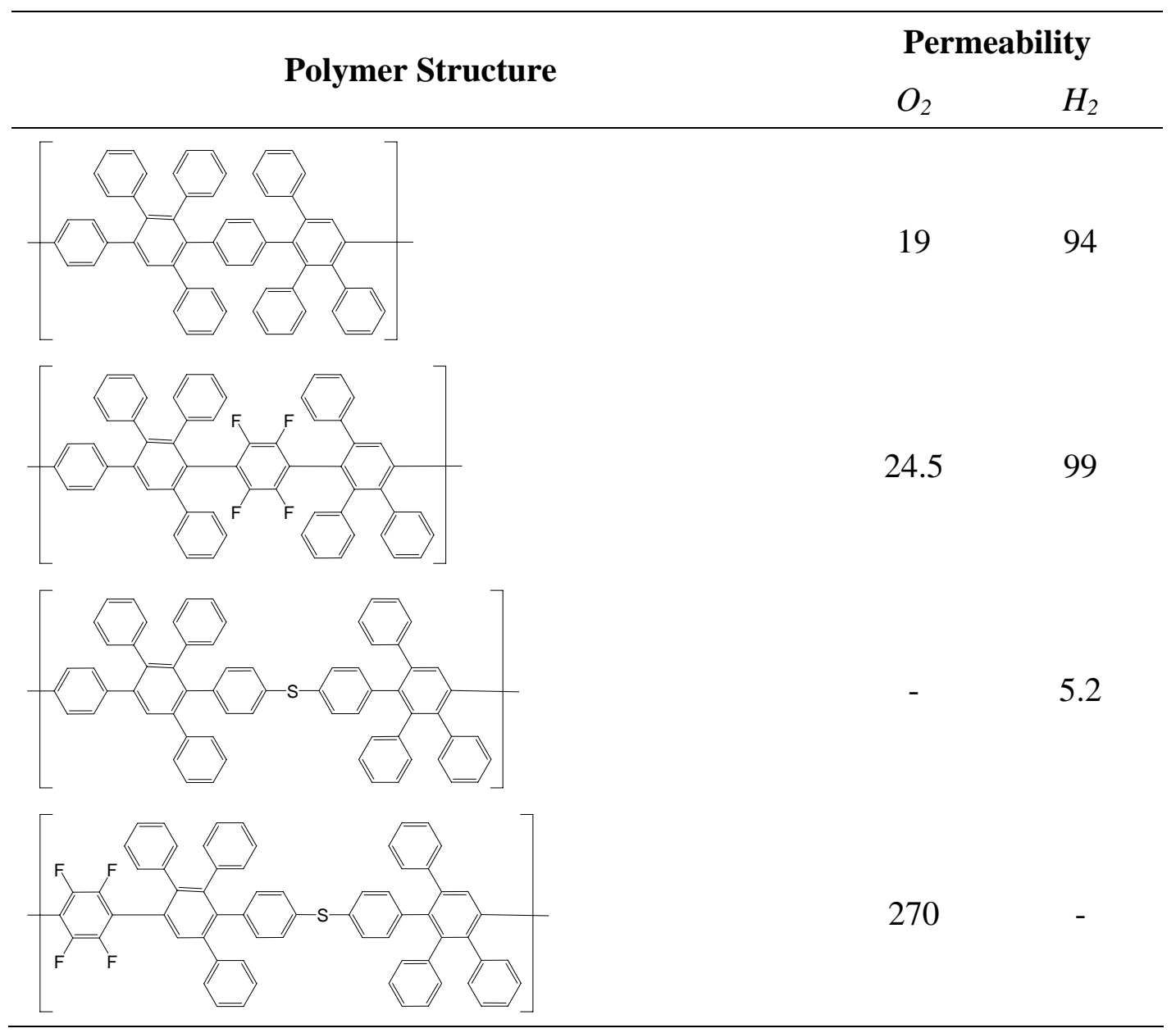

Permeabilities are the average of three samples from the same film. The feed pressure was 4 atm for each gas and the temperature was $35^{\circ} \mathrm{C}$. (Barrers, $10^{-10} *_{\mathrm{cm}}^{3}(\mathrm{STP}) \mathrm{cm} /\left(\mathrm{cm}^{2} *_{\mathrm{s}} * \mathrm{mmHg}\right)$ )

\section{Conclusions}

The poly(phenylene)s synthesized via Diels-Alder condensation resulted in polyelectrolytes that could be post sulfonated in a controllable manner with chrolosulfonic acid. The aryl backbone resulted in a tough rigid-rod material, indicated by its high Tg and inherently high thermochemical stability. This type of high glass transitional temperature material possesses physical properties that are attractive in high temperature fuel cell applications. In addition, the backbone stiffness does not negatively affect membrane properties such as water uptake (21 to $137 \%$ ) and proton conductivity (13 to $123 \mathrm{mS} / \mathrm{cm}$ ) with IEC that are typically employed with sulfonated aromatic polymers (1.04 to $2.2 \mathrm{meq} / \mathrm{g}$ ). The resultant polymers could be solution cast into robust, creaseable films and displayed properties that suggested this class of sulfonated polymer is a potential candidate for hydrogen and methanol fuel cell applications. Strategies to enhance their conductivity especially under partially dry conditions are being explored. 
SDAPPe electrodes seem to not have any intrinsic catalytic activity problems and show equivalent Tafel slopes to Nafion-based electrodes. There is some Tafel slope increase for SDAPP as compared to Nafion at low relative humidity, but that investigation is still an ongoing. The platinum ECA of SDAPP catalyst layers is slightly lower than in Nafion-based catalyst layers, but this may not be a limiting performance factor in formulating hydrocarbon based electrodes. By decreasing the polymer weight percent in the electrodes, it is possible to increase the measurable ECA by hydrogen adsorption/desorption cyclic voltammetry. The porosity of SDAPP catalyst layers are greater than or equal to that of Nafion catalyst layers. This is an important factor in the design of novel catalyst layers because gas pores throughout the electrode are critical to obtaining high current density MEAs. It is thought at this point that the limiting factor in SDAPP-based electrodes is the mass transport resistance of a thin layer of polymer over the platinum electrocatalyst. By increasing the permeability of the polymer binder in the electrode, the mass transport problems in SDAPPe-based electrodes can be overcome. The targets for the next generation of SDAPP electrodes are fluorinated SDAPP variants, which are known to have higher gas permeability than the ether variants. 


\title{
Ionomer Acid-Base Blends
}

\begin{abstract}
A series of acid-base blends of an acidic polymer (SDAPP) and a basic polymer (PVI) were prepared and cast into films. Evaluation for changes in water uptake, conductivity, and methanol permeability was determined as a function of blend composition. Methanol permeability and proton conductivity of SDAPP4 decreased with increasing content of PVI.
\end{abstract}

\section{Introduction}

The preparation of membranes from polymers with both acidic and basic functional groups will result in proton conductive domains formed by the acid-base interactions. These membranes should then be able to conduct protons even at low relative humidities at elevated temperatures due to the labile nature of the dissociated protons. In order to test this concept, blends of acidic polymers (SDAPP) and basic polymers (PVI) were prepared and cast into films.

\section{Experimental}

To make the blends, two stock polymer solutions were prepared. Stock solution 1 was a $5 \mathrm{wt} \%$ (wt./wt.) solution of SDAPP4 in dimethylacetamide (DMAc). The SDAPP4 had an IEC value of $2.2 \mathrm{meq} / \mathrm{g}$ and it was in the sodium salt form. Stock solution 2 was a $5 \mathrm{wt} \%$ (wt./wt.) solution of PVI in DMAc. The PVI was purchased from GFS Chemicals and it had an approximate molecular weight of $7000 \mathrm{~g} / \mathrm{mol}$. Various weight ratios of solutions 1 and 2 were stirred together and then cast on a glass plate under vacuum at $80{ }^{\circ} \mathrm{C}$. The films were then peeled off the glass and soaked in $1 \mathrm{M} \mathrm{H}_{2} \mathrm{SO}_{4}$ at $80-90{ }^{\circ} \mathrm{C}$ for $1 \mathrm{~h}$ and then soaked in water at room temperature for $24 \mathrm{~h}$.

\section{Results and Discussion}

Results from the acid-base blend membranes are listed in Table 11. The effective IEC is calculated by subtracting the number of basic groups per gram of polymer blend from the number of acid groups per gram of polymer blend. Since both nitrogen atoms in a PVI repeat unit can accept a proton, the effective IEC calculation assumes two basic groups per repeat unit of PVI. Because PVI has a much smaller repeat unit than SDAPP, relatively small amounts of PVI cause large decreases in the effective IECs of the blends. The measured IEC values, however, were not as low as the calculated effective IECs. This is because the membranes were soaked in sulfuric acid prior to characterization so some of the basic groups reacted with $\mathrm{H}_{2} \mathrm{SO}_{4}$ rather than with a sulfonic acid on the SDAPP (Figure 53).

Both water uptake and conductivity were strongly affected by the amount of PVI added to the blends, despite its relatively small impact on the measured IEC. The dramatic decrease in conductivity must be due a dilution effect. The neutralized PVI polymer chains cannot conduct protons and therefore they act as a filler material that obstructs the movement of protons in the SDAPP. The neutralized PVI is still an ionomer so it should tend to aggregate in the hydrophilic domains of the membrane, thus emphasizing its effect on proton conduction which also occurs in the hydrophilic domains. 


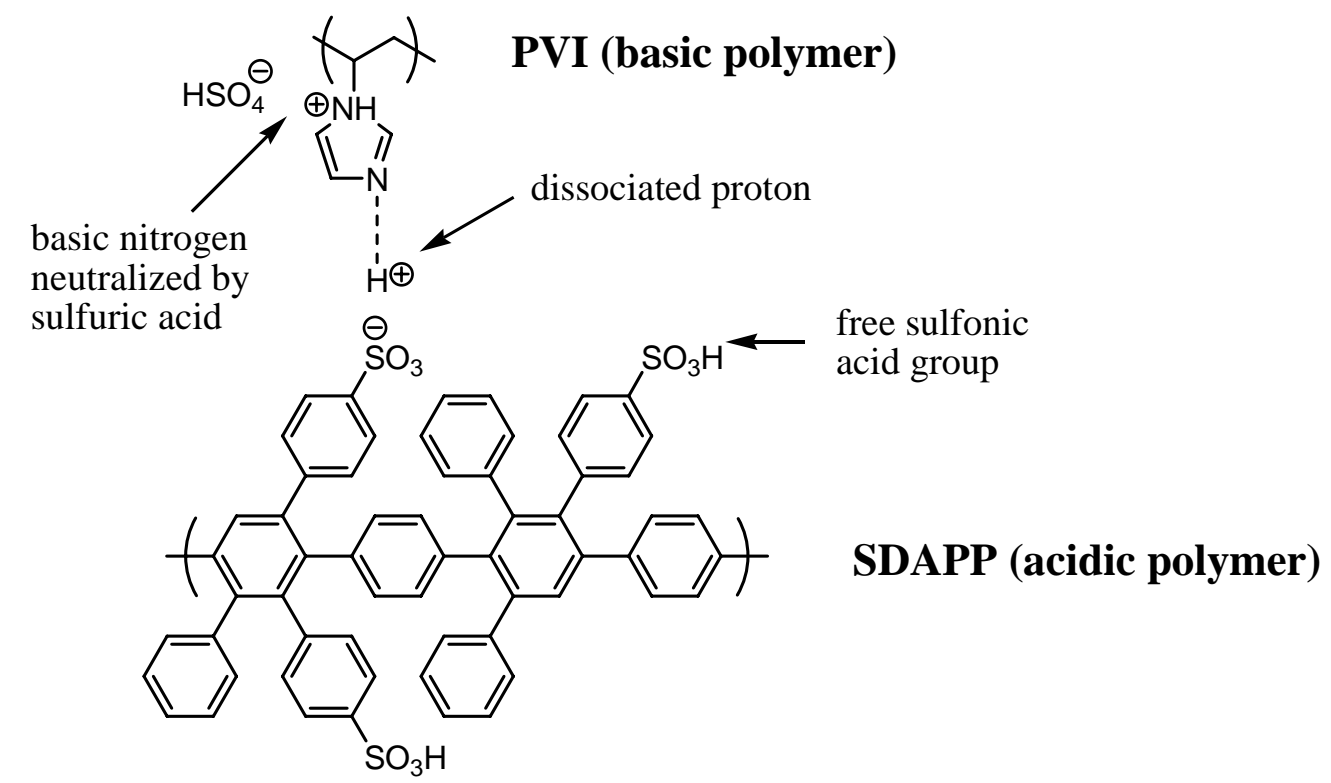

Figure 53 Acid-base Interactions in Blend Membranes.

Table 11 Characterization of Acid-Base Blends of PVI and SDAPP4

\begin{tabular}{ccccccc}
\hline $\begin{array}{c}\text { SDAPP:PVI } \\
\text { (wt.:wt.) }\end{array}$ & $\begin{array}{c}\text { Effective } \\
\text { IEC } \\
(\mathrm{meq} / \mathrm{g})\end{array}$ & $\begin{array}{c}\text { Measured } \\
\text { IEC } \\
(\mathrm{meq} / \mathrm{g})\end{array}$ & $\begin{array}{c}\text { Water } \\
\text { Uptake } \\
(\%)\end{array}$ & $\begin{array}{c}\sigma \\
(\mathrm{mS} / \mathrm{cm})\end{array}$ & $\begin{array}{c}\mathrm{DH} \\
\left(\mathrm{cm}^{2} / \mathrm{s}\right)\end{array}$ & $\begin{array}{c}\text { Relative } \\
\text { Selectivity }\end{array}$ \\
\hline $100: 0$ & - & 2.20 & 137 & 123 & $2.5 \mathrm{E}-6$ & 1.0 \\
$98: 2$ & 1.73 & 2.20 & 73 & 102 & $1.6 \mathrm{E}-6$ & 1.3 \\
$97: 3$ & 1.50 & 2.10 & 80 & 112 & $1.6 \mathrm{E}-6$ & 1.4 \\
$96: 4$ & 1.26 & 1.90 & 59 & 73 & $1.1 \mathrm{E}-6$ & 1.4 \\
$95: 5$ & 1.03 & 1.80 & 56 & 63 & $1.0 \mathrm{E}-6$ & 1.3 \\
Nafion 117 & - & 0.91 & 36 & 100 & $2.1 \mathrm{E}-6$ & 1.0 \\
SDAPP2 & - & 1.40 & 36 & 49 & $8.3 \mathrm{E}-7$ & 1.2 \\
SDAPP3 & - & 1.80 & 75 & 87 & $1.5 \mathrm{E}-7$ & 1.2 \\
\hline
\end{tabular}

\section{Conclusions}

Acid-base interactions in the blends were also predicted to decrease the permeability of methanol through the membranes and potentially minimize the amount of water necessary for proton conduction. Minimization of This was confirmed by the relative selectivity numbers in Table 9 which are higher for all of the blends than for the pure SDAPP4 membrane. SDAPP2 and SDAPP3 have higher selectivities than SDAPP4 but they also have lower conductivities. The acid-base blend membranes have higher selectivities than the pure SDAPP membranes without suffering a comparable loss in conductivity. 


$\begin{array}{lll}1 & \text { MS0188 } & \text { C.E. Meyers, 1011 } \\ 1 & \text { MS0188 } & \text { H.R. Westrich, 1011 } \\ 1 & \text { MS0188 } & \text { D.L. Chavez, 1011 } \\ 1 & \text { MS0724 } & \text { L.J. Shepard, 6000 } \\ 1 & \text { MS0741 } & \text { M.L. Tatro, 6200 } \\ 1 & \text { MS0734 } & \text { J.K. Kelley, 6245 } \\ 1 & \text { MS0513 } & \text { R.H. Stulen, 1000 } \\ 1 & \text { MS1427 } & \text { J.M. Phillips, 1100 } \\ 1 & \text { MS1415 } & \text { G. Gutierrez, 1114 } \\ 5 & \text { MS0734 } & \text { C.J. Cornelius, 6245 } \\ 1 & \text { MS1415 } & \text { G.S. Grest, 1114 } \\ 1 & \text { MS0734 } & \text { M.R. Hibbs, 6245 } \\ 1 & \text { MS0888 } & \text { C.H. Fujimoto, 6245 } \\ 1 & \text { MS0734 } & \text { M.A. Hickner, 6245 } \\ 1 & \text { MS0888 } & \text { C.L. Staiger, 6245 } \\ 2 & \text { MS0899 } & \text { Technical Library, 9616 } \\ 1 & \text { MS9018 } & \text { Central Technical Files 8945-1 } \\ 1 & \text { MS0161 } & \text { Patent \& Licensing Office, 11500 }\end{array}$




\section{Appendix I: List of Presentations and Publications}

Fujimoto, C. H.; Loy, D. A.; Wheeler, D. R.; Jamison, G. M.; Cornelius, C. J., “Gas separation by thin-film Diels-Alder polyphenylenes", 224th ACS National Meeting of the American Chemical Society, Boston, MA; American Chemical Society, Washington, DC; 2002, POLY243.

Fujimoto, C. H.; Cornelius, C. J.; Loy, D. A., "Sulfonated Diels-Alder Polyphenylenes: Synthesis and Properties of a Novel Polyelectrolyte", 14th North American Membrane Society Annual Meeting, Jackson, Wy. 2003, POST-13.

B.R. Cherry, M.D. Nyman, C.H. Fujimoto, C.J. Cornelius, G.P. Holland, and T.M. Alam, "Materials Characterization with High Speed Solid-State ${ }^{1} \mathrm{H}$ MAS and Double Quantum NMR", 45 ${ }^{\text {th }}$ Rocky Mountain Conference on Analytical Chemistry, Denver, CO, July 2003.

B.R. Cherry, M.D. Nyman, C.H. Fujimoto, C.J. Cornelius, D.A. Loy, H. Fan, and T.M. Alam, "High Speed ${ }^{1}$ H MAS NMR and Double Quantum NMR Investigations of Materials", $44^{\text {th }}$ Experimental Nuclear Magnetic Resonance Conference, Savannah, GA, 2003.

Cornelius, Chris; Fujimoto, Cy H., “Application of sulfonated Diels-Alder polyphenylenes in hydrogen based PEM fuel cells”, 226th ACS National Meeting, New York, NY, United States, September 7-11, 2003 (2003), FUEL-178

Chris J. Cornelius, Cy H. Fujimoto, Douglas A. Loy,” Molecular Chemistry/Engineering of Hybrid Organic-Inorganic Materials for PEM and/or Gas Separation Membranes”, Exxon Mobil, Annandale, NJ, September 11, 2003 (Invited Talk).

Chris J. Cornelius, Eva Marand, Pavla Meakin, and Anita J. Hill., "Molecular Chemistry/Engineering of Hybrid Organic-Inorganic Materials for PEM and/or Gas Separation Membranes”, 7th International Symposium on Polymers for Advanced Technologies, Fort Lauderdale, FL, September 21-24, 2003 (Invited Talk).

Chris J. Cornelius, Cy H. Fujimoto, Douglas A. Loy, "Polyphenylenes: An Alternative to Nafion?“, Los Alamos National Laboratory, Los Alamos, NM. September 30, 2003 (Invited Talk).

Lilin He, Dvora Perahia Cy H. Fujimoto, Christopher J. Cornelius, "The correlation between molecular and phase structure in highly ionic polymer”, American Physical Society, Montreal, Quebec, Canada, March 22-26, 2004.

Fujimoto, C. H.; Cornelius, C. J., "Sulfonated Diels-Alder Polyphenylenes: Synthesis and Properties of a Novel Polyelectrolyte", 15th North American Membrane Society Annual Meeting, Honolulu, HI. June 26-30, 2004

Cornelius, Chris, Fujimoto, Cy H., "Physical properties of sulfonated diels-alder polyphenylenes: Applications for PEM Fuel Cells”, 227th ACS National Meeting, Anaheim, CA, March 28-April 1, 2004, POLY-279 
Staiger, Chad L.; Cornelius, Chris J.; Wheeler, David R. Hydrogen gas separations using a highly microporous polymer. Abstracts of Papers, 228th ACS National Meeting, Philadelphia, PA, United States, August 22-26, 2004

Tsige, Mesfin; Grest, Gary S. Molecular Dynamics Study of the Evaporation Process in Polymer Films. Macromolecules (2004), 37(12), 4333-4335.

Tsige, Mesfin; Grest, Gary S. Interdiffusion of solvent into glassy polymer films: A molecular dynamics study. Los Alamos National Laboratory, Preprint Archive, Condensed Matter (2004), 1-17

Tsige, Mesfin; Grest, Gary S. Interdiffusion of solvent into glassy polymer films: A molecular dynamics study. Journal of Chemical Physics (2004), 121(15), 7513-7519.

Tsige, Mesfin; Grest, Gary S. Molecular dynamics simulation of solvent-polymer interdiffusion. I. Fickian diffusion. Los Alamos National Laboratory, Preprint Archive, Condensed Matter (2003)

Fujimoto, Cy H.; Hickner, Michael A.; Cornelius, Christopher J.; Loy, Douglas A. Ionomeric Poly(phenylene) Prepared by Diels-Alder Polymerization: Synthesis and Physical Properties of a Novel Polyelectrolyte. Macromolecules (2005), 38(12), 5010-5016.

Cherry, B. R.; Fujimoto, C. H.; Cornelius, C. J.; Alam, T. M. Investigation of Domain Size in Polymer Membranes Using Double-Quantum-Filtered Spin Diffusion Magic Angle Spinning NMR. Macromolecules (2005), 38(4), 1201-1206. 